Illinois State University

ISU ReD: Research and eData

Theses and Dissertations

5-7-2018

\title{
A Critical Interpretation of Study Abroad, Participant Identity, and Second Language Learning
}

Laura Edwards

Illinois State University, Icedwar@ilstu.edu

Follow this and additional works at: https://ir.library.illinoisstate.edu/etd

Part of the Educational Administration and Supervision Commons, and the Linguistics Commons

\section{Recommended Citation}

Edwards, Laura, "A Critical Interpretation of Study Abroad, Participant Identity, and Second Language Learning" (2018). Theses and Dissertations. 947.

https://ir.library.illinoisstate.edu/etd/947

This Dissertation is brought to you for free and open access by ISU ReD: Research and eData. It has been accepted for inclusion in Theses and Dissertations by an authorized administrator of ISU ReD: Research and eData. For more information, please contact ISUReD@ilstu.edu. 


\section{A CRITICAL INTERPRETATION OF STUDY ABROAD, PARTICIPANT IDENTITY, AND SECOND LANGUAGE LEARNING}

\section{LAURA EDWARDS}

202 Pages

In this study I explore the history of study abroad as a sojourn for the privileged, notions of whiteness, institutional racism and inequality, and nationality and linguicism, and apply theory from critical applied linguistics and post-colonialism to analyze and interpret data collected from five participants of either a semester or year-long study abroad at the Centre International d'Études Françaises (CIDEF) in Angers, France. The principal research questions are: What is the nature of how students negotiate their identities (racial, national, and gender), L2 learning, and engagement (or lack of) with various communities of practice while studying abroad in a non-English dominant country? How can an understanding of study abroad students' identities and participation in communities of practice abroad inform administration and implementation of study abroad programs to encourage L2 learning? Findings include that study abroad participants' approach to their experience is highly influenced by socially learned and accepted understanding of nationality, race, language, and gender, and most choose communities of practice and language based on investment in reifying these identities.

KEYWORDS: Identity; Critical Linguistics; L2 Learning; Community of Practice; Language Socialization 
SECOND LANGUAGE LEARNING

\section{LAURA EDWARDS}

A Dissertation Submitted in Partial

Fulfillment of the Requirements

for the Degree of

\section{DOCTOR OF PHILOSOPHY}

Department of Educational Administration and Foundations

\section{ILLINOIS STATE UNIVERSITY}


(C) 2018 Laura Edwards 


\title{
A CRITICAL INTERPRETATION OF STUDY ABROAD, PARTICIPANT IDENTITY, AND SECOND LANGUAGE LEARNING
}

\author{
LAURA EDWARDS
}

COMMITTEE MEMBERS:

Beth Hatt, Chair

Pamela Hoff

Juliet Lynd

Stacy Otto

Rachel Shively 


\section{ACKNOWLEDGMENTS}

I humbly admit that pursuing a Ph.D. at this time in my life would not at all have been possible without the support of an incredible community of friends, family, colleagues, and professors. Both my mom and my dad raised me to believe that I was capable and worthy of doing great things, even when they were not on my own radar. My dad incorrectly called me Dr. Edwards for years in the hopes that I would take on a doctoral program to further my education and professional opportunities. I am eternally grateful that he knew that I had embarked on this pursuit before he died. I dedicate this in part to you, Dad.

Many professors in EAF and English taught courses whose content informed my thoughts for this dissertation: in particular, Dr. Palmer, Dr. Burt, and Dr. Smith. Dr. Nur-Awaleh, my first advisor in the doctoral program supported me as my focus turned to study abroad, mentored me in preparation for my first conference presentation, and provided a space for me to research study abroad in more detail during an independent study with him.

I am fortunate to work with many great colleagues in Languages, Literatures, and Cultures who have cheered me on and shown empathy about this process. I am grateful to my Chair, Dr. Bruce Burningham for allowing me flexibility in my schedule as I wrote my dissertation.

My committee is made up of five incredibly wise, underappreciated, extraordinary women, each with incredible strengths that they contributed to my endeavor. Dr. Hoff was professor of my first class in the program, Cultural Foundations of Education. This class turned my world upside down as I learned through auto-ethnography and curriculum redesign about the role that my whiteness plays in perpetuating racism and injustice in society. Dr. Hoff does such meaningful and important work and I am truly honored to have her voice and wisdom on my 
committee. Dr. Lynd's sharpness and command of postcolonial studies along with her own experience with study abroad and expertise in L2 teaching and learning have been an invaluable contribution to my research. Equally important are the innumerous times that she has listened to me, empathized, and talked me away from the edge. Dr. Lynd is an esteemed colleague and a cherished friend. Dr. Otto, whose great writing modeled how an interdisciplinary approach can be both meaningful and successful, taught me not to be afraid and to see the strengths of research grounded in critical theory. I am grateful for this very significant direction. Dr. Shively’s expertise in Applied Linguistics and SLA in study abroad has been critical to my richer understanding of the field and to this study. She mentored my pilot study about Chev and has devoted hours of her time discussing my project with me, helping me brainstorm, and suggesting ideas and articles. She also introduced me to others in the field by encouraging and helping me present at a national conference. I am profoundly thankful for her generous support. Dr. Hatt, my committee chair, is the epitome of someone who goes to bat for you. She recognized my vision, understood the obstacles, and despite taking part in more than 17 other committees at the time, added me to her load. Dr. Hatt's skill at teaching how to do and write about qualitative research, as complicated and as messy as qualitative can be, is beyond compare. She has devoted many, many hours and days to meeting with me and reading over my drafts, discussing every single aspect of my chapters in detail, and giving me the tools to write and rewrite until I get it. As fully consumed by each of her obligations as she is, Dr. Hatt, with patience and mindfulness, always approaches me as a whole person, and has walked alongside me, through all kinds of weather, guiding me through what has been one of the most difficult accomplishments of my life.

Communities of Practice are meaningful in all contexts and our TGIF group provides a supportive place to negotiate meaning between university and home life that I could not have 
lived without. To Alex, Bea, Becky, Ben, Caleb, George, Gio (the pizzaiolo), Isla, Jessica, Julie, Katie, Luca, Ragheb, and Sue: Cin Cin and thank you for your continuous friendship. Thanks, too, to my life-long friend Veronika and Norwegian sister Grete for always being there, and to my Norwegian host parents, Eva og Ole-Fredrik.

My dear friend and colleague Sue has listened to many complaints, provided sage advice from her own experience and research expertise, has kept me sane with animal (and more importantly, Cornelius and Esther) videos, and give me last-minute, sanity-saving help.

Muchas gracias to El Portón for their friendship and delicious food that nourishes my (sometimes frustrated) writing soul every Saturday dinner without fail.

Heartfelt appreciation to my Sunday dinner friends (former members the Cowderys and the Hogensons), Carolyn, Chad, and their children (Miranda, Camille, Daniel, and Ethan) for your enduring friendship as we watch our children grow and we ourselves grow professionally and personally. We have shared travels, books and music, fears and sorrows, celebrations and the mundane; through our common love of preparing and sharing food, our friendship is a reminder of what truly matters most in life.

Finally, I address my immediate family, who has borne the greatest brunt of these oftenstressful times. To my nephew Lukas, I'm so sorry that your time living with us coincided with me writing my dissertation. I would have been a much nicer aunt to live with and I promise to make it up to you. To my daughter Leah, I apologize for not being present enough when you needed me most. Thank you for being proud of me and for being one of the big reasons I've worked to be a better person. To my son Nico, thank you for your curiosity and for your pleasant demeanor, for recognizing my hard work, and for playing such beautiful music that rejuvenates 
me at the end of each day. And to my fur-son, Riky, thank you for lovingly staying by my side as I write. Some may say that you are the actual author of this work.

No one in this world deserves more heartfelt appreciation or profound respect than my husband, Giovanni Testolin. For keeping all of our household affairs in order, for making delicious and healthy meals every single day, for your constant reminder of the importance of family and friends, and for ensuring that I do not take myself too seriously. You had confidence in me even when I did not. I have never met a person as patient or as forgiving as you, and I know that you have had to exert a lot of patience and forgiveness over these past years. You are as selfless as they come and I don't know how I ever deserved you. You are the true key to my success and ti amo per sempre!

L. E. 


\section{CONTENTS}

Page

ACKNOWLEDGMENTS

TABLES Xii

FIGURES - xiii

CHAPTER I: INTRODUCTION 1

Purpose of the Study 1

$\begin{array}{ll}\text { The Problem } & 1\end{array}$

$\begin{array}{ll}\text { Researcher Positionality } & 3\end{array}$

$\begin{array}{ll}\text { Theoretical Framework } & 7\end{array}$

Overview of the Study $\quad 9$

CHAPTER II: LITERATURE REVIEW 10

$\begin{array}{ll}\text { Overview } & 10\end{array}$

$\begin{array}{ll}\text { Historical Context of Study Abroad } & 10\end{array}$

$\begin{array}{ll}\text { A History of Study Abroad } & 12\end{array}$

$\begin{array}{ll}\text { Knowledge Enhancement } & 12\end{array}$

Dissemination of Power and Dominance $\quad 13$

Dominance Through Social Status and Construction of Social Hierarchy 13

$\begin{array}{ll}\text { More Recent Abroad Sojourns } & 14\end{array}$

The Past One Hundred Years of Study Abroad 15

$\begin{array}{ll}\text { A Critique of the Telling of History } & 17\end{array}$

$\begin{array}{ll}\text { History Books } & 18\end{array}$

Representation of Geographic Areas $\quad 21$ 
Europe Situated as the World Authority

History of Second Language (L2) Learning 25

$\begin{array}{ll}\text { Communities of Practice } & 28\end{array}$

$\begin{array}{lr}\text { Legitimate Peripheral Participation } & 29\end{array}$

Poststructural Views on Identity in L2 Learning $\quad 30$

Positioning and Imagined Communities $\quad 32$

Motivation Versus Investment, and Critical Experiences 33

$\begin{array}{ll}\text { Critical Applied Linguistics } & 34\end{array}$

Language Hegemony $\quad 35$

English is a Language That Privileges Dominant Groups 36

$\begin{array}{ll}\text { Linguicism } & 39\end{array}$

$\begin{array}{lr}\text { Implications for Study Abroad Programs } & 40\end{array}$

CHAPTER III: METHODOLOGY 44

$\begin{array}{ll}\text { Introduction } & 44\end{array}$

$\begin{array}{ll}\text { Interpretivist Methodology } & 45\end{array}$

$\begin{array}{ll}\text { Paradigm } & 46\end{array}$

$\begin{array}{lr}\text { Data Collection/Instruments } & 48\end{array}$

$\begin{array}{ll}\text { The ACTFL OPI } & 48\end{array}$

$\begin{array}{ll}\text { Data Analysis } & 51\end{array}$

$\begin{array}{ll}\text { Theme Analysis } & 51\end{array}$

$\begin{array}{ll}\text { Researcher Positionality } & 53\end{array}$

$\begin{array}{ll}\text { Ethics } & 55\end{array}$

$\begin{array}{lr}\text { Trustworthiness } & 56\end{array}$ 
Significance of the Research

CHAPTER IV: PILOT STUDY $\quad 60$

$\begin{array}{ll}\text { Description } & 61\end{array}$

$\begin{array}{ll}\text { Data Collection } & 62\end{array}$

$\begin{array}{ll}\text { Gaming Community } & 64\end{array}$

$\begin{array}{ll}\text { Proactive Search } & 64\end{array}$

$\begin{array}{ll}\text { First Visits } & 65\end{array}$

$\begin{array}{ll}\text { Observations From the Periphery } & 65\end{array}$

A Textbook Example of LPP 66

$\begin{array}{ll}\text { Acceptance by Other Members } & 67\end{array}$

$\begin{array}{ll}\text { Full Integration } & 68\end{array}$

$\begin{array}{ll}\text { Shared Repertoire and Acceptance } & 69\end{array}$

$\begin{array}{ll}\text { Host Father } & 71\end{array}$

$\begin{array}{ll}\text { Arrival and Rules } & 71\end{array}$

$\begin{array}{ll}\text { Rules and Routine } & 72\end{array}$

Introduction to Friends and Other Parts of the Community 73

$\begin{array}{ll}\text { No Longer a "Wacky Foreigner” } & 73\end{array}$

$\begin{array}{ll}\text { Discussion } & 74\end{array}$

CHAPTER V: PARTICIPANT DESCRIPTIONS 76

$\begin{array}{ll}\text { Introduction } & 76\end{array}$

$\begin{array}{ll}\text { Description } & 76\end{array}$

Participants, Length of Stay, and Location 76

$\begin{array}{ll}\text { Magda } & 78\end{array}$ 
Lesley

Becky

Sasha

Charlotte

Summary

Key Themes in Critical Linguistics

Nationality

Gender/Sexuality

103

Race/Ethnicity

Social Class

Discourse/Linguistic Inequality

Negotiation of Critical Themes in Identity

Magda

Nationality

Gender/Sexuality

Race/Ethnicity

Social Class

Discourse/Linguistic Inequality

Lesley

Nationality

Gender/Sexuality

Race/Ethnicity 
Social Class

Discourse/Linguistic Inequality

Becky

Nationality

Gender/Sexuality

Race/Ethnicity

Social Class

Discourse/Linguistic Inequality

Sasha

Nationality

Gender/Sexuality

133

Race/Ethnicity

Social Class

Discourse/Linguistic Inequality

Charlotte

Nationality

Gender/Sexuality

Race/Ethnicity

Social Class

Discourse/Linguistic Inequality

Trajectories of Nationality

Low to High Trajectory (Lesley and Sasha)

Low to Mid Trajectory (Becky and Magda) 
High to Low Trajectory (Charlotte)

Trajectories of Gender/Sexuality

Harassment Stories That are Raced

Feeling Free

Finding Love

Willingness to Navigate Gendered/Sexual Power Structures in the Name of L2

Learning

Completely Shut out Romance

Trajectories of Race/Ethnicity

Colorblind Experience

Color-Conscious Experience

Highlighting East-Asian Students

Trajectories of Social Class

Colonizer Studying Abroad

Conflation of Being American but Wanting to Look Worldly

Trajectories of Discourse/Linguistic Inequality

Only American Friendships

Dislike of Ugly, English-Speaking Americans

Finding Love, but Only in English

Host Family Connections

Classroom/School Connections 
Identity

L2 Learning

Engagement

Epiphanies (What I Did Not Expect)

Study Critique

Significant Contributions

Future Research

Focus More on National Identity

Focus More on POC

Exploratory Studies

More Critical Approaches in SA Research

Conclusion

REFERENCES 


\section{TABLES}

Table

Page

1. Data Accounting Log $\quad 50$

2. Demographic Data 97

3. Unofficial OPI Results $\quad 98$

4. Key Themes-Pre-Departure 146

5. Key Themes-Midterm 147

6. Key Themes-Return 148 


\section{FIGURES}

$\begin{array}{lll}\text { Figure } & \text { Page }\end{array}$

1. OPI Levels and Sublevels 98 


\section{CHAPTER I: INTRODUCTION}

\section{Purpose of the Study}

Using critical linguistics and postcolonial theory as lenses, the purpose of this study is to contribute to the field of study abroad and second language acquisition (SLA) with further investigation into the why and how of fluctuations in second language (L2) learning during study abroad. It seeks to understand what motivates or hinders students during their abroad sojourn to make significant or less significant strides in the L2. While this is a growing area of research, an increased focus is needed on students as whole persons with varying levels of cultural, political, socioeconomic, racial, gendered and national identities to understand better their influence on how students respond to new situations that can on the one hand, broaden their perspectives and L2 learning, and on the other hand, threaten who they are.

Within chapter one I will lay the groundwork of the problem of L2 learning abroad and introduce the Oral Proficiency Interview, how it works and its significance to the study. I will then discuss my positionality, including my upbringing and experiences that bias my perspective and bring me to research this problem, followed by an introduction to my main theoretical framework, critical applied linguistics. I end with an overview of the entire study.

\section{The Problem}

While many studies in Applied Linguistics show that intercultural competence and L2 learning improve during a study abroad, others have shown that a good number of students return with minimal linguistic improvement (e.g., Downey \& Gray, 2012; Huesca, 2013; Lindseth, 2010; Martinsen, Baker, Dewey, Bown, \& Johnson, 2010; Pavlenko, 2002; Segalowitz, 2004). Despite being effectively immersed in classes in the target language every day, interacting with locals in the L2 on a regular basis in public settings such as grocery and clothing stores, bars and 
restaurants, and living and spending mealtimes with their host families, many students abroad seem to devote significant time and energy to their American' counterparts abroad or to the social media that keeps them connected to family and friends back home (Kinginger, 2009).

Furthermore, American social groups abroad provide psychological safety and comfort needed in a situation where one takes on a semester or year abroad with a different language and way of life. Studies in International Education point out notions of American study abroad participants as perpetuating colonialism and neoliberal consumer culture. One major issue of focus is that students' varying cultural, political, socioeconomic, racial, gendered and national identities can influence their approach to interacting with the host culture and their tenacity to learn about other ways of life when abroad (Block, 2003; Norton, 2013).

An equally important problem refers to program retention and completion at the university level. In this study I explore why many students studying an L2 abroad return to the U.S. with inconsistent linguistic improvement (Lafford, 1995; Lindseth, 2010; Segalowitz, 2004) as measured by the American Council for the Teaching of Foreign Languages (ACTFL) Oral Proficiency Interview (OPI).

The OPI is a 15-30-minute interview in the L2 with a certified OPI interviewer, usually over the telephone, to ascertain one's oral proficiency. Many world languages education majors are required to rate at Advanced Low proficiency on the OPI in order to student teach, but often half or more of them are not successful (Swender, 2003). Students must consequently either

'In this dissertation, I use the term "American" to refer to the national identity of those citizens of the United States of America. I recognize that it is problematic because it refers to all of North, Central, and South America, not only the United States. Furthermore, it is a colonizing term that is often used as a default (even in the French "américain/Américain"). It is also a term that encompasses and perpetuates colonial constructions of race, class, and power. In this dissertation it is difficult to avoid and still capture the language of the students and/or refrain from using more verbose descriptions, such as "student from the United States" or "United States citizen." 
continue to try to pursue Advanced Low (at a cost of U.S. \$139 per interview) or they must switch to the non-teacher-education major. While the OPI requirement is only for world languages teacher education majors at my university, it is important to point out that all L2 majors have the desire and goal to be as proficient as possible, and the OPI is a recognized measure of proficiency. Higher education educators strongly encourage study abroad for students as the be-all-and-end-all in L2 acquisition, and students (often incorrectly) assume that if they go through the motions of a study abroad, their language skills will naturally improve to the desired proficiency. The more we know about aspects surrounding L2 learning abroad, the better we can prepare students before, during, and in anticipation of the end of their studies abroad. The current study will provide significant data to inform practices for all study abroad (SA) programs - not only those in which L2 learning is the goal - as universities seek to improve their SA programs in both quantity and quality.

\section{Researcher Positionality}

Many of my formative experiences inform my approach to this research. When I was fourteen years old I spent a year studying in Norway. Leading up to my year abroad I had a generally good life as the only daughter and youngest child in a white, middle-to-upper-class

family until the year preceding my Norwegian sojourn when I got involved with some drugs and a social group that took part in racially motivated disputes. I did not know why my friends were fighting Black people_-I did not fight them—but I was a member of the group. Prior to my year abroad, I often acted out as a self-entitled little brat who expected things to be based on the dictates of my own comforts and perceived notions of culture.

When I flew to Norway, I remember wondering what kinds of grass, plants, and trees I might encounter once I landed. I imagined an almost alien place, as if I were flying to another 
planet. What a surprise then, when, on a walk somewhere in the mountains outside of Oslo my first evening in Norway, the wind smelled sweet and the sun kissed my skin just like home. Even the plants and trees were not so different. I'm not sure why this sticks out in my memory so much, but this moment seemed critical in establishing the sameness of our human experience despite living in completely different places. I had imagined, and had grown up to consider differences, but this realization of sameness opened my heart to the idea of one humanity in the world, not varying levels of it.

Of course, many situations surprised and challenged me when they did not meet my expectations. As a typical teenager, my standards were based on those of my peer group: being anything other than heteronormative was wrong and embarrassing. My host sister Grete, her friend Karina, and I would often spend weekends on our own at a cabin across the fjord from where I lived. One afternoon, we were taking a walk along a road and Grete and Karina put their arms around each other as they walked, and they also held hands. I felt dreadfully threatened by what their actions said about me. What were others thinking who saw this demonstration? As cars drove by, I called out to the drivers, “They're not gay, so I'm not sure why they're holding hands!" Soon after, Grete and Karina explained to me that I was the one embarrassing myself, first, by speaking in English because no one out there expected to hear English, and two, because same-sex friends hold hands all the time in Norway and there was nothing sexual about it! Another striking moment during my year in Norway was around mid-October. My parents had just visited for a long weekend and I was not going to see them again until the following July. Back then it was way too expensive to call on the phone; there were no computers, no texts, and letters once sent, required a good 15-25 days for a response. My host family announced to me that they "knew" that I understood Norwegian already and they were 
going to stop speaking English with me, effective the next morning. I remember my diary entry that night as if I wrote it today: "What the hell gives them the idea that I can understand Norwegian? Just because I can say a few sentences doesn't mean that I understand!” My reaction to no longer being allowed to use my mother tongue in my interactions was to want to go back to the United States, although I did not follow through. Those following months turned into an extremely trying time. I was teased for some of my pronunciations and I made so many mistakes! But by Christmas, I was not only speaking Norwegian, I was also speaking the local dialect.

There were countless ups and downs that year. I had been plagued with homesickness and paranoia that my host parents were hiding my mail, jealousy-tinged fights with my host sister, hounded by weight gain, my periods stopped, and I often felt really alone. Over and over, everything that I held as the standard in my life was turned upside down. I spent a lot of time with my own thoughts which were tainted by my instability. My experiences in Norway caused me to regularly question the structure of my values and expectations, and at age fourteen, that was pretty scary stuff. When I returned from Norway the following summer, people barely recognized me. I looked different, I had an accent when I spoke English, and to be honest, I did not really fit in anymore. My worldview had expanded, my awareness so heightened, and my tolerance of difference so strengthened that I found myself rather lonely back "home" when my friends did not see things as I did. I studied abroad two more times after my year in Norway, and each time was a painful period of intense growth and discovery mixed with some of the best memories of my life. Study abroad, when it involves a combination of discomfort, disorientation and relative loss of self-identifying factors, amazing moments of awe, (and daily reinforcement that the world is not going to end even though you're living in a different way and speaking a 
different language), can be a critical experience not only in language acquisition, but also in building a truly global citizen, not one that just looks good for the job market, but a thinking, loving, person capable of contributing to the good of humankind.

My experiences are the ground that I have to stand on when I ask students and professors not to fall into the trap of allowing their studies abroad to be credit-bearing tourism. Students should not be allowed to simply dip the tip of their toe into the water, they have to attempt full immersion despite the difficulty. Learning is often sensory; in fact, I would argue that the vast amount of my wisdom has been gained less through books and more from personal experiences and interactions, along with much critical reflection. Study abroad could be such an effective learning experience for students today if it is approached openly, critically, and reflectively.

I must remember, however, that my experience was influenced by my own cultural, political, socioeconomic, racial, gendered and national identities. I must fully admit that it would have most certainly been different had I not been a white, American, middle-class woman. I may not have even been able to take advantage of a study abroad experience if I did not come from this background. My experience might also have been drastically different had the advances in technology and internet that exist today been available back then. I might not have readily interacted with my host family or made friends with neighbors and other locals. In chapter three I will discuss further how my positionality interacted with the study.

Each person brings their own personal baggage into the equation, affecting their cultural and linguistic acquisition. The antiquated idea that a study abroad with no pedagogical interventions will result in meaningful cultural and linguistic acquisition is short-sighted and is part of why continued study into the participant as a whole person is merited. This study acknowledges and lifts up the complex significance of identity, and the idea that language 
learning is either more or less successful because of it. Weedon (1997) argues that our "sense of ourselves" or, our "subjectivity, is socially constructed" (p. 21) and, as Norton posits, "historically embedded" (2013, p. 15). In the next section I will explore this in more detail.

\section{Theoretical Framework}

I approach this study choosing a theoretical framework with several interconnected ideas in mind:

1) language development is a social learning experience that shapes who we are and how we understand the world (Block, 2014; Kinginger, 2009); 2) the world around us is understood and reiterated by means of social constructs that reinforce social hierarchies (Block, 2014; Pennycook, 2001); 3) our identities affect our approach to most every event in our lives, as we consciously or subconsciously position ourselves in a social hierarchy (Block 2014); 4) we choose or want to belong to communities or groups in which our actual or perceived identities are legitimized and reified (Block, 2014; Norton, 2013); and 5) learning occurs depending upon our investment and membership in those communities or groups (Lave \& Wenger, 1991; Norton, 2013). I will discuss these ideas and the theory connected to them in detail in chapter three.

I use critical applied linguistics (a critical approach to applied linguistics) to analyze my data because of its ability to highlight "the importance of micro relations of applied linguistics to macro relations of society, the need for a critical form of social inquiry as a constant questioning of assumptions, and something that includes an element of self-reflexivity in critical work" (Pennycook, 2001, p. 2). Applied linguistics is "the study of second and foreign language learning and teaching" and "the study of language and linguistics in relation to practical problems, such as lexicography, translation, speech pathology, etc.” (Richards, Platt, \& Weber, 1985, p. 15). Critical applied linguistics was born out of applied linguistics as a way to analyze 
more profoundly, understand, and problem-solve by scrutinizing the "interrelationships of dominion (the contingent and contextual effects of power), disparity (inequitable access to material and cultural goods), difference (the construction of and engagement with diversity), and desire (the operations of ideology, agency and identity)," (Pennycook, 2008, p. 170). In this study I focus on notions of power, disparity, and dominion that are manifested through words and actions by study abroad participants. Critical applied linguistics focuses analysis on such issues as ideologies, institutions, systems and notions of gender, race, ethnicity, sexuality, social class, and discourse (Anya, 2011). Use of this theory is also apt for this study because of its meaningful connection to language socialization, a multifaceted theory that includes notions of identity, investment, and membership that has been applied to understanding second language acquisition of both in-classroom and study abroad participants over the past two decades. Chapter two is devoted to describing these ideas and the frameworks associated with them in more detail.

My purpose for this study was to understand to what extent the previously stated notions affect L2 learning and study abroad participants, and for this I posed the following questions: Research Questions

1. What is the nature of how students negotiate their identities (racial, national, and gender), L2 learning, and engagement (or lack of) with various communities of practice while studying abroad in a non-English dominant country?

2. How can an understanding of study abroad students' identities and participation in communities of practice abroad inform administration and implementation of study abroad programs to encourage L2 learning? 
To respond to these questions, I examined data collected from study abroad participants on either a semester or year-long sojourn in Angers, France. Using interviews, surveys, and email communications through participant-researcher interaction, I investigated and analyzed my participants' experiences. I present the findings of my five participants as individual case studies looking at patterns and anomalies one chapter at a time, but as Stake (2003) argues, "we cannot understand this case without knowing about other cases" (p. 136). I also analyze themes that can be seen across all participants in the final chapter.

\section{Overview of the Study}

As I describe in chapter one, I learned language very easily while abroad and felt that all other study abroad participants should too. However, many studies over the years have shown that L2 learning in study abroad is not consistent and Block (2010) and Norton (2013) have written quite extensively about how identities affect perspective and approach to it. The immediate problem is how minimal L2 learning affects teacher education programs in which students must rate at a specific proficiency level on the OPI. The greater problem is how a study abroad as a social endeavor is approached and understood given power structures that we carry in our ideologies that may affect investment and membership in communities of practice abroad.

Through the lens of critical applied linguistics this study of American, L2 learning SA participants hones in on micro areas of gendered, socio-economic, national, and racial identities and investment in communities of practice during a study abroad. I will show through results from this study that study abroad participants manifest their power both consciously and subconsciously through these critical identities, and that study abroad programming at the institutional level lacks critical pedagogical tools and preparation. The results may be used to inform university study abroad and internationalization programming. 


\section{CHAPTER II: LITERATURE REVIEW}

\section{Overview}

This literature review is divided into three main parts in which I historicize the concept of study abroad in order to show the deep-seeded notions of power that affect institutional and societal structures and mindsets and set standards. I begin with a history of study abroad back to its ancient roots in which travel was intended for knowledge acquisition (religious or otherwise) but also for spreading power, dominance through social status, and construction of social hierarchy. Then I focus on the composition of study abroad over the past 100 years to the present, honing in on the structure and policies of today's study abroad programs. In the next part I take specific issue with the telling of history, critiquing various preparatory institutions, both corporate and social, for their influence on the public mindset, an ethos that consequently shapes

the identity of study abroad and its participants. The final part gives an overview of the history of the study of second language acquisition (SLA), language socialization (including communities of practice, legitimate peripheral participation, identity and identity negotiation and construction), critical applied linguistics, a history of English in the United States, and language hegemony. All of these themes together have a scaffolding effect on how knowledge has been created, reified, and continues to be what is referenced as we establish, prepare for, and send students on studies abroad.

\section{Historical Context of Study Abroad}

A historical contextualization of study abroad lays the groundwork for deeper understanding of a social structure that has been culturally maintained and controlled, in many ways, subconsciously, over centuries and even millennia. Before I can delve into understanding the American study abroad participant, I must historicize the concept of study abroad by digging 
deep into the roots of these longtime participated sojourns, because we perpetuate meaning today that has been constructed by those in our past.

What follows is the history of study abroad based on versions of recorded history. It begins with a history of pilgrimages and conquests, both spiritual and rapacious, as well as sojourns where the privileged spend an extended period of time taking part in educational and unrestrained actions that further solidify their social standing.

This section continues with a description of the two most recent evolutions of study abroad over the past 100 years, which are 1) study abroad to increase one's knowledge, and 2) study abroad to increase or sustain a nation's power. Understanding this progression within study abroad culturally situates the significance of study abroad today. I will introduce the idea that current study abroad practices: 1) perpetuate the financial and philosophical goals of American institutions, 2) affect how institutions represent study abroad to students, and 3) affect students' subconscious understanding of themselves and their positionality during study abroad. Students themselves care most about perceptions of who they are and how they fit in the world (Block, 2010), therefore, student identity affects their experience abroad, including their second language acquisition.

Later in this chapter I will critique the telling of history for the constructs that it has imposed on society, on our institutions, and on our students. I will critique the telling of history based on those who have the power to construct it, by giving examples of the permeation of these constructs into institutions in our society from which American citizens gain knowledge and understanding. Finally, I will argue that all of this has a critical effect on the mindset of the typical American study abroad participant, who carries this with them on their SA sojourn. 


\section{A History of Study Abroad}

In this section I reference reasons why people have historically studied abroad to lay the groundwork for the motivation and investment that informs current participants. There are two main impetuses for study abroad throughout time. The first is based on those who seek spiritual immersion in search of knowledge with the hope of richer, deeper understanding of oneself, others, other ways of living and speaking, and where a person can "escape the intellectual and geographical restrictions of their home environments and enhance their learning" (Edwards,

Hoffa, \& Kanach, 2005, p. 5). The second is through exploration of other lands with the goal of gaining some kind of social or economic capital, or to the extreme, imposing one's own culture upon and acquisition of those lands. Furthermore, one impetus might have led to the other, leaving the two motivations to overlap.

\section{Knowledge Enhancement}

Under the impetus for knowledge seeking, some of the earliest known concepts of study abroad go back to ancient times when tribal leaders would travel in order to increase their sensitivity to sacred practices and accrue wisdom that would qualify them as better leaders (Hoffa, 2007). This practice also applied to religious scholarship. Indeed, Centers of Learning at various Persian Universities between 600 B.C. and A.D. 250 were significant venues for those who wanted to study sacred texts and Persian approaches to medicine, philosophy and literature (Hoffa, 2007). Finally, Greeks understood early on that knowledge was acquired and disseminated through travel to other lands. Plato and Aristotle's method of teaching encouraged the process of learning and interpreting through the crucial act of travel, especially in search of wisdom lost during the Early Middle Ages (Hoffa, 2007). These (historically considered) great thinkers and this groundwork of knowledge-seeking informs (if only subconsciously) modern 
thinkers' desire to seek knowledge through travel and study and partially sets the stage for future generations' educational travel.

\section{Dissemination of Power and Dominance}

It seems plausible that exploration of lands stemmed from the search for knowledge. However, it often resulted in the desire to dominate and take advantage of that knowledge acquisition by imposing one's own culture. Hence, religious crusades, imperialism or trade are part of the second objective of "study abroad" through time. Romans traveled to and conquered regions from which they would return with artifacts that inspired people to travel back to those regions to study them further (Hoffa, 2007). Even Marco Polo could be connected to this binary of consumerism and advancement of knowledge, since, while he worked primarily in trade, discovery of the existence of artworks and goods such as the compass and the printing press advanced knowledge and customs in his homeland (Hoffa, 2007).

\section{Dominance Through Social Status and Construction of Social Hierarchy}

Study abroad as we know it today has been modeled after travels, structured and unstructured, on which dominion was reinforced by people before us. What better way to dominate knowledge acquisition than to send rich Americans to Europe to be educated? In colonial times, Americans went abroad to "go beyond the limitations of colonial college offerings," expanding the idea of study abroad into a representation of socio-economic stature (Brockington, Hoffa, \& Martin, 2005, p. 6). The reinforcement of accepted social and cultural constructs of the United States as a dominant power at home and abroad came through education abroad of those with particular social status. Young British men during the 17th and 18th centuries (who were often members of the aristocracy) took part in The Grand Tour (Gore, 2005), a long trip across the European continent, stopping to stay with "relatives, important 
families and courts" to be exposed to foreign ways and values (Hoffa, 2007, p. 15). These travels were meant to prepare men in the areas of etiquette, networking and social connections more than to pursue academic knowledge. Gentlemen's success was assured when it became apparent to all how much could be learned about life by leaving one's home culture to hear unfamiliar languages and see ancient and modern architecture; to get firsthand knowledge of geography; and to learn about the politics, cultures, art and antiquities of the continent (Hoffa, 2007).

Study abroad, while at its appeal might have been meant for individual enrichment, evolved into unofficial preparation of families of privilege for diplomatic and aristocratic roles through international "social and political connections" (Brockington, Hoffa, \& Martin, 2005, p. 6). This manner of travel was the precedent for standards held by Americans in the 19th century "as part of the educational imperative for up-and-coming young men" (Gore, 2005, p. 28).

\section{More Recent Abroad Sojourns}

The Grand Tour was a precursor to the wanderjahr, essentially an extended period of travel and learning through experience and adventures of meeting people in new places. It was during this time when the young man would have to learn to survive despite any complications or unknowns that might arise. While some of these travelers were artists or writers, others were apprentices to craftsmen, and were not necessarily well off (Hoffa, 2007). Compared to The Grand Tour, the wanderjahr had no underlying social requirements or ambitions. In fact the year was meant to live to its fullest "a youthful life of minimal adult responsibilities, on the open road and in towns and cities. When funds ran out, dangers threatened, or homesickness overtook them, these wanderers went home (p. 18). Furthermore, there were no academic requirements for the trip; there was no acquired course credit or book learning required. However, it was 
presumed that the traveler would learn life lessons that could be applied to future professional or familial roles (Hoffa, 2007).

Finally, there is what might be considered a modern version of the wanderjahr, the Gap Year. This experience is a response to the idea that there is more to know than what is taught in school and that interactive, real-world understanding can help prepare a student during the period after secondary school or before university to supplement and enhance this understanding (Hoffa, 2007).

To conclude, most of these travels were nearly impossible to undertake without a background of privilege, power, and connections. The majority of the participants were primarily affluent, white men. It is also evident that these sojourns had the common goal of increasing one's understanding sur place, often without textbooks as intermediary, about political, cultural, educational and linguistic variations from one's own. Moreover and of relevance to the mindset of participants in this study, these sojourns effectively set the stage for the study abroad of the twentieth and twenty-first centuries.

\section{The Past One Hundred Years of Study Abroad}

Over the past 100 years, the semester or year abroad as Grand Tour or Gap Year has rebranded and focused its efforts, first on academic development, and later on a more globalized higher education institution. These changes have evolved in two different ways. First, up through the 1980 s, in response to growth in communication and transportation, Americans became more informed about the world and more eager to explore it (Brockington, Hoffa, \& Martin, 2005). I note that SA remained primarily an option for the elite, exhibited by the focus on those who were pursuing a university education. The first evolution highlighted scholarly activity and the first real push for universities to encourage study abroad programming. One particular focus was the 
Junior Year Abroad (JYA). Initially a trip aimed at cultural immersion, this program, begun in the 1920s, evolved over decades into more extensive language study along with a homestay (Edwards, Hoffa, \& Kanach, 2005). An interesting shift in demographics began with the JYA, as the inclusion of women participants became more commonplace.

The second evolution of study abroad came about as a result of increased economic influence outside of academia. By the end of the 1980s, the world was transitioning to a postcold war environment where communications and technology were in rapid development and people and ideas were more quickly and readily traded across borders. This led to the perception that all economies were part of a global marketplace. Globalization is defined as the "opening of local and nationalistic perspectives to a broader outlook of an interconnected and interdependent world with free transfer of capital, goods, and services across national frontiers" (Globalization, n.d.). In an effort to increase revenue, universities took on the global economy as well, which ultimately changed the meaning (both philosophical and fiscal) of study abroad at the university level. Professional schools and trustees became the driving forces, diverging from traditional, more academic and knowledge-based goals, to world economy-inspired transformation of college and university programs (Brockington, Hoffa, \& Martin, 2005). Today, higher education increasingly adheres to the neoliberal model, one that Giroux (2005) defines as "the belief that the market should be the organizing principle for all political, social, and economic decisions... under which everything either is for sale or is plundered for profit" (p. 2). Kubota (2016) argues that higher education has increased "privatisation, marketisation and branding as well as an emphasis on human capital development and lifelong learning" (p. 347). Universities today actively work through an intense marketing and branding process that puts pressure on enrollments, turning the student into "human capital development" (p. 347). In response to this 
shift in policy and ideology in higher education, the discourse and understanding of what a student needs to be successful has changed. Kubota explains that "a neoliberal social imaginary constructs an image of the neoliberal subject as equipped with communication skills, a global mindset, and intercultural competence and thus as competitive in global labour marketplaces" (pp. 347-348). Consequently, study abroad has become more commodified than ever having evolved from an experience that increases knowledge and understanding of cultural and linguistic variations to what Sweeney refers to as the exploitation of multiculturalism (2013). Indeed, study abroad is often touted as a means of gaining a more competitive advantage in the marketplace under the guise of diversity and globalization of participants and institutions. This section shows the impetuses and the steps taken to shift the university's motivation for knowledge-seeking to one of financial gain, which affects the incentive for promotion of study abroad programs.

\section{A Critique of the Telling of History}

History provides a standard of living and thinking to which many adhere, including our mindset about language learning and study abroad, but whose version of history can be trusted to provide the whole story? There is a long-standing lack of history written by or about people of color, low socio-economic status, or those who are not from the Western world. We read and/or teach these histories with the erroneous assumption that the people described within have equal power and access to recount their perspectives and experiences. We then learn about history in school and over time the essence of that knowledge permeates our consciousness and becomes our truth. It stands to reason that many of our traditional sources of information do not tell the whole story and that they privilege certain national or local hegemonic beliefs. Zinn (2005) writes that any country's history “conceals fierce conflicts of interest...between conquerors and 
conquered, masters and slaves, capitalists and workers, dominators and dominated in race and sex" (p. 10). These dynamics show that not all histories are created equal and infer that the lens used to tell a story depends on who has power to control the discourse. Carter G. Woodson (1933) writes: "If a race has no history...it stands in danger of being exterminated" (p. 73). African Americans' part in history has been neglected because many historians have not considered their contributions to be important. Furthermore, according to Willinsky (1991), history is often used to justify the continued oppression of people of color by misconstruing or excluding altogether their part in history in textbooks. This ideology has broad-reaching implications on American discourse both in popular culture but also in the structure of our institutions as content that is taught and learned is reified in public life, at home, at school, in business transactions, in creation of policies, during a study abroad, and so on.

\section{History Books}

History books provide information that influences the way that people think about and live in the world so those involved with deciding the content of these books hold a great amount of power to reinforce commonly held beliefs, structures, and rules. This is significant to the discussion of language, identity, and study abroad because, through travel, study abroad participants carry with them and disseminate these ways of knowing and power structures that reify colonization, language hegemony, and raced power structures. Furthermore, people interpret their experience based on these learned standards and expectations. In Learning to Divide the World, Willinsky (1998), points out the extent to which the United States education system and very culture are dominated by the idea that the Western world is the gold standard of true civilization. When Christopher Columbus "took possession of the New World" in 1492 he gives a description of the people that he encounters upon his arrival as "well built with fine 
bodies and handsome faces...friendly, naked, and in color, neither [B]lack nor white" (as cited in Willinsky, 1998, p. 55). Columbus goes on to say that he will "bring a half a dozen of them back to their Majesties, so that they can learn to speak" and concludes by saying "And I believe that they would easily be made Christians, for they appeared to me to have no religion" (as cited in Willinsky, 1998, p. 55). These words, sent to the Queen and later to be read by schoolchildren worldwide, not only highlight a self-imposed superiority and justify the white man's invasion and stealing of land. Willinsky (1998) describes it as a will to know, that reinforces power and entitlement because objects and peoples are categorized from a European perspective and used as a tool to enforce imperialism.

Cultural constructs become embedded in our minds through what is learned in school. Students are not taught to question the veracity of what they read and many textbooks represent discourses of separation and hierarchy by pointing out the sophistication of the Western world compared to other places through use of the words "us" and "them" in their recounting and categorization of history. In this manner, students are invariably taught to "other" without question from early moments in their educational experience leaving a vacation or a "study" abroad to be grounded in the idea of exoticism and difference, in entitlement and acquisition.

Postcolonial critique argues that binary distinctions such as West/East, developed/developing, or normal/exotic evoke a pejorative connotation of othering that perpetuate colonial forms of discourse of "power and control present in the First World representations of the Third World" (Echtner \& Prasad, 2003, p. 668). Examples of this can be found in many history books used to teach school children. In Leinwand's 1986 textbook unit called Cradles of Civilization, the terminology "our" and "their" is used throughout, such as "Our Debt to Ancient Greece," and "Their Ancient Splendors” (in reference to India and 
Southeast Asia) as a reference to the "infancy" or an undeveloped precursor to the civilization that would come much later, of which they would not be a part (as cited in Willinsky, 1998, p. 127).

Another example of textbooks normalizing colonial discourse is Leinwald's definition of civilization as "a term applied to a people who have reached a certain level of culture" inferring that the uncivilized or those previously civilized people could not reach a true level of culture comparable to today's Western ideals (as cited in Willinsky, 1998, pp. 127-128). A blatant example of this refers to Africa and India as having "contributed to civilization" without being considered fully "civilized" (pp. 127-128). Other examples are when many centuries are ignored in the textbook in and jump from strategically chosen significant events such as "A Journey from Medieval to Modern Times" and "Democracy Triumphs over Absolutism in Europe," (p. 128) with blatant disregard for the importance of any human activity other than what occurred in the European and Western world. Such a focus makes the reader/learner suspect that either very little of worldly importance happened during those years void of description but it is likely that the author makes choices, conscious, unconscious or both, through his own bias to highlight the Western world to the detriment of the rest.

The labeling of non-Western countries as less civil and blatant disregard for the significance of and value to history of other parts of the world affects our ideological approach to travel. It influences our behavior in other lands towards other people. It permits us to critique and disdain or exoticize the way that others eat, dress, and interact both socially and professionally. The underlying tone in historical stories shapes the way we perceive study abroad and influences our level of motivation to learn an L2. Not only that, this perception influences who studies abroad in terms of socio-economic class, gender, and race. 
The history book cited in the previous section is from the 1980s, but even in the second decade of the 2000s this misrepresentation continues unabated by those with the power to decide content for textbooks used by American children, effectively perpetuating white power structures in children's minds. In fact, the state of Texas has been one of the decision-makers for the content of the nation's textbooks for decades. Texas received this honor because of its large size, the number of school children in the state, and because it pays 100 percent of all textbook costs. These basic justifications have provided Texas carte blanche to bias the textbook content as they see fit. Since the 1960s, Texas has insisted upon conservative explanations that go hand in hand with Christian religious principals and the second amendment:

No matter where you live, if your children go to public schools, the textbooks they use were very possibly written under Texas influence. If they graduated with a reflexive suspicion of the concept of separation of church and state and an unexpected interest in the contributions of the National Rifle Association to American history, you know who to blame. (Collins, 2012, para. 1)

Among the textbooks used in the United States, approximately 80 percent of them are written to Texan standards, indoctrinating our schoolchildren with a view of the world that privileges a singular narrative about American history as the story of the triumph of Western ideals over the inferior cultures of the world (2012).

\section{Representation of Geographic Areas}

Another aspect of history's influence on our social and cultural understanding is on world maps and our perceptions of the geopolitical formations of the world. Maps are a powerful representation and reinforcement of the world, especially because they have been drawn based on human perception of it and often, human possession of it. Willinsky (1998) argues that the 
world has been defined and presented "through this projection of discovery and conquest..." and “...renamed in imperialism's image” (p. 137) giving geography a prestige and value that simultaneously reified imperialism.

As people consider a study abroad and/or learning an L2, there is an implicit visual understanding of where they may go or the language they may learn based on geopolitical boundaries set by centuries and millennia of "othering." Mappa Mundi were some of the first maps drawn up showing the earth as an area divided into three equal parts, Asia, Europe and Africa. In this version of maps, Jerusalem was at the center, probably as a result of the mapmaker's faith (Willinsky, 1998). During the Renaissance, Ptolemy's map from A.D. 150 was improved upon by Islamic scholars such as ash-Sharif al Idrisi to help ships more effectively navigate waters between ports, "and in them Europe, Asia and Africa were drawn with manmade separate borders" (p. 138). It is believed that three thousand years ago the Greeks influenced the mindset that Western thought was more distinguished, thus piquing the idea of superiority of the West over the East, but before that time, Europe did not hold the same prestige, considered just "an outpost on the continent of Asia" (p. 138). Willinsky points out very clearly that this way of thinking about Europe and Asia comes from a deliberate shaping of our beliefs through geography:

We have then, on the one hand, to think of how firmly Europe is set apart from Asia in our minds, and, on the other, to consider how hard-pressed we might be, after all those school days spent coloring maps and working with atlases, to mark a map the precise line that geographically divides Europe from Asia. (p. 139)

In sum, Europe and the West are esteemed and equated with superiority, effectively othering any other place in the world in comparison. This has been instilled in our minds through 
maps and by our travel to locations on those maps. Inclusion of this argument serves to understand better how our assumptions were constructed.

\section{Europe Situated as the World Authority}

During the Enlightenment, the Cartesian will to know, was another way of asserting Western cultural superiority. Whereas prior to this time, humans looked for similarities amongst themselves, 17th century imperialism may have encouraged the idea that "human intellect support[ed] a greater order and equality in things than it actually [found]" making the will to know "a calculable form of identity" and of hierarchy (Willinsky, 1991, p. 27).

Postcolonial theory explains how Western modernity itself is inextricable from the colonial history upon which it is built. Said (1978) theorizes how European culture itself created and perpetuated its own superiority as they compared themselves to all other countries and cultures through an "epistomological distinction made between "the Orient" and (most of the time) "the Occident" called othering (p. 2). Questioning even the broad "East-West" binary, Said continues that consequently, writers of all kinds, from fiction to philosophers, politicians to economists fully accept the distinction between East and West, "as the starting point for elaborate theories, epics, novels, social descriptions, and political accounts concerning the Orient, its people, customs, mind, destiny, and so on” (p. 3). Said (2001) argues that humans perpetuate this mindset through what Gramsci calls hegemony, where society places importance on certain ideas which dominate and influence mainstream culture and beliefs. Gramsci argues that those in power maintain their position as a result of cultural socialization (1971). This occurs when religious or educational institutions are used to standardize discourse and "engineer the consent both of privileged and of marginalized members of society...in order to perpetuate particular balances (or imbalances) of power" (Caton \& Santos, 2009, p. 192). 
This complex reinforcement of power, entitlement, othering, and highlighting differences and exoticism, is part of what shapes our mindset about our approach to travel and learning about and speaking with others. Modern study abroad participants (who are 74 percent white, Open Doors, 2016) could, according to Ogden (2008), also be termed the colonial student-they are the ones who want to study abroad but do not want to have to suffer much of any discomfort during their experience. They are also most likely to enroll in English-only programs, they often have a sense of entitlement, like the world is theirs, and their experience of new cultures is often akin to a business transaction: something to be purchased and owned. As Ogden writes, "Rather than immerse themselves into the host community to the extent possible, they embrace the privileges afforded to them as short-term guests" (p. 38). Colonialism is when people go to new territories and take them over all while maintaining loyalty to one's home country and culture. It could be argued that students who go abroad emphasize and reify the privileged position of the student over the local. Ogden asserts that:

If we are merely transposing to foreign soils an American bubble of U.S. higher education concerned mostly with access, consumption, and personal gain, we may be doing little more than establishing a colonial-like presence in what appears to be our country's dominions abroad. (p. 40)

This section served to provide a clearer understanding of the values and beliefs that study abroad participants carry with them into their sojourns abroad that might inform their motivation (or lack thereof) to learn an L2. When famous explorers who, through their power and unquestioned authority influence mainstream thought and consciousness over centuries, when textbooks tell the stories of superior beings that are spread and accepted to the extent that they are difficult to repute, when maps that are drawn to benefit exploration and imperialist ventures 
create a point of view on the world so biased but that most people unquestioningly accept, when language is tied not only to a nationalistic identity, but one which perpetuates the hegemony of First World versus “other," when study abroad is reified as exclusive and exclusionary, this affects who participates and the values and beliefs that they carry as they participate.

\section{History of Second Language (L2) Learning}

In this section, I discuss the history of L2 learning and research. I previously discussed the long history of travel and education abroad and it is equally important to understand how people learn an L2 and the approaches that have already been taken in research. This is part of what lays the groundwork on which I can begin my study.

Second Language Acquisition (SLA) research in study abroad began as predominantly quantitative. According to Block (2003), from 1966 to 1980, SLA focused on linguistic and communicative competence through the very narrow focus of the relationship between language teaching and SLA (p. 3). Carroll conducted some of the early research on the benefits of study abroad, with results indicating that second language proficiency increases more in those who study abroad than those who do not (1967). Carroll's study was based on test scores that measured linguistic improvements and, while it might have been an initial indicator of linguistic outcomes in study abroad, it did not include qualitative measurements of improvement (Freed, 1995). Other quantitative studies in the 1970s and 1980s showed similar results boasting the positive outcome of a study abroad but were flawed either because of "lack of systematic investigations of the effects upon linguists of a period of residence abroad" or because of lack of comparative studies (p. 9).

By the 1990s, researchers began to look beyond length of stay for elements that affect L2 learning abroad. A major finding was the outcome from social interaction in the language. 
According to Duff (2007), language socialization is what occurs when a beginner/novice speaker and member of a community and culture learns the linguistic and cultural behaviors needed to effectively communicate. Ochs (1999) defines language socialization as "how language practices organize the life span process of becoming an active, competent participant in one or more communities" (p. 230). Language socialization focuses on the understanding that occurs between a novice and veteran speaker through different theoretical points of view such as "local theories of mind and emotion, local concepts of paths to knowledge, local modes of legal and political decision-making, language ideologies, and the like" (p. 231).

Ochs (1999) points out that because of the social and interactive nature required for language acquisition, the focal point of the researcher should not be on the participant, instead it should be on the activities and their interactional social and linguistic effects. In sum, language socialization is what occurs in a connection between two or more interlocutors of differing abilities that helps guide understanding in communication based on intricate social structures and awareness passed down from a more learned speaker to the novice one. Language learning, including L2, cannot sufficiently proceed without this important interactive aspect.

In light of inconsistent study results regarding length of stay of L2 learners in a SA setting, researchers began studying whether increased contact with target language speakers would increase language proficiency and found mixed results. Segalowitz and Freed (2004) compared students abroad in Spain and students at home and found a significant difference in OPI score in those who had contact with Spanish speakers versus those who did not. While Magnan and Back's (2007) study of students who spent a semester in France showed that students might make improvement in their speaking abilities, interaction with French speakers could not predict whether or not gains would be made. 
Second language socialization is more complex because it often occurs when a learner is older and has an already-established personality and mindset about the world of "linguistic, discursive, and cultural traditions and community affiliations..." (Duff, 2007, p. 310). This preestablished identity may keep L2 learners from fully investing in becoming socialized or may be met with resistance when interacting with those in the target culture and may influence their desire to become "fuller members in the new L2-mediated worlds" (p. 310). In their critical article, Firth and Wagner (1997) examined the predominant view of second language acquisition (SLA) at the time, noting that it was very "individualistic and mechanistic" and it "fails to account in a satisfactory way for interactional and sociolinguistic dimensions of language" ( $p$. 286). Firth and Wagner then argue for a reconceptualization of the study of SLA using sociological and cognitive dimensions by focusing on "a) a significantly enhanced awareness of the contextual and interactional dimensions of language use, b) an increased emic (i.e., participant-relevant) sensitivity towards fundamental concept and c) the broadening of the traditional SLA data base" (p. 286). They argued that this new approach would allow for use of broader theory (including those outside traditional SLA research), methodology and better explanation of SLA. This new approach would emphasize that language is more than just a cognitive acquisition because "it is acquired and learned through social interaction" (p. 287).

Language socialization has an important place within applied linguistics because of the understanding that it gives to the process of language learning, its influence on identity construction, ideologies, and other behaviors that come from being a member of a community. In the next section I provide an overview of Communities of Practice because of the importance that a sense of community and membership has on L2 learning, and of Legitimate Peripheral Participation because of its explanation of how we, as social beings, come to feel that we can be 
legitimate members of those communities.

\section{Communities of Practice}

The concept of Communities of Practice (CoP) is born from the idea that people learn from taking part in a common interest and work on it together, creating a sense of community (Wenger, 1998). CoPs have more recently been associated with applied linguistics because of the obvious similarities to language socialization (Block, 2009).

A CoP is a place of social interaction for a group of people with a common goal, referred to as mutual engagement (Wenger, 1998). This common goal and time spent together, referred to as joint enterprise, encourage the development of relationships and a feeling of belonging (Wenger, 1998). Time spent together in joint enterprise allows for the development of groupspecific shared repertoire such as words, tools, gestures or other ways of doing things so social interaction becomes meaningful to the group (Wenger, 1998). CoPs allow their members to recognize parts of themselves in others, creating an "identity of participation" (p. 56). It is through the common goal and feeling of belonging in a CoP that shared histories of learning are constructed (Wenger, 1998). When participants feel invested in a community of practice, it becomes part of who they are, allowing their practice to be an investment in learning.

Wenger (1998) asserts that there are three central themes within a CoP: Negotiation of Meaning, Practice, and Participation. We negotiate the meaning of our interactions as we engage with the world. Meaning comes from social interaction within everyday events, called Practice (Wenger, 1998). Participation comes from being an active member in a social community (Wenger, 1998). As an example, graduate students in Spanish who are also teaching assistants, may develop a community of practice in which, through their common interest in teaching Spanish, will actively pursue improvement and eventual expertise by sharing with each other 
ideas, stories, activities and ways of approaching common problems in the classroom. They may discuss disciplinary issues, or their fears of not being prepared, or confusion with grading papers, and they may share with each other their tools for handling different situations. All of this becomes the makeup of a community of practice because through it and their interaction with each other, the graduate students learn from each other how to be better teaching assistants and feel a sense of belonging. Wenger (1998) says that we learn through how we see others and ourselves.

Communities of Practice are groups in which members have a common goal. Members find meaning together through actions that are mutually agreed upon and in which all members take part. These common actions and mutually accepted meaning allows members a feeling of belonging where learning takes place. Given that L2 learning is a social endeavor, joining an L2speaking CoP could have positive consequences on L2 learning.

\section{Legitimate Peripheral Participation}

Legitimate Peripheral Participation (LPP) is the process of newcomers becoming members in communities of practice (Lave \& Wenger, 1991). The idea came from Lave and Wenger's time in Africa where they observed tailoring apprenticeships in which the participant gained comprehensive understanding through "situated learning," not just being the object who receives factual knowledge (p. 95). Learning through LPP involves social practice as the source of learning through a process of observation first from the periphery (to first gain access to sources of understanding) by "both absorbing and being absorbed in the culture of the practice" (p. 95). Through observation, an LPP participant learns to talk about (through telling stories, or community lore) and talk within (through an exchange of information) a practice as part of their peripherality and movement toward becoming a full member. In this study I look at whether and 
how students join CoPs. Recent studies have used LPP/CoP as the theoretical framework in the case of second language learning in a study abroad. Dings' (2012) study focused on a student's interactions with a native speaker during a year abroad in Spain that she considered LPP; Douglass' (2005) case study of a student who lived and studied in France on two separate studies abroad showed the difficult side of attempting to become a legitimate participant; Kalocsai (2009), showed how exchange students on the Erasmus program are socialized through CoPs using English as a lingua franca (ELF) where within those CoPs they successfully develop new modes of speaking and new ELF identities; Morita (2004), studied how students from Japan and their instructors negotiated their new community of practice in the L2 classroom and shaped their learning through their own initiative while negotiating their positionality or identity; and Trentman (2013), whose study of Arabic learners during a study abroad in Egypt focused on both COPs and LPPs. All of these studies show the different ways that students negotiate their identities through LPP in CoPs. Results of studies such as these can and should inform university administrators of study abroad and internationalization programming because joining an appropriate CoP can increase student learning and understanding while abroad.

CoPs and LPPs are useful for studying L2 acquisition in SA because just as in any group situation, an L2 learner does not fully feel that they are proficient until they observe from the sidelines and slowly make connections, both spoken and unspoken, that give them the feeling and confidence and identity as a legitimate speaker. These frameworks may also be useful when looking at notions of critical identities and how they are reified through CoPs.

\section{Poststructural Views on Identity in L2 Learning}

The study of L2 acquisition has evolved from drills and rote memorization pre-and postWorld War II to interactionist communicative competence in the ' 80 s, to collaborative learning 
and sociocultural theory in the '90s. This gave birth to the "social turn" (Block, 2003) in SLA, focusing on "the social and cultural identity of language learners" (Norton, 2013, p. 207). While social interaction has been shown to have some positive impact on L2 learning in study abroad, there are many instances in which it does not. Along with the social turn in SLA, researchers have begun to focus more on variations of SA participants' identity and how it affects their motivation or investment in L2 learning. Identity, according to Block (2014), is defined through "universal laws or rules of human behaviour" or "the product of social conditions in and under which it has developed" and as being "shaped and formed by (one's) culture" (p. 14). The study of identity in SLA focuses on how L2 learning is affected by such social constructs as race, gender, class, and sexual orientation (Norton, 2013).

Poststructuralism is the idea that the world around us is "nuanced, multileveled and ultimately, complicated" leaving us lacking in "secure foundations for knowledge" and carrying an "instability of meaning" (Block, 2014, p. 15). SLA research has shifted to include a focus on the whole person and a Poststructuralist approach has become prolific such as Norton (2000), in studies about immigrant women in Canada; Pavlenko et al. (2001), about language learning and gender; Omoniyi (2004), about language choice, language mixing, and language identity in light of language identity construction; and Pavlenko and Blackledge (2004), regarding negotiation of identity in different political and cultural contexts. Norton's (2013) poststructuralist definition of identity is, "the way a person understands his or her relationship to the world, how that relationship is constructed across time and space, and how the person understands possibilities for the future (p. 15). As a person learns to speak a new language they are constructing "a sense of who they are and how they relate to the social world" (p. 15). Given that the student's independent relationship with the world is often just beginning to develop, it is important to keep 
in mind how an L2 learner's sense of self is quite significant to how they approach L2 socialization. A poststructuralist approach includes the mindset that there are indeed many complicated layers to understanding and properly highlighting the complexity of how power and identity shape study abroad. The study of SLA is crucial to include when analyzing study abroad. First, because it provides a larger picture of language socialization, and second, because within language socialization, notions of power such as those discussed in the history of study abroad in the previous section lay a groundwork for language hegemony and English used as lingua franca, (which I will explain in a later section) all of which influence reification of power structures.

\section{Positioning and Imagined Communities}

An additional aspect of poststructuralism in SLA is the theory of positioning, which is "the discursive process whereby people are located in conversations as observably and subjectively coherent participants in jointly produced storylines” (Block, 2014, p. 22). Block argues that through positioning, language learners often create "imagined" communities of speakers of which they see themselves as future members (2014). However, it is possible that otherwise motivated students do not feel that an investment is worthwhile if they do not see themselves using their L2 in an everyday capacity in the future. An additional negative outcome of imagined communities can arise if they are presented in stereotypical cultural practices that Norton (2013) says "promote racialized discourses that homogenize" or "other" them (p. 22). Just as Anderson (1991) described nationality as a socially constructed reality based on members' understanding, acceptance, and upholding of the symbolism of belonging to the group, (also termed "imagined communities,") so do study abroad participants take part in, reify, and fulfill the discourses of an imagined community. Furthermore, SA participants construct and 
reify an imagined identity of themselves before, during, and after their sojourns that can affect their investment in L2 learning and in their study abroad experience overall (Norton, 2013). These discourses of imagined community and identity are born from ideas perpetuated through institutions and social interactions in society which I will discuss in more detail in the next section.

\section{Motivation Versus Investment, and Critical Experiences}

The study abroad experience can summon up pre-established notions of power and affect motivation to fully immerse. For the past decade or so, SLA has focused on student motivation in L2 learning. Norton (2013) has argued that investment is a better term. While students may often show sufficient motivation to learn, they may not end up with significant L2 learning. Instead, the notion of investment takes into consideration power relations within the SLA environment. Norton argues that those who invest in L2 learning will result in increased symbolic and material resources (knowledge, education, future career opportunities, money) as well as cultural capital and social power (p. 17). As L2 learners increase their investment their desire to learn increases.

There are however reasons to consider why a student would not invest in language learning. Some students do not because of unequal power relations in their learning environment such as a sexist male professor with female students, or they may not invest because they are too shy or ashamed to speak and make a mistake when with a group of native speakers. Others may be more invested in their pre-established identity (national, racial, social class, etc.) from home and instead find ways to retain it, which I will focus on in depth in this study. A strong influence on one's identity can come from when a person moves to a new place where cultural values and rules are different. This can disrupt a feeling of stability, leading a person into a period of loss of self. Block (2002) refers to this as a critical experience. In essence, many people (especially 
white, middle-class) have not given much thought to their identity especially when their whiteness allows for unquestioned belonging. Block elaborates on critical experiences as a time during which:

prolonged contact with an L2 and a new and different cultural setting causes irreversible destabilization of the individual's sense of self. There is, in a sense, an element of before and after in critical experiences as the individual's sociohistorical, cultural, and linguistic environment, once well-defined and delimited, becomes relatively ill-defined and openended. (2002)

Within this critical experience there is an ambivalence of "feeling (both) a part and feeling apart" where you feel both near and far away, both a stranger to your surroundings even as you are an inhabitant of them leading to the need to reclaim a stable group membership (Block, 2002, p. 26). This may be the first time a person experiences feeling "othered" and is possibly exposed to their colorblindness.

I bring up this shift in terms from motivation to investment along with the previous examples to highlight more nuanced notions of power that may affect a motivating idea. Furthermore, it shows why investment is a more appropriate term for use in this study.

\section{Critical Applied Linguistics}

A significant part of identity research in SA and L2 learning is the amount of social hegemony a person experiences depending on gender, race, socioeconomic status, and nationality, and the influence that they have and that it has on them in social situations. Social hegemony is the power of accepted norms over the majority population, and in Gramsci's terms, was often decided upon by the bourgeoisie or the dominant class (Cox, 1983). Pennycook describes critical applied linguistics as the study of "how forms of power affect language use and 
how power may operate ideologically through language" (2001, p. 46). Critical linguistics looks at ways of relating micro relations of language use to macro relations of social context, where micro might refer to conversation in English, and macro might refer to the system of global capitalist relations. It is important to recognize the connection "between people's place in the societal hierarchy, and the linguistic and other kinds of oppression that they are subjected to at different levels" (p. 51). English-speaking CoPs that form during SA are based on linguistic inequality because students consciously or unconsciously place themselves in a location where the principal language is not their own, but then find a group of people in which the socially accepted language is English, which not only brings them comfort, it reifies unequal power relations that students feel when they cannot speak the local language. Americans, as speakers of one of the most used lingua franca in the world, can get away with this. Participants in Englishspeaking CoPs actively mark their social identity. Cameron (1995) asserts that "how you act depends upon who you are, but critical theory argues that who you are depends upon how you act” (p. 53).

In the next section I take a closer look at the a brief history of the language use in the United States. I also describe the power of language as a socially constructed part of American identity, reiterated in all that we say and represent.

\section{Language Hegemony}

In order to understand what affects students who study abroad to learn a second language, it is meaningful to point out possible reasons why many study abroad programs overall do not even promote second language acquisition. I focus on money and power as two principal reasons for the perceived superiority of the English language. 
Throughout approximately the past 200 years of American history there has been a growing antipathy toward use of languages other than English (Pavlenko, 2002). While students of a certain socio-economic class are encouraged to study abroad, it is not considered essential that they learn the local language. In her 1995 study, Freed surveyed study abroad offices across the country regarding their program organization, data collection procedures, and pre- and posttest language study practices. Results showed that $80 \%$ of the respondent universities had not initiated data collection regarding study abroad participants' language skills (p. 15). Study abroad programs had very little interest in linguistic acquisition abroad in the 1990s and this has not changed today. The 2016 Open Doors report shows that emphasis is placed on increasing the number of students who participate in study abroad (2.9\% in 2015), and that second language acquisition is downplayed. This assertion is supported by Open Doors statistics that show that the most frequented locales are still countries where English is spoken or where courses are offered in English (Open Doors, 2016). These statistics lead to the next section in which I discuss the use of language for power and how this informs dominant American social constructs of "foreign" languages.

\section{English is a Language That Privileges Dominant Groups}

Official or commonly accepted languages gain capital because of the structures

established by those in power. It is not a coincidence that the rise of Castilian as the most spoken language in Medieval Spain was connected to Columbus' military conquests in 1492 because the language spoken by those in power represents an especially forceful social construct (Willinsky, 1991, p. 191). In the United States, despite its founding as a country of immigrants with multiple linguistic backgrounds, around the turn of the 20th century during what Pavlenko (2002) terms the Great Migration, or the years between 1880-1924, because of the estimated 24 million 
immigrants that entered the United States at the time, the government began English language testing as part of naturalization, leading to the commonly accepted idea that those who speak English are more American.

Currently there is strongly accepted discourse that English is the language of the world and it is certainly the language of power (Johnson, 2009). What is the history of English as the national language of the United States (and for most Americans, the lingua franca all across the world) and how has this influenced Americans' willingness or lack thereof to learn and speak other languages and not revert to English when abroad?

Pavlenko (2002), who explores language and national identity in the United States beginning in the 17th century up until the present, argues that national identity has not always been based upon a common language. Indeed, the European idea of American national identity affirmed the desire to commit oneself to liberal political principles and individual achievement (2002). Pavlenko notes that when our Constitution was written there was no mention of English as our national language (2002). Moreover, knowing more than one language was considered practical and necessary for national unification, which resulted in many governmental practices conducted in multiple languages. For example, the California Constitution of 1849 required the publication of all laws in both Spanish and English and the Louisiana legislature and courts were all bilingual English and French in the 19th century (Pavlenko, 2002). Of particular note however, is the socially constructed hierarchy, even with regard to non-European world languages. Indigenous languages as well as Japanese and Chinese were disregarded, as they were considered uncivilized people and were segregated from the rest (Pavlenko, 2002).

World War I and its anti-German discourse helped to encourage anti-immigrant movements. The Americanization movement was a response to immigrants who came from 
Eastern Europe, an area considered culturally, ethnically, and linguistically inferior (Pavlenko, 2002). Furthermore, strong anti-German sentiment changed the previous tolerant environment of bilingualism and multilingual journals, schools, and government. The English First movement, where evening schools and civics education were taught was one consequence (Pavlenko, 2002). Furthermore, employers such as Henry Ford and others promoted Americanization by saying that low English proficiency affected workers by making them "easy prey to socialist propaganda" and thus instituted English schools (p. 180). Bilingual and world language education lost their importance when it was suggested that speaking in another language might affect cognitive and linguistic development of immigrant children, and eventually world language instruction was removed from the elementary school (Pavlenko, 2002). In 1919 President Roosevelt said:

We have room for but one language here, and that is the English language, for we intend to see that the crucible turns our people out as Americans, of American nationality, and not as dwellers in a polyglot boardinghouse; and we have room for but one sole loyalty, and that is the loyalty to the American people. (p. 184)

This discourse, passed down from generation to generation in teachings at school and at home, is part of how whites socially construct Americanism, internalized in thought and deed. Contemporary media and societal discourse continues to connect patriotism and use of English as superior qualities, and this is reinforced by higher education institutions. Lacey asserts that: A point in history has been reached where global power relations have been significantly tipped in favour of Anglophone countries such that encountering situations where English is required or useful are more likely than for any other language. (2015, p. 3)

Study Abroad entities such as Generation Study Abroad highlight the importance of a global education to the ever-growing global economy and at the same time the United Kingdom 
remains the top (i.e. English-speaking) location of choice for American students, leaving it fairly clear that Americans do not place world language acquisition as a priority (IIE, 2016).

\section{Linguicism}

In the United States and around the world, it is apparent from schools to businesses that English is highlighted and used as a privileged language and a language for the privileged. This construct in effect excludes and stigmatizes those who do not speak it. Linguicism refers to an unequal division of power based on the languages that people speak (Pennycook, 2001, p. 61). A simpler way of defining it is discrimination carried out through language. Phillipson posits that as English becomes more dominant and accepted through its common and frequent use across the globe, it becomes a kind of English linguistic imperialism, as it perpetuates "continuous reconstitution of structural inequalities between English and other languages” (1992, p. 47). Some argue that English language teaching to foreigners in the United States and abroad is a guise for English linguistic hegemony, a way in which "the explicit and implicit beliefs, purposes, and activities which characterize the ELT profession...contribute to the maintenance of English as a dominant language" (p. 47).

Speakers of official languages such as English tend to hold all linguistic rights, and the fact that English is used in 90 percent of information online, may underline this suggestion (Hsiao, 2014). English is also the language of communication in global business, art, culture, politics and more (Hancock, 2007). According to Pennycook, those who do not speak it or who do not speak it well are "othered" (2001). Othering permits people to be placed in inferior social and economic classes. It highlights English's superiority, carries it across societies, and spreads understanding and acceptance of its power and social capital to those who speak or know about it across the world. English-speaking communities of practice (CoPs) in SA are based on linguistic 
inequality. The unequal power structure within the target language community threatens the habitus "the physical embodiment of cultural capital, to the deeply ingrained habits, skills, and dispositions that we possess due to our life experiences" (Bourdieu, 1984) so much that study abroad participants naturally drift toward an English-speaking group of people, so as not to lose the power that comes along with that with which they have identified their entire lives. Pennycook argues that "language and social class are connected to power in different ways in different groups/settings where language allows for social advantage, and highlights cultural difference" (2001, p. 53). Study abroad participants who speak English are involved (consciously or subconsciously) with what is referred to as cultural imperialism. This is the "imposition of certain aspects of culture (manners, art, language) of one nation over another" (Hsiao, 2014, p. 14). American culture has permeated the far reaches of the world through war, capitalism, consumer culture (food, art, movies, tv, music, fashion), and travel. Study abroad students who speak English also help with the spread of American culture, values, language, and social construct of its power by emphasizing and reifying the privileged position that they have as Americans over the local culture. In all, critical linguistics looks at how we can relate "micro relations of language use to macro relations of social context" and might help explain why SA participants feel legitimized in taking part in English-speaking CoPs during study abroad (Pennycook, 2001, p. 64).

\section{Implications for Study Abroad Programs}

The history of study abroad and of second language acquisition in the previous sections helps to set the stage for my study because it gives an in-depth background of the spiritual, institutional and theoretical structure of human travel and learning. In this section I describe the implications on study abroad and internationalization programming. 
This history and subsequent critique of study abroad must be taken into account when analyzing data, considering the implications, and planning for future study abroad participants and L2 learning. One's racial, gendered, and sociocultural background are determining factors not only in their linguistic and cultural outcomes, but also in who studies abroad in the first place. It is important to note that study abroad remains largely for the privileged and white, despite strategic plans that show that diversification efforts are in progress. Furthermore, the 2016 Open Doors report shows statistics that people of color continue to be underrepresented. While white participants were at 72.9\% in 2014-2015, a combination of Hispanic/Latino(a), Asian/Pacific Islander, Black/African-American and Multiracial participants adds up to just $26.6 \%$ in that same year (Open Doors). It is rather apparent that our institutions are not structured to support students from these "othered" backgrounds, making language learning and study abroad opportunities an experience that feels quite out of their reach, let alone relevant to them (Sweeney, 2013). Ta-Nehisi Coates (2015) in Between the World and Me elaborates on his confusion at the meaning of French courses in junior high to his present or future life:

I remember sitting in my seventh-grade French class and not having any idea why I was there. I did not know any French people, and nothing around me suggested I ever would. France was a rock rotating in another galaxy, around another sun, in another sky that I would never cross. Why, precisely, was I sitting in this classroom? (p. 117) It certainly seems that study abroad researchers, administrators and world language educators have not considered the depth of disconnect that exists between the person who sees the world as their oyster to explore compared to those whose demographic circumstances have impeded them from seeing the use of such experience and knowledge. On the other hand, learning a world language could be a very powerful tool. A different example comes from 
Angela Davis, who, a French major in the mid 1960s, used her fluency in French to her (and her sister's) advantage. One day, back in her home town of Birmingham, Alabama, she and her sister went shopping downtown. For Angela and her sister, shopping in a southern American state required that they shop in a back room instead of in the front showroom. On this day, they decided to speak only in French and feign being from Martinique, and it worked! The storekeeper did not direct them to the back room; instead they were served and treated well in the showroom of the store. After some minutes passed, Ms. Davis could no longer hold in her secret and broke back into English only to confront the storekeeper about the hypocrisy of their treatment as suspected foreigners compared to Black Americans (Kaplan, 2012). This is one way of using a second language to one's advantage. Another powerful tool is using it to gain knowledge to respond to and refute certain facts in the media, in studies, or history books written in the language of the colonizer.

Finally, it would be incomplete to ignore other hindrances to successful L2 learning during study abroad, such as the notion of students as tourists/colonizers with a worldview and mentality of entitlement, or internet culture, obsessive cell phone use, helicopter parents, as well as risk averse students, parents, and institutions. It is also critical to note the transformative possibility of study abroad, but we as educators must give students the tools to help them be more critical of what they see, hear, and read, as well as be aware of their own thoughts and actions in order to open their eyes in curiosity and acceptance to other ways of life. Said (2001) speaks in favor of a symbolic self-imposed exile, in which one may distance oneself from all cultural identities, in a situation in which one does not feel at home anywhere. Said believes that universities have a crucial role in this. In a New York Times review of Said's book, Nussbaum describes universities' obligation to students: 
...to unsettle and oppose, to test all orthodoxies, to offer routes by which young minds may travel from one culture to another and learn a valuable type of estrangement from their own. This role requires that the university itself should not be organized around ethnic or racial identity politics, but should seek to open the entire realm of culture to all. (2001)

While the benefits of study abroad can be undeniable, such as learning how to see things from a new perspective, providing students an opportunity to understand themselves, their way of life, and their place in the world, all while setting the stage for a more fruitful future, (Dolby, 2004), study abroad can also be an experience in which the participant's subconscious power is reinforced. The preceding sections provide an argument for how control by a powerful few over dissemination of information has a substantial impact on the way in which most publicly educated Americans interpret the world. Moreover, language throughout much of modern history has been imposed as an additional tool to show dominance. American students who study abroad and continue to use English instead of learning and speaking the local language, whether they mean to or not, perpetuate colonial imposition. In the next chapter I will discuss the methodology used for the study. 


\section{CHAPTER III: METHODOLOGY}

\section{Introduction}

Second Language Acquisition (SLA) studies of SA participants result in mixed linguistic outcomes. Some students experience significant L2 learning, while others do not. In the 1980s and 1990s this was often attributed to the length of the study abroad sojourn and whether or not a student stayed with a host family, however, the social turn in SLA in the late 1990s to early 2000s introduced the idea that research must look into additional characteristics that affect a student's effort during and realization of study abroad (Block, 2003). Results from subsequent research indicate more distinct issues that affect learning and SLA abroad such as program length versus pre-departure L2 proficiency (Lindseth, 2010; Segalowitz, 2004), and motivators such as living arrangements (Martinsen, Baker, Dewey, Bown, \& Johnson, 2010), gender (Kinginger, 2009), identity (Block, 2006; Dolby, 2004; Pavlenko, 2002) friends and attitudes (Isabelli-García, 2006), and the effect of Facebook and other social media (Downey \& Gray, 2012; Huesca, 2013). Some who conduct identity research ignore how a student's gender, race, nationality, and socio-economic status accentuates power dynamics in the host culture that can influence their experience abroad, and more importantly, whether they study abroad at all (Norton, 2013). Furthermore, in using critical applied linguistics researchers can point out language development as affected by social constructs of power that are reiterated in school and in society through a history written by the privileged (Pennycook, 2001). There is preliminary evidence that students' L2 learning and motivation is affected while abroad because of specific demographics or identities. For these reasons, I pose the following research questions: 
1. How do student-participants negotiate their identities (racial, national, and gender), L2 learning, and engagement (or lack of) with various communities of practice while studying abroad in a non-English-dominant country?

2. How can an understanding of study-abroad participants' identities and participation in communities of practice abroad inform administration and implementation of study abroad programs to encourage L2 learning?

\section{Interpretivist Methodology}

My methodology is grounded in interpretivism. Interpretivists believe that the distinction between the natural and human sciences is that of inherent meaning. Schwandt (2000) theorizes in order to understand a human or social action, "the inquirer must understand the meanings that constitute" it (p. 191) and gives examples of how a "wink is not a wink or a smile can be interpreted as wry or loving" (p. 191). In order to find meaning in any action, one must interpret what a person is doing, and to interpret is to understand. To understand the meaning of a person's intent, one must "get inside the head...to understand...(their) motives, beliefs, desires, thoughts, and so on" (p. 192). While Schwandt maintains the interpreter is able to separate from "his or her historical circumstances in order to reproduce the meaning or intention of the actor" (p. 192), others are dubious. Nevertheless, the idea remains that an interpreter tries to get an "inside understanding" of the actor through "looking over the shoulders of the actors and trying to figure out (both by observing and by conversing) what the actors think they are up to" (p. 192).

An abundance of preexisting quantitative research in SLA has not been necessarily successful at getting to the heart of the matter. Furthermore, over the past decade there has been a growing understanding of the unique, individual experience of the study abroad participant. 
Coleman (2013), in bringing up aspects of the SA participants' experience such as their focus "on romance, on discovery of self and others, on people and places," (p. 29) points out the importance of approaching SA participants as whole people:

Study abroad research can escape the narrow confines of cognitive SLA and see its subjects not just as language learners, but as rounded people with complex and fluid identities and relationships which frame the way they live the study abroad experience.

This kind of focus can allow for in-depth understanding of how students are influenced by identity and power. For these reasons, a qualitative, emic, interpretative approach is needed in order to gain a greater understanding of how students experience and attribute meaning to study abroad. Qualitative methods are a meaningful and compelling way to learn more about the whole person and "seek(s) to make sense out of actions, narratives, and the ways in which they intersect" (Glesne, 2011, p. 1).

\section{Paradigm}

A paradigm is a way of thinking that refers to "assumptions about the nature of reality and truth, the kinds of questions to explore, and how to go about doing so" (Glesne, 2011, p. 5). My study is located within two paradigms, critical and interpretative. Since my theoretical framework is in Critical Linguistics, my paradigm is mainly critical, which I will describe later in this section. However, my study is also informed by the idea that understanding is based on individual perception, which relies on “accessing others' interpretations of some social phenomenon and of interpreting... actions and intentions" (p. 8). Those who take an interpretivist approach believe that reality is socially constructed and is manifested through "language and thought of wider society" (p. 8). The research goal of interpretivism is to understand the 
perspectives of "those who are actors in that social world" (p. 8). While Glesne describes the main purpose for use of the interpretivist paradigm as "understanding," she describes "emancipation" as the purpose for a critical paradigm. Furthermore, Glesne describes the term "critical" as "the detecting and unmasking of beliefs and practices that limit human freedom, justice, and democracy" (p. 9). Building on the interpretivist idea that reality is socially constructed, critical theory takes it an important step further to "reveal and critique these distorting ideologies and the associated structures, mechanisms, and processes that help to keep them in place" (p. 9). Two aspects of research design often affiliated with critical theory that inform my approach are 1) researchers see their "research as a political act, because it not only relies on values systems, but challenges value systems... and advocate(s) understanding from perspective of the exploited and oppressed" (p. 10), and 2) researchers tend to focus on rules of language such as "what can and cannot be said, who can speak with the blessings of authority and who must listen, whose social constructions are valid and whose are erroneous and unimportant" (p. 10). While I seek to understand what affects language learning during a SA from an interpretivist epistemological perspective, I do so acknowledging institutional imbalances and injustices regarding language learning and study abroad from a critical epistemological perspective. I seek to go beyond description to reveal oppression and to raise awareness in order to enact change.

In conclusion, a critical, interpretivist approach uses qualitative methods in order to provide a richness of detail about the whole person through their own personal narratives over time, through well-developed, complex descriptions that may aid in an understanding from a unique point of view. "Accessing the perspectives of several members of the same social group about some phenomena can begin to say something about cultural patterns of thought and action 
for that group" (p. 8). When dealing with notions of identities, a critical and interpretive paradigm will help understand how participants' reality is "socially constructed, complex, and ever changing" but also "interwoven and difficult to measure" (p. 9). In the next section, I will provide in detail information about the context of the study and participants.

\section{Data Collection/Instruments}

With each participant, I began by administering consent forms which they all read and signed, followed by a written pre-departure questionnaire that requested their goals for their sojourn, as well as a self-assessment regarding their oral and written abilities in French. I then conducted a semi-structured pre-departure interview in English, followed by an unofficial OPI in French.

\section{The ACTFL OPI}

Given that my question about study abroad participants regarded shifts in L2 learning, it was important to me to somehow gauge my participants' oral proficiency. I first took part in a one-week OPI training course at Brigham Young University and then proceeded through all of the stages of becoming a certified OPI interviewer over more than one year of practice interviews and feedback (ultimately not completing the final stage) so that I could conduct and rate unofficial interviews in my research. I found the unofficial OPI a useful tool in measuring student proficiency across time, especially given research such as Lindseth's study (2010), which showed on average that students who have completed the third, fourth or fifth semester of language at the university level typically rate around intermediate low and Segalowitz's (2004) study, that showed that students on average increase their OPI rating by approximately one sublevel after a semester abroad. Of course, the OPI had to remain unofficial because, although I 
have been through extensive training through ACTFL and LTI, I am not a certified OPI interviewer.

After their first week abroad, participants completed a short, written survey about their living situation and their initial reactions to their new experience. Over the next weeks of their semester or academic year abroad, participants were requested to complete a bi-weekly survey regarding the amount of time they spent online or texting in either English or French, the amount of time they spent reading books or newspapers in either English or French, the amount of time they spent watching movies or TV programs in either English or French, the amount of time they spent on the phone or in person speaking in either English or French. All of the participants completed some of the surveys but none of them completed all of the surveys. Participants also provided information on their experiences via email throughout their time abroad.

At midterm, I administered a semi-structured interview in English, followed by an unofficial OPI in French to each participant. Each student also completed a second selfassessment regarding their oral and written abilities in French.

Upon their return, I administered a semi-structured interview in English, followed by an unofficial OPI in French to each participant. Each student also completed a final self-assessment regarding their oral and written abilities in French, as well as a response regarding their global impressions of their study abroad. Furthermore, all teacher Education majors are required to take a certified OPI upon return to meet teacher education requirements. All of these instruments can be found in the appendix. Below is a data accounting log depicting all of the data collected for each participant. 


\section{Table 1}

Data Accounting Log

\begin{tabular}{lcccccc}
\hline Elements & $\begin{array}{c}\text { Student Name } \\
\text { Year or Semester }\end{array}$ & Magda & Lesley & Becky & Sasha & Charlotte \\
& & Year & Year & Spring & Year \\
\hline Pre-departure Interview / English & & $\checkmark$ & $\checkmark$ & $\checkmark$ & $\checkmark$ & $\checkmark$ \\
Pre-departure Interview / OPI & $\checkmark$ & $\checkmark$ & $\checkmark$ & $\checkmark$ & $\checkmark$ \\
Pre-departure self-assessment & $\checkmark$ & $\checkmark$ & $\checkmark$ & $\checkmark$ & $\checkmark$ \\
Pre-departure written response & & $\checkmark$ & $\checkmark$ & $\checkmark$ & $\checkmark$ \\
Survey after first week & $\checkmark$ & $\checkmark$ & $\checkmark$ & $\checkmark$ & $\checkmark$ \\
Biweekly survey & $\checkmark$ & $\checkmark$ & $\checkmark$ & $\checkmark$ & $\checkmark$ \\
Email correspondence & $\checkmark$ & $\checkmark$ & $\checkmark$ & $\checkmark$ & $\checkmark$ \\
Casual correspondence & $\checkmark$ & $\checkmark$ & $\checkmark$ & $\checkmark$ & $\checkmark$ \\
Midterm Interview / English & & $\checkmark$ & $\checkmark$ & $\checkmark$ & $\checkmark$ \\
Midterm Interview / OPI & $\checkmark$ & $\checkmark$ & $\checkmark$ & $\checkmark$ & $\checkmark$ \\
Midterm self-assessment & $\checkmark$ & $\checkmark$ & $\checkmark$ & $\checkmark$ & $\checkmark$ \\
Return Interview / English & $\checkmark$ & $\checkmark$ & $\checkmark$ & $\checkmark$ & $\checkmark$ \\
Return Interview / OPI & $\checkmark$ & $\checkmark$ & $\checkmark$ & $\checkmark$ & $\checkmark$ \\
Return self-assessment & $\checkmark$ & $\checkmark$ & $\checkmark$ & $\checkmark$ & $\checkmark$ \\
Return response & $\checkmark$ & $\checkmark$ & $\checkmark$ & $\checkmark$ & $\checkmark$ \\
Member checking & $\checkmark$ & $\checkmark$ & $\checkmark$ & $\checkmark$ & $\checkmark$ \\
\hline
\end{tabular}




\section{Data Analysis}

As I analyze my data, I attempt what Glesne describes as "mak[ing] sense of actions, narratives, and the ways in which they intersect" (2011, p. 1). I approach data analysis humbly, not sure whether I will do it correctly and in the hopes that my results will be given credence. Wolcott argues that qualitative researchers realize that they "... are never going to get it all right" and pursue analysis "...to whatever extent it is important to be correct...in the sense of being dependable, accurate, reliable..." (1994, pp. 173-174). The next section describes the phases by which I approach the data.

\section{Theme Analysis}

Wolcott (1994) discusses in an empathetic way the ease with which researchers are able to collect data, but how difficulty arises when researchers actually have to do something with that data. Wolcott advises that the approach to data analysis travel through three phases: description, analysis, and interpretation, and then honing in on each in more specific ways to transform their collected data into a more organized and presentable analysis. For the purposes of this study, I have chosen to use Wolcott's framework for analysis to analyze my data.

According to Wolcott (1994), emphasis on description is a significant part of qualitative analysis. For this, I give a detailed background of each of my participants within chapter five. The choice of what to describe and how to describe it is not simple. Wolcott writes that it is: ...an intuitive as well as an objectifying act (that) requires not only what to observe and report but exquisite judgment about what not to report, a keen sense of what is focus, what is periphery, and how to maintain a perspective and balance between them. (p. 56) Out of the variety of ways to approach description, Wolcott's recommendation of "progressive focusing" will be used to frame my description, which he explains is a description in which the 
focus goes in either direction, "slowly zooming from broad context to the particulars of the case, or starting with a close-in view and gradually backing away to show more context to include more context," (p. 18), or zooming in and out as needed. The second phase, analysis, involves expanding from the description to analyze in a systematic way, looking for key terms or themes, and any relationships or patterns among them (Wolcott, 1994). Wolcott's suggestion of “displaying your findings" will be used for analysis, which he describes as an important "alternative to prose, not only for conveying information, but for dramatizing or emphasizing a particular aspect of a study" (p. 31). Put simply, a display of one's findings can be through tables, graphs, charts, diagrams, posters, and videos that help the reader visualize the concepts of a study in a different way (Wolcott, 1994). Finally, interpretation, the third phase, can begin either right after the description or after the analysis. Wolcott says that interpretation is not necessarily as "scientific" as analysis, because it goes beyond description of word-for-word data. Interpretation "make(s) sense of what goes on, to reach out for understanding or explanation beyond the limits of what can be explained with the degree of certainty usually associated with analysis" (p.11). Wolcott warns researchers that interpretation is "subject to excesses" (p. 36), and not to reach too far beyond the data of the case when interpreting, suggesting instead a number of strategies for interpretation. Out of these, I will use "turn to theory" which he describes as one of the more concrete ways of providing structure because it "link(s) our case studies, invariably of modest scope, with larger issues" (p. 43).

While Wolcott (1994) does not seem altogether impressed with the use of theory, he agrees that "linking power, rather than explanatory power" (p. 43), is theory's strength. What I particularly appreciate is his suggestion that it is sometimes through the use of theory that a 
researcher can come up with an eclectic solution. This may be of particular import when relying on theory that is meant to "reveal and critique" (p.43) in order to enact change.

The type of analysis of my participants' data began holistically; that is, I read through everything to understand their overall story, but then honed in on specific aspects of their case, focusing on key issues in critical linguistics. I first describe my participants, then themes within each of the cases, and then break down those themes to key ideas that will answer my research questions, followed by a cross-case analysis, showing common themes among the participants, followed by my interpretation of what those themes might mean. With each step of data collection, data was analyzed by finding clusters of similar ideas that I grouped together according to critical linguistics and language socialization theory, along with supporting detail from and triangulation of all oral interviews or written communications. Participant description and analysis can be found in chapters four and five.

\section{Researcher Positionality}

In chapter one I described my experiences studying abroad and how it led me to my topic. In this section I will discuss my professional role at the university and my relationships with my study participants in relation to my positionality.

First, I am an Academic Advisor for all majors and minors in the Department of Languages, Literatures, and Cultures. All of the students who participated in my study were my advisees. In addition, they were all students in the Second-Year French Part II course that I teach at the university, coincidentally, that each student took during the semester or a few semesters before they studied abroad. I taught and encouraged them to focus on bettering their French through speaking, reading, and writing, and so I do have some preconceived ideas of who they are and how hard they work to learn. Furthermore, some of them were active in the French honor 
society here at Illinois State for which I am faculty advisor. Finally, I am the faculty advisor for the Angers, France study abroad program. This means that I am the point of reference when a student has questions or problems before or during their study abroad. I do not assign grades to students, I am only in this role to prepare them for and facilitate their experience.

It is essential to mention the personal connection that grew during the time that these students took part in my study. I developed warm feelings for the students that could get in the way of pointing out some of the critical issues that came up during their sojourns. It is especially trying to write up this analysis knowing that these former students may be upset with some of my discerning observations. My first instinct is to protect my relationship with them as a mother might protect her own children. Furthermore, I must remain aware of my positionality as a white woman. This was particularly salient with Becky when I found myself unable to help her navigate some aspects of her experience abroad as a Black woman, and may have limited what she divulged in her interviews with me. Finally, I cannot underscore enough how being a white woman from an upper-middle-class background shapes my understanding of study abroad issues and informs my interpretation of them. As a result, I might have either misperceived or I might have ignored comments or behavior because of my lack of awareness regarding issues connected to people of color or lower social class. I also might have had different expectations of my participants because of my own easy access to public, social settings abroad. As I analyzed and interpreted this data, I have remained as cognizant as possible to work against this background by acknowledging and being aware of my bias, although I admit that some subconscious bias cannot be completely erased. 


\section{Ethics}

This section references how my research is used, how I treat my participants, and the ways that I interpret the data that I am provided. While it is difficult for my own personal experience and perceptions not to inform my analysis, I must remain cognizant that my research does not become a mere reflection of my own personal or professional agenda.

In order to secure the consent of my participants, I first completed an Institutional Review Board (IRB) protocol request in which I described the study, my research, data collection and instruments, as well as the letter of request and the consent form. The first time that I undertook this process it took almost four months. Although it was frustrating, it was a reflective process during which I was required to consider the effect that the content of my interviews might have on my participants. Furthermore, I had to consider whether my role as faculty advisor or advisor for their major/minor program put me in a position of excessive power that might intimidate my participants or make them feel obligated to take part in the study. This time of contemplation aided in my choice of questions, ensuring that I was not leading my students to give the answers that I wished to hear, or pressuring them to participate in something that they were not interested in. Feedback from the IRB at times presented me with potential problems that I might encounter that I would not have previously considered.

I transcribed the participant data myself. This tedious and long task was a conscious choice that was not based on frugality. Instead, it was a way in which I was able to re-live those moments with my participants, re-inhabiting our discussions where I could truly hear the responses as well as reflect upon what was being conveyed (which was good for assessing themes). However, it is critical to keep in mind the power of the transcriber and not be tempted to purposely misinterpret meaning while transcribing. I attempted to transcribe visible and 
audible emotion and gestures, laughs and sighs, hesitation and boldness, and included every word that the participants uttered (including unending "likes") before beginning my interpretation.

My participants may have benefitted from this study in several ways. First, I was an additional sounding board for them regarding their experience. Sometimes it helps clarify meaning to articulate one's opinions and feelings out loud. Second, it may have been interesting for students to be able to have their experience recorded in such a way that they could reflect on and view in retrospect various situations that they had endured. Finally, it was likely eye-opening to them to see how their language abilities changed over the period of a semester or academic year.

There may have been some disadvantages that students felt. The weekly quantitative survey seemed burdensome and boring to them. I cannot be certain of this, but I could tell that many students just took a guess and gave the same response each time they responded to the survey. In fact, some off-the-record conversations with my participants in-part confirmed this, and this is one of the reasons why I relied primarily on oral interviews to inform my data analysis. In addition, students may have been annoyed with my reminders to complete out the survey.

In all, I feel that these students were willing participants who were, in fact, even curious to read everything in its final draft. It was a delight to communicate with them because they were engaging and thoughtful in their responses and reflections.

\section{Trustworthiness}

Finally, issues of trustworthiness or validity are very important to qualitative research. Glesne (2011) describes eight procedures often used in qualitative research to increase 
trustworthiness. Of these, I address five in the process of this study. The first one is "prolonged engagement in the field and persistent observation" in order to develop trust, learn the culture, and check out hunches (p. 49). I was unable to interview or observe my participants on-site as is consistent with rigorous, interpretivist qualitative methodologies, so this is a limitation of my study that should be factored by readers into my findings, yet I am familiar with the site itself. I spent one year myself at the CIDEF in Angers, France, so I have firsthand experience with the setting and I have a rich understanding of the culture, structure of the program, typical issues with host families, teachers, students' social life, and so on. I was in contact via email with my participants outside of the pre-determined interviews allowing for less-structured communication, as well. Also, this study has continued over several years and across a variety of participants, giving me a good number of different participant perspectives to triangulate over a prolonged period of time. The second process is "triangulation of multiple data sources" (p. 49). My study includes data collected through written surveys, oral interviews, and casual email communication allowing a variety of different ways for participants to describe their experience, which also permitted triangulation of their stories and my analyses of them. The third process is "clarification of researcher bias" (p. 49). At the beginning of this study, I reflected on my own positionality as a person who has studied abroad multiple times and who has learned second, third, and fourth languages while abroad. Having clarified this at the beginning, it remains a constant reminder of my initial bias. In this section, I referred to my professional bias and expectations. As an advisor and language instructor, it is my job to facilitate my students' experience abroad and hopefully have students who return with language gains. I must also remain aware of my positionality as a white woman and how it can affect my interpretation of others' experiences. The fourth process in maintaining trustworthiness is "member checking” (p. 
49). For this I shared interview transcripts and the description and initial analysis with my participants to ensure that I have represented them and their ideas in a way that feels fair and accurate to them. All of my participants had a positive response to my descriptions and interpretations. Magda said "I really enjoyed reading your description and analysis; I found them to be fair and accurate, even if not always the most flattering." Lesley said: "What you said about me being defensive about being American and feeling even stronger about being American was true. I'm still that way!” While Becky had more to say about her raced experience, she said that I was too hard on myself about being complicit in it. Her overall reaction was this:

I loved it because I thought it was a very accurate representation of where I was when I first started, before I left, how I felt, because how I felt in France first semester compared to second semester was completely different. And I thought that that came across very well. There were aspects that I (had) completely forgotten about, or, and it's just, I thought it, it was just very - I loved it, I absolutely loved it.

Sasha said that it "was so interesting to read this! Definitely puts me back into the mindset of that time. I notice I use 'like' a lot when I speak - ha ha!’ Finally, Charlotte gave me the following feedback:

Your review and analysis of our interview is spot on and articulates my year so much better than I ever could have! Your words ring true and I loved reading it - I will treasure having this. I know it was written for your Ph.D. but I'm so excited to have these as a reflection on my time abroad!

Based on their feedback, everyone found my descriptions and initial analysis fair, and appreciated having such a detailed memory of their experience. 
The fifth process that I have used in sustaining validity in this study is my use of "rich and thick description" (Glesne, 2011, p. 49). This is important to more fully allow the reader access to the research context through description that goes beyond "bare reporting...[that] describes and probes the intentions, motives, meanings, contexts, situations, and circumstances of an action" providing an understanding that goes beyond generalizations through "observing, eliciting, and describing...meanings and contradictions" (p. 35). I did this by giving the reader a complete and detailed description of each participant and their overall experience, but then dove into particular details to understand deeper meaning, question their intentions, and provide context through patterns and my theoretical frame.

\section{Significance of the Research}

This study is an important addition to the body of research on identity and its connection to L2 learning during a study abroad. While a good number of studies have focused on some components of identity such as gender, very few focus on race, nationality, and power relations, and I am unaware of studies that have taken such a holistic, critical and historical approach of identity construction as I have. The uniqueness of each person and their experiences is why qualitative research is critical, but study results, just like people, can vary greatly. There is a need for critical identity research in the field of study abroad to increase our understanding of the intricacies of identity-related influences on L2 learners in SA as well as general study abroad programming. Furthermore, in our current political climate, the call for increased awareness of who we are and the constructs of that consciousness both in social and educational spheres, are an important addition to discourse in higher education in general, as well as the “internationalization” of colleges and universities. 


\section{CHAPTER IV: PILOT STUDY}

As the faculty advisor of the Angers/CIDEF study abroad program at my university I already had quite a bit of anecdotal and experiential information about how students navigate their studies abroad with regard to L2 learning. Each time a student would return and tell me their story I knew that it was a missed opportunity to collect important data that could be put to use to better understanding the complexities of L2 learning during study abroad. Chev's study was the first IRB-approved, systematic study that I conducted, and it served as a pilot study for the cases discussed throughout this dissertation. His study was used to refine my interview questions, approach to data collection, and to begin thinking more in depth about theoretical frameworks, such as Communities of Practice.

The study about Chev was a qualitative design based on the "case" of a student participating in a CoP and LPP during his study abroad. While initially, my research about Chev was not meant to be a pilot to my dissertation study, it ended up playing an important role in informing the tools that I used and helping me clarify my intentions for my dissertation. Glesne (2011) describes pilots as helping clarify research statements and questions as well as something that will "challenge and uncover some of your assumptions about your proposed topic" (p. 56). Furthermore, in discussing with my professors some of the data and uncertainties in my interview procedures (the types of questions asked, my fear of saying too much during follow up questions or comments, frameworks to consider for analysis) I learned how to conduct and better my study in a very concrete way. Glesne points out that a pilot study helps you learn more about the "research process, interview questions, observation techniques, and yourself" (p. 56). In this way, I gained confidence in my interviewing technique, my ability to listen and respond, and I was able to identify which questions worked and which ones did not and make changes for my 
future study. One very distinct change to my interview technique after Chev was my ability to administer and rate unofficial OPIs. With Chev, I had not yet taken the intensive, more than year-long certification course through American Council for the Teaching of Foreign Languages (ACTFL) and so my interviews in French did not take the same structure as an OPI as they did with my future participants. Although my research about Chev varies significantly (which I will discuss in more detail at the end of this chapter) from the other cases described in the dissertation, I felt it was important to include a description of my work with him and how it functioned as a pilot.

\section{Description}

The following is a thick description of Chev, his language and travel background, and a summary of his main activities while abroad. "Chev," was a 22-year-old undergraduate student at a medium-sized Midwestern university. Chev chose his pseudonym for this study. He is a white, middle-class male, American English speaker who majored in French Education and studied abroad at the French language learning institute CIDEF in Angers, France, during the spring semester of his junior year. Prior to his semester in Angers, Chev had studied French for six years, beginning in high school. He had never lived abroad over an extended period of time before, although he had traveled abroad to Monterrey, Mexico for a week, he had spent a day in Paris, and had spent four weeks studying in China through his community college a few years before.

Chev took a placement test the day after he arrived in Angers and placed at a high enough level at which he could take the electives that he had originally planned, including French History, History of French Art, Literature, Grammar, Oral Expression and also a general French language class. All of his classes were taught in the target language. Classes at the CIDEF are 
specifically meant for international students who are there with the express purpose of learning French. On average, the majority of students who attend this program are from China, followed by the United States, and Japan, and those from Japan and China often do not have strong English skills, which some American students appreciate because that means that the Lingua Franca among international students is more likely to be French. Other common participants are from Korea, Germany, Spain, Libya, Canada, Great Britain, and Russia.

Chev lived with a French host dad (Jean) in Angers. Jean lived alone; Chev assumed that he was a widower, but never asked. Chev described spending at least 1-2 hours per day speaking in French with his host dad. Typical interactions were at home over dinner or watching TV, however Chev and Jean went to the symphony on Sundays, and took a few other excursions together.

Chev also took part in a local board-gaming club twice per month not far from where he lived called La Sympathique Société Ludique where he went mainly to play a game that both Americans and French play called Warhammer Battle in France, but Fantasy in the U.S. Chev proactively searched for gaming societies in Angers before he left the United States, found the online forum to this club and introduced himself on it. There were around 30 members of this club and they were all French men, between the ages of 20-60 years old. None of the members of the club could speak more than a few typical sentences in English and so all interactions took place in French. Next I will describe the data collection.

\section{Data Collection}

The primary data consist of three recorded interviews of semi-structured format either over the telephone or in person between Chev and me, prior to and during his study in Angers, upon his return, and once more about three months after he had returned to the U.S. The pre- 
departure and midterm interviews were divided into two parts, conducted first in French and then in English. The French part was used as an in-house proficiency assessment in which the student was asked relevant questions such as (for the pre-departure interview) why he was interested in studying in France, what his background was in French (classes and other information that he must refer to by using the past tenses), what he expected to like and not like (and what he did like and did not like once he was there) about France, he had to self-evaluate his proficiency and assess what he planned to do or was doing in France that might help and hinder his language acquisition, and he had to also give a description of how he anticipated life being (good and bad) as his study abroad approached, and once there, as it continued. Follow up questions were based on details given in his answers. The Return interview was conducted only in French. The Delayed Post Interview was conducted only in English. The pre-departure interview lasted about 30 minutes in total. The Midterm, Return, and Delayed Post Interview all lasted between 45 and 75 minutes. Other primary data were two long journals written during Chev's fourth month in Angers and out of 14 weekly surveys, Chev wrote short journal entries for 5 of them. I also conducted one interview with Chev's host dad, during which we discussed Jean's perceptions of Chev's behavior, assimilation and language acquisition, as well as Jean's expectations of foreign students who come to study in Angers, which helped me triangulate some of Chev's data.

Chev responded 14 times to a quantitative survey meant to be a weekly survey that measured time spent (in hours) reading, speaking with TL speakers, watching shows, listening to music, doing homework, texting, and telephoning using the TL and English. Chev also completed a written self-evaluation of his fluency pre-departure, at midterm and upon his return to the U.S. An official OPI was administered upon his return for which he rated at Advanced 
Low proficiency and an unofficial OPI was administered at the time of his Delayed Post interview and his proficiency remained about the same.

The data from Chev's study differs from the other participants' because it was strictly focused on use of language. I had not yet studied Language Socialization, and I was certain that the main impediment to language learning was related to time spent on computers and cell phones, so the interviews did not include questions pertaining to identity. At the time, I thought that the quantitative survey measuring hours spent in the target language or in English would produce rich results. I realized only after my research with Chev that it was ok to ask more personal questions to get to know each of my participants in a more in-depth way, and I could ask follow-up questions, since that is the idea of the semi-structured interview process. In the next section I will describe two key aspects of Chev's experience while abroad: his participation in a gaming community and his relationship with his host father.

\section{Gaming Community}

The first part will consist of the following: 1) a description of Chev's proactive search for a gaming community, 2) an examination of his first visits where he remains a self-described novice, 3) Chev's observations from the periphery, 4) a perfect example of Chev's LPP 5) Chev's acceptance by other members, 6) a feeling of full integration in the CoP and 7) understanding of shared repertoire and acceptance into French society.

Proactive search. Chev planned to join a gaming community in Angers because of his affiliation to a similar one in the United States. In his pre-departure interview, Chev anticipated that certain aspects of his life in France would contribute the most to the bettering of his French proficiency. In particular, Chev described that taking part in a gaming community in France would put him in contact with real life situations, as opposed to situations in which he would 
only say irrelevant things such as "The cat is black." Chev then described how the game is played and how players refer to a rule book as they play, allowing for multiple literacies of both speaking, reading, and understanding.

In sum, Chev hoped to find access to a club to which he already had access in the U.S. and with which he already was a self-identified member. This references first the importance that belonging to a $\mathrm{CoP}$ has to $\mathrm{Chev}$, and second, the idea that in learning to speak a foreign language one must find a sufficient adjustment between one's first culture and the target culture. It is notable that Chev recognizes that participation in this could positively affect his language acquisition.

First visits. By the time of his midterm interview (late April), Chev had made contact with this figurine and gaming society via web forum and had begun frequenting the gaming community in person as well, which was located not far from his apartment in Angers. Based on the LPP theory, Chev was not yet considered a member because he did not yet know the language specific to officially take part: "In fact there's a forum that they have where they talk and they use French slang that I don't know - I don't know at all." As this quotation shows, Chev has made contact but feels little connection to sources of shared understanding such as language.

Observations from the periphery. I received two expansive journal entries from Chev during the month of May, in both of which he describes himself as a peripheral observer. In the first one he described the similarities between gaming in the U.S. and France and the way in which that made him able to approach possible membership in the group:

So, what's been almost too coincidental for me is that this group of people is exactly what you'd see in America, maybe with the language changed only. What 
I mean to say is that a worldwide culture has destroyed the barriers of a local one. It's some surprise that I can come and participate and spend time with people I have already spent a great deal of my life with. They use the same gestures, complain about the same things, just in a different tongue. In what's been the greatest gift is the solidarity I can share with them. At least in my hobby there is an attitude of sticking together and even among somewhat strangers the goodwill has endured. We barely share the same language. In America I'm not sure we'd be friends....

It is at this point where Chev begins to notice important aspects of shared repertoire within the gaming community such as gestures and words that create meaning for the group. In his second journal entry sent a few weeks later, Chev refers to gradually joining the gaming community, but still sensing himself as lacking important shared repertoire:

I think not interacting in meaningful French can be a severe impact on the rest of it. It's like when I go to that gaming night I'm a little overwhelmed because whereas I've learned to speak, certainly I haven't learned to communicate (at least to me) all the little phrases and quirks and lingo which is difficulte [sic] to get when you're sitting in a class talking about history.

A textbook example of LPP. Chev described to me how he remained on the periphery as he observed the actions of the members. Chev said that it would start out with him observing on the sidelines for more than two hours (each game takes about an hour and a half). During this time he would watch and listen to the way that they played the game and the way in which they interacted. Eventually game players would engage in small talk with Chev and, as Chev described, "Finally somebody would be like 'Hey! We're starting something. Do you want to 
join in?' Ok." Chev used this peripherality as a way of gaining access to sources of understanding such as the groups' common goals and procedures.

Acceptance by other members. As he continued to observe, and in the hopes that he might feel comfortable enough and the community might ask, Chev had brought his own game to share, but waited for one of the gamers to invite him. An important moment in his interaction with the gamers was when he was allowed to explain to them how to play his game. Chev had to first acquire the vocabulary needed to interact. After that, he was able to share his knowledge of the game, which invited acceptance from the official gamers.

Sharing of the rulebook symbolically represents entry through negotiation of meaning. At the same time, a shared vocabulary and specific language was initiated-something Chev referred to as trash talk, represent a transition from peripherality. I asked him how he was able to expand his vocabulary relevant to the game and so he described one interaction to me:

C: One dude in their group got that main rulebook as a pdf scan (illegally) and they printed off a bunch of these really high res color copies and like one game I played and he crushed me and it was like this hilariously bad defeat for me but anyway we just kind of joked about it and I was like, "Oh man I suck." and he was like, Yeah."

L: How did you say "I suck!”

C: $\mathrm{Um}-\mathrm{je} \ldots$

L: Je suis nul [I'm useless/terrible], or...?

C: Yeah, like $n u l$ or I said, the big thing I picked up from them was like-if you want to be really French you just say "Putain!” [Fuck!] a bunch! The biggest phrase I always remember is like, "J'ai envie d'un six - ah putain-cinq!" [I want 
a 6-oh fuck - five]. Like that and that was most of it so you just kind of picked that up. And I remark now the hardest thing was it wasn't so much remembering my conversation as not being a solid flow it was like this was attacking him. In normal English it is like alright he's going to attack him, he's going to attack him but it's like, "him, him.” Like caveman French, but it worked though cause fortunately the rules are simple and everything's evident enough.

Chev's ability to use slang and other language within his group made him feel as if his French was more authentic. He described it as, "It means that you're like actively joining a community and not just observing it, via like a textbook."

Specific language is critical to being a member of $\mathrm{CoP}$ and $\mathrm{Chev}$ recognizes that he has the ability to talk within and talk about his practice. The entire process of vocabulary acquisition, shared tools (rulebook) and shared repertoire (the game itself) as well as acceptance of Chev's knowledge-sharing by the gamers describes an official entry into the community of practice.

Full integration. This anecdote shows integration into the culture of practice through shared repertoire, reflected by the history of Chev and the gaming community's mutual engagement through routines, words, tools, gestures and other ways of doing things. It is the critical moment where Chev realized that he was a member of this gaming community and he recognized how it would feel if he really lived in Angers:

C: Oh, did I ever tell you the really cool thing about it? This is a cultural thing. When you walked in there you had to shake hands with every person.

L: Ok. Like greeting every person so, if there were 30 people you were shaking hands with 30 people. 
C: Unless the guys looked really busy in their thing. But even then if you walked up to their table they'd be like, "Oh! Bonsoir!" And you'd be like....

L: At least you make like a connection if it's not physical.

C: Yeah, so you'd be playing a game and people would come in and they'd just shake your.... And that was the nice thing cause like even at that point it was established a little bit as an outsider but still like people....

L: You're part of the....

C: I wasn't, like, separated..

L: That's cool. Did you feel that being a part of that made you more Angevin [a citizen of Angers]?

C: Gave you a little bit a sense of regularity. Cause you have your hosts and the kids you hung out with at school and then like the only French people you ever try to interact with are people you're trying to get services from. So this was like a nice type of, like, "this is what it would be if I really lived here!"

In the end, Chev negotiated a new identity for himself no longer as tourist but as a person who is much more integrated into French language and culture. In this context, Chev builds an identity connecting the local and the global because he has negotiated local ways of belonging to this more global gaming discourse.

Shared repertoire and acceptance. Chev explained that one of the guys in the gaming community gave him a copy of a gaming rulebook in French that Chev had wanted but would have never bought because it cost 80 Euro. Chev saw this gift in two senses, both symbolic and realistic of his acceptance to the group: 
C: Cause without that you can't really, well, most people memorize the rules anyway cause once you play it enough it's kind of a fingertip feeling. But it's nice to, like, if you don't have it it's also kind of a sign that says oh, you can't play! If that makes sense, cause you don't, if you don't have it, you don't know the rules, you can’t play.

L: Uh-huh. Do you in any way compare that to your, having the rulebook for life in France?

C: [laughs] A very deep thought.

L: Well, the way you wrote it, it kind of felt like a deep thought.

C: I was like, “Ahhhhhh, everything's so nice!” But no, I guess yeah, it was a really heartfelt kind of expression to me coming a couple times being so inclusionary, like they have an internet forum that you post like, I'm showing up today and so everyone had been so inclusionary on the forum and like when you got there it was like, "Oh you're the American, what's up?" And finally, some guy being like, "Hey - you've only shown up here like four times but here's this thing!” And so, yeah, I don't know if it overall reflected my experiences in France but it was definitely to me like a watershed moment where I could just transition from someone who was just visiting to like someone who was staying.

The description of being "someone who was staying" shows a feeling of belonging and the sharing of the rulebook symbolically and pragmatically described a feeling of being accepted. As a member of this CoP, Chev's language learning is legitimized and from this he gains confidence as a French speaker. 


\section{Host Father}

The second part of the two key aspects of Chev's SA experience is Chev's interactions with his host father, Jean. These interactions cover the following highlights: 1) Chev's arrival at Jean's apartment for the first time, 2) Jean's setting rules and routine, 3) Jean's introduction of Chev to his friends and other parts of the community and 4) Chev's discovery that he no longer considers himself a "wacky foreigner."

Over the course of his semester in France, Chev became a member of another community of practice through LPP with his host father, Jean. His experience follows the same rules of observation from the periphery, learning the rules as a newcomer/novice, acquiring a common language and understanding of what it entails to be part of that CoP, and finally, fully integrating. While some may argue that a CoP denotes more than two participants, Wenger and Lave give examples where during master-apprentice relations of midwives, tailors and naval quartermasters learning is attained through observation often of one very experienced, older member (1991), indeed, Dings' study (2012) also supports the idea that only a novice and an expert are required.

Arrival and rules. When Chev arrived, Jean picked him up from the train station and brought him home. Chev described an initial barrage of strict rules that Jean set up for him from the moment they arrived at the apartment from not wearing your shoes inside, to showering in a certain way in order to protect the shower, opening and closing the shutters at appropriate times of day and no cooking in the kitchen. As a newcomer, Chev was confused and misunderstood the requirements set by Jean.

C: Did I ever tell you the first time I arrived there and I got to his apartment and he has a no shoes in his apartment rule which I totally understand, he's very up 
about his apartment.... I laughed with him about this story toward the end cause I'd never admitted it to him for the longest time, but the first time we got there I didn't speak a lot of French, I was jet lagged and I was like, ah bed and internet that's all I want! So we get to the door and he's like pointing at my feet and being like obviously I know now he's saying enlève les chaussures like enlève tes chaussures but I'm like, I'm looking and he like opens the door and I start to walk in and he's like, "No. George, est-ce que tu peux enlever les chaussures," and I'm like, “take my shoes off?” And he's like, "Yeah!” I just didn't know what to, I was like, "Ughhhh!” So I thought that was hilarious.

Here Chev was doubly affected both by the language barrier and by rules that had not yet been attributed meaning or understanding. I was unsure whether Chev was bothered by these strict requirements or not because he stated it in a joking fashion, but he clarifies in subsequent interviews.

Rules and routine. By midterm, Chev admitted to spending "the majority of my time with my host dad." Once Chev had observed and understood the rules set by Jean, a routine was formed where it was recognized that Chev would return from school around 6pm, bring Jean the local newspaper and Jean would then make dinner while Chev relaxed in his room for an hour or so. They would then have dinner together and have discussions and / or watch typically-French TV shows like "Les Guignols," a political satire show where famous people are manifested as Muppets, and Jean would eventually fall asleep in his chair. When I asked Chev if this meant that they were pretty comfortable with each other, he replied, "Yeah, I followed all of his rules; I think he was pretty happy about that." In the midterm interview with Chev, Jean answered the phone and so a conversation ensued. When I asked if Chev was behaving well, Jean immediately 
replied that Chev was "learning all of the rules." It is probable that this negotiation of rules and subsequent acceptance allowed for mutual recognition and for creation of an identity of participation in which Chev defined and reified himself through his mutual engagement with Jean.

\section{Introduction to friends and other parts of the community. Chev and Jean's} relationship expanded to Jean helping him learn to navigate life in France. He helped Chev with the purchase of a bike, suggested places to visit and learn about in the area and introduced him to some of Jean's good friends. When I asked Chev how or if his connection to Jean affected his assimilation into French culture and life in France he responded:

I think it was nice cause he just helped expose you to a lot more things, like French people, too. I met Michel and Martine and I met his boss Marc, and Sabine who lived in the same hotel. I know a couple times he like found brochures for me. He drove me around. Honestly, I'm happy he took me to Flunch [a French fast food restaurant]. I thought it was funny. I thought it was a jokey little routine and I loved every part of it.

No longer a "wacky foreigner." An important final step in LPP and CoP is feeling authenticated, or as an actual member of the group. Towards the end of our delayed post interview I referred to something that Chev had said in a previous interview: "I can't help but feel like the wacky foreigner when I speak French!” and asked him if he still felt that way based on the interactional learning experienced with his host father. He answered:

No, it's just probably, like, I'm someone unremarkable, but not a French person, but several ticks before.... Andy Kaufman was the wacky foreigner! So I always felt like, well Andy Kaufman was just, like, I knew goofy idioms and said things occasionally and 
people would be like, ugh — him. But now it's, I feel like if I went back it would just be like I could integrate fairly quickly.

This quotation indicates that Chev feels legitimate in his membership in the gaming community, and also as someone who has the cultural and linguistic capital to belong in France.

\section{Discussion}

It is evident that Chev's gradual assimilation into two meaningful CoPs had a profound effect on his L2 learning. He transitioned from newcomer or novice to one who is knowledgeable about how to speak French and live among the French, rather than remaining on the periphery. Chev makes several remarks during his interviews that specifically point out the difference between the expendability of in-classroom information and the significant meaning and realworld usefulness of the outcomes of his group connections.

Unfortunately, Chev may be an anomaly. He was extremely proactive in researching and seeking out his gaming community and he was also very tolerant and patient with his host dad's strict rule system. First, most students are just not as forthcoming as Chev and would be too reticent to approach a community because it would take them too far outside of their comfort zone. Second, many students would have had a difficult time with such a demanding host and would have lost any desire to be open to what Jean had to offer, impeding them from gaining any learning of substance that Chev did. While it is evident that CoPs are a very effective way in which students abroad can flourish, one must be cognizant that it is not always easy to approach new situations whether it is the language barrier, shyness, or other social or identity-related issues. In some cases, faculty members travel along with their students and are there sur place to introduce them to these opportunities, helping assuage their hesitations and fears. Incorporating this aspect into students' studies abroad would be beneficial, however, may not be feasible. 
The most important limitation that I found in this study was a lack of focus on critical themes and their significance in informing and affecting a student's desire to invest in second language identities. I focused much more on quantitative questions measuring time spent in language-speaking activities. I did not ask Chev anything about his nationality, his whiteness, how being a male in France may have affected his experience, and we did not discuss the linguistic hegemony of English. While it is likely that Chev's study abroad was shaped by male privilege, and it is also likely that all of the men in his gaming group and his host father were white, I cannot be certain, because I did not ask. It was only as a result of this study that I began asking more critical questions related to identity. For the case studies specifically for my dissertation, I added questions such as, "What does being American mean to you?; How do you anticipate your identity to shape your language and cultural acquisition while abroad?"; and "Are there times when you have felt uncomfortable for any reason? Can you describe this?" In other words, while this study was very useful in expanding my knowledge of language socialization, CoPs, and LPP in study abroad settings, it stopped short of acknowledging the whole person and critical issues of identity. For all of these reasons, and ones given at the start of the chapter, this study is a pilot and remains separate from the rest. 


\section{CHAPTER V: PARTICIPANT DESCRIPTIONS}

\section{Introduction}

In this chapter, I first provide an overview of Wolcott's explanation of the role of description. I then give a descriptive introduction of each participant, their background, and length of stay, along with a description of the study abroad (SA) location.

\section{Description}

Wolcott (2011) explains description as answering the question, "What is going on here?" and telling the story based on observations by the researcher (p. 11). Wolcott says that the researcher should try to remove him/herself and permit the story to come as much as possible from the participant's own words from which the most poignant details are chosen, leaving the rest behind. As a result, while the description is as much the participants' words as possible, it is still relayed through the eyes of the researcher, or as Wolcott lightheartedly calls it, void of "immaculate perception" (p. 13). After description, the researcher may begin looking for key themes and interrelationships among them through analysis. Wolcott describes analysis as reflecting a theoretical or conceptual frame and "pulls data transformation toward the more scientific and quantitative side of our work" (p. 174). Within this chapter, I will focus on description and context of the study, while in the next chapter I will focus on analysis, which emphasizes patterns and relationships in the data.

\section{Participants, Length of Stay, and Location}

This section provides context to the study through a description of the participants, the program, and the study abroad site. Five females participated in this study. At the time they were all 19-22-year-old university students who spent either one semester or one academic year abroad. One participant is African-American while all of the other participants are white. All but 
one were French or French Education majors, with the exception being one who was a French minor and an English major. Two of them studied abroad during their sophomore year, the others studied abroad during their junior year. Within each participant description is description of each student's language abilities, with a table provided at the end of this chapter. None of the participants had spent more than a couple of weeks abroad before and one of them had never previously travelled abroad. Of those who had travelled abroad, all but one of them had travelled before to France. One of them had travelled to Ireland. Each of the participants made up their own pseudonym used for this study. The above information is shown in a table at the end of this chapter.

All of the participants studied in Angers, France, a city of approximately 180,000 inhabitants along the Loire river valley, about an hour and a half by fast train southwest of Paris, at the Université Catholique de l'Ouest (Catholic University of the West-UCO) in the Centre International d'Etudes Françaises (International Center for French Studies-CIDEF) program in which over 1500 students and teachers from more than 75 countries take part each year. This French language-learning institute is part of the larger university at which French natives also take courses toward various degrees. All of the classes are taught in the target language and are divided by placement level. Classes at this school are specifically meant for international students who are there with the express purpose of learning French. The majority of students who attend this program are from China, the United States, and Japan, (and anecdotally, those from Japan and China often do not have strong English skills, something often noted by my participants.). Other common students at the CIDEF are from Korea, Germany, Spain, Libya, Canada, Great Britain, and Russia. CIDEF has been in place for 70 years as the only program of French for foreigners in Angers. Next, I provide a description of each participant so that readers 
can get a greater sense of who they are and a general overview of what their study abroad was like.

\section{Magda}

Magda, a 21-year-old white, middle-class French teacher education major from a small Midwestern town, spent the spring semester of her junior year abroad. She had already taken four years of French in high school, and many semesters of college French, including Intermediate French Part II (FRE 116) with me, plus three advanced level courses after that. Magda was very forthcoming about her feelings and opinions. She had a dry sense of humor, and was a little dramatic, meaning you never had to guess what she was feeling because she was not shy about expressing it. She was also a very good teacher candidate because she was organized and reliable. She was a devoted French learner who spent time outside of class tutoring others and asking questions about concepts learned in class in order to be a more thorough learner. Both of Magda's parents are educators, which I imagine informed her perspective. Magda had a serious boyfriend who she was hesitant to leave behind, but understood the importance of this semester abroad to her French language learning and, as a French teacher education major, the Oral Proficiency Interview (OPI) for which she was required to rate at Advanced Low. I administered an unofficial OPI to Magda during the course of the pre-departure interview, and she rated at approximately Intermediate Mid on the ACTFL scale. This was marked by Magda speaking in many inter-connected sentences about ideas related to her family, friends, and school, but with English influence evident. Her ability to narrate in the present tense was strongest, as she had difficulty remaining in the past tense when narrating about an event in the past. There were many inconsistencies in gender and agreement, and Anglicisms often replaced vocabulary of which she was unsure. 
Magda anticipated really enjoying the excellent public transit in France, understanding that the train system was efficient and easy to use, and being able to easily walk and bike around town. Since she had some health issues (on which she did not elaborate), and since she had already visited France, Magda was aware of what to expect with respect to food in France.

I love food and they, just good food, healthy, food, I mean a lot, just a lot, the consciousness of what you're putting into your body is very different in France and I think that's going to be like good for me.

Magda was quick to declare her anticipated frustration at the language barrier that would exist when she arrived in France. "I think at the beginning it's going to be really awful. Like, I'm a talker and I have, like, things I want to say. Like, having that language barrier is going to be really frustrating for me." She wanted to be able to express herself in any situation "especially because I'm hilarious!" and knew that this would initially be a stumbling block. She did not look forward to the feeling that one has being far from home, although she imagined that international texting apps would, in part, alleviate this. She seemed also to believe that it was not ok to want to remain in touch with friends and loved ones at home. "Those, like, little comforts, like, being able to like, call your mom, like you can't just call your mom, you know, when you're abroad, it's just like, little things - they're all so secretly important." Finally, having visited France before, she had a slight idea of what it is like as an American who needs government-sponsored services, like the post office or the airport, and had certainly heard from previous study abroad participants that "bureaucracy is going to be terrible," in reference to setting up a bank account, or other situations in which an American is used to client-centered service, but she decided to accept that as just a part of European/French culture. When I asked her how she would cope with her disappointments or bad days, she said that Facebook would help her remain in touch with 
friends, and that would lift her up when she was feeling down: "If it gets to those days where it's been like too much France I can, like focus in (on Facebook), and just like, not be French for a little bit. And just pretend."

Once in Angers, Magda spoke in very positive terms about her host family, a white French husband and wife with grown children who came home fairly often. Her initial response was "We [she and her roommates] lucked out. They are nice, supportive, and take care of us." She said that when she was sick, her host mom took her to the pharmacy and then to the doctor when she did not get better. The host family spoke only French. She learned some slang from them and they helped her with her pronunciation, too. Magda ate most dinners and breakfasts on the weekends with her host family. She liked to run errands with her host mom such as going to the bakery, the market, or to walk the dog, and her host mom even took her along to hear a French author talk. Having this kind of connection with them made Magda feel "very integrated into the town."

Magda took four classes at the CIDEF, Langue, Expression théâtrale, Littérature du XIXe siècle and Histoire française. She says that the literature was difficult and required a lot of reading. The Theatrical Expression class had a rough start because it was too large and so they divided it into two classes and got a new teacher who was good, but encouraged them to speak in their first language which Magda did not like. Finally, Langue was too easy.

Magda spent most of her time with her roommate, who was a student at the university of Notre Dame. They would often speak in French when together. Magda would sometimes hang out with other students from her home university, but also made friends with some of the other international students, of which some are Japanese and some Chinese, who lived in the dormitory. Magda pointed out that her American friends did not allow the group conversation to 
be conducted in French, and she was not interested in speaking in English during her semester abroad.

When asked what she liked about living in France, Magda immediately pointed out the "pace of life." Referring to eating well, spending time together, and slowing down, Magda said that the French mentality of "quality of life is important" really stuck out to her. The second thing that Magda said she liked was how you can walk everywhere, and how easy public transport was in helping you be able to explore. Furthermore, she remarked that there was so much to see and do that was not very expensive. Finally, she loved how eating healthy was a way of life in France. She noted that she ate so much better in France and shopped at the outdoor market every weekend.

When I asked her what she disliked, Magda spurted out without any hesitation "It kind of sucks not knowing exactly what someone is saying to you!" She remarked that while she had begun to do ok in situations like getting instructions or in daily conversation, she misunderstood the nuances that came along with that. "I can't make myself understand French better. So just like, missing those little pieces, just like the very nuanced parts of a conversation is just kind of, uh, kind of annoying." While she said that being far from her family was not as bad as she had anticipated (because of texting apps and Skype), she did really miss American breakfast, especially cereal, French toast, and pancakes!

Magda felt very sure that living with the host family and being around French being spoken — just absorbing it - "taking it in" was a good source for pronunciation as well as for cultural knowledge. She quietly admitted (until I assured her that it was okay to talk about it) that going out to the bars had also been very helpful because she was able to meet other people her age who spoke French. Some of them were French locals, and others were international students 
like her who spoke French. Finally, she became friends with a French middle school English teacher and was even invited to her home for dinner and to meet her family. While they did not always speak in French, Magda considered her a rich learning resource.

\section{Lesley}

Lesley, a 19-year-old, white, American French major from a middle-to-upper-class suburb of Chicago, decided to spend her entire sophomore year studying abroad. She had been there two times prior on short exchange programs of about 10 days each. She also had a French boyfriend who lived near Paris, which probably influenced her desire to study abroad as much as anything else. Lesley was active in sports (specifically soccer) and had a strong personality both in the sense of the kind of person who would do a lot for someone else, but also strong opinions against other ways of doing things, and she was not going to change her ideas for others. I will discuss this in more detail during the analysis section, but one example is that Lesley really did not care to make friends with non-American students while abroad. In an email communication during her year abroad in justifying this choice, she wrote, "We are all going through the same thing and we connect because we all have the same experiences and opinions about life in Angers." Lesley had taken French all four years in high school. Her freshman year she had a French native as a teacher, but she found him to be rude and mean. This might have dissuaded her from continuing, but she knew that she was obligated to complete at least two years of high school foreign language, and so she continued. She described her French teacher her sophomore year as much more helpful, which convinced her to continue. Her teacher in both $11^{\text {th }}$ and $12^{\text {th }}$ grades was not only nice and supportive, but introduced students to an exchange program in which Lesley took part in both $11^{\text {th }}$ and $12^{\text {t }}$ grades. She had two French students stay in her home both years and she also spent time with them in France. At the university, Lesley had taken two 
semesters of French as a freshman and did well enough without having to put in a lot of effort but not enough to earn As. She took Intermediate French Part 1 (FRE 115) taught by a graduate student from Morocco, and Intermediate French, Part 2 (FRE 116), as my student. She was at the intermediate low-to-mid level (based on an informal pre-departure OPI) marked by slow speech, hesitations, inconsistent tenses (often reverted to the present tense) but able to discuss appropriate intermediate subject matter such as self, daily activities, school, friends, etc., and used phonetically appropriate pronunciation. Lesley's interest in French increased the most through making friends in her exchange programs and by realizing that she "could actually use it to talk to someone." She described "math is a foreign language to me, like, learning French was easier-once I actually started trying, it became easier and I really liked it."

Lesley spoke about several things that she expected to appreciate about living in France. She looked forward to the change of scenery, meeting different people and "the food is good, so I'm excited for the food!" Having been in France before she knew that she would appreciate an architecture that is "really old compared to here." She also looked forward to how everyone dresses in France, "how they put themselves together and like, they actually put effort."

Lesley anticipated the language barrier as something that she would not like because it would be overwhelming to her. She was also concerned about not being in close proximity to her family. In a previous exchange experience in France with a host family during a one-week stay, she encountered French parents who were cold and hands-off. She described them as giving off the feeling that it did not matter if she did not understand them. She also recounted that they were not close with their children and were fine with them "go[ing] and do[ing] what you want." Lesley was afraid of French drivers and being a pedestrian in France. She was worried in general about transportation, about finding her way, and not getting lost. Lesley was insistent on having 
access to her friends and family back home while abroad because talking with them and keeping in touch was important to her, "because, like, I am coming back here!” Finally, she was concerned with being stared at. She could not explain this in much depth. I asked her if it was because people would know that she was different and she said, "Yeah. I'm okay with people knowing that I'm American but it's just like, the fact that they stare at you is what I thought was weird." I will return to this later on in the analysis section.

Lesley's host family was made up of a widow and her son. The host mom worked three nights a week and her host brother (an 18-year-old) spent a lot of time alone in his room. The host dad died a few years before and the son was suffering. The host mother and son shared a bedroom, it seemed so that they could accommodate two exchange students in the other bedrooms. Lesley ate meals with them during the first month there, and subsequently just once per week. The host mom cleaned Lesley's room and moved her stuff around which Lesley found weird, but was not fully bothered by it. She appreciated that her host mom did not have a problem with her being a vegetarian.

Lesley took five classes each semester at school, some of which were Langue, Compétences écrites, Grammaire, Littérature du XIXe, and Expression orale. Lesley did not like Compétences écrites because she did not feel confident in her writing skills. Overall, she reported getting pretty good grades but admitted that she was "not great" at conjugating verbs while speaking.

Lesley spent time with students from Saint Mary's College, and with two or three students from her own program. She spent the majority of her free time (every weekend) away from Angers with her boyfriend who lived outside of Paris. She described it as hard to settle in Angers being gone every weekend. 
Lesley liked that the drinking age was 18 , and that homework requirements were "lax," that is to say that she could turn it in anytime she wanted before the end of the semester. She liked the food, the way people dress ("You can tell who is American by who wears yoga pants.”), and she really liked the fact that there were so many students from around the world.

\section{Becky}

Becky, a 22-year-old, African-American French major is from a working-class family from a large Midwestern city who decided to study abroad for her entire senior year of 20142015. Becky was always very upbeat when we would meet, showing excitement, first for learning French, and later for her chance to study abroad. Becky's goal was to be fluent in five languages, first English and French, then, "I want to stay in the Romance family so, Italian, French, Portuguese, and Spanish.” Becky was proud to have learned from teachers from different Francophone countries to have access to a variety of French accents, "So, I've had like, American accents, I've had a Belgian accent, I've had African accents, and [her current professor] is like, her French accent is, like, she's, like, very French, so uh, yeah.”

Becky took Beginning French Part II (FRE 112), Intermediate French Part II (FRE 116), Advanced French Conversation and Contemporary Culture (FRE 214), and Advanced Techniques in Written French (FRE 213) before she left for Angers. I administered an informal pre-departure OPI and Becky showed language at around the Intermediate Low level, represented by quite a bit of hesitation, shorter sentences (not paragraphs) and Anglicisms. Becky narrated sufficiently in the present tense with regard to content referring to herself, school, and her family, but was unable to remain consistent when narrating in the past. Becky experienced language breakdown when she attempted to narrate more than three to four sentences. 
Becky wanted to approach her study abroad in the best way possible, so she set up a blog, and tried to be aware of cultural differences that she should pay attention to:

I'm not going to lie, well there's just certain cultural differences that I have to learn to adjust to - me, I love bright colors, I think I'm a bright person and I like bright colors, so I was telling my mom I don't want to be targeted as an American but I also don't want to, like, lose my identity.

Becky rarely brought up anything negative about her experience. She also seemed purposely to keep her distance about personal issues.

Becky had taken eight French classes in total between high school and college, and at the time, had just finished her second advanced level French course. She had been a student of mine in Intermediate French Part II (FRE 116) one year earlier in the fall of 2013. Becky was motivated to learn French and often met with me outside of class to discuss her ideas and questions. Becky worked at the University library, a job that she really enjoyed and from which she garnered confidence and good friends. Becky also enjoyed sports, particularly playing basketball. Becky felt very strongly about studying abroad for an entire academic year as opposed to one semester, but she was dissuaded quite a bit by her family. Her father was unemployed at the time because of an illness, and her mother was busy raising her brother. Her mother was particularly concerned about Becky studying abroad and so we set up a meeting about 6 months prior to her departure to assuage some of their worries. I worried that Becky might experience anxiety while abroad because of familial issues, but I was also apprehensive about Becky's experience in France as an African-American, knowing that I had little familiarity with how it might be for her there to advise or prepare her. When I asked her what she thought she'd like about living in France, Becky answered, “The food! Um, sports. I'm looking forward 
to that - football and tennis. The French Open. I'm looking forward to that. Um, and travel!" When I asked Becky what she might not like about living in France, aside from wearing bright clothes, I asked her what might result in her sticking out as an American she responded, "Well, you know, um, theft. I worry about that. My mom is freaking me out cause she thinks I'm going to lose my passport, so I'm worried about that."

Becky was placed with a host family in which the father is Korean and the mother is white and French. Aside from the couple's two children, four international students lived with them from Japan, Korea, and the United States. In general, the ambiance of the home was multicultural. The mother had a home daycare which caused some annoyance for Becky: "So like, if I come home for lunch I can't cook anything or like I have to, like, tiptoe around and stuff because the kids are asleep." There were also restrictions on when she could take a shower and she had to be careful to label her food in the kitchen or else someone else would eat it. When I asked if she had enough of her own space to herself given the home daycare and 8 total people who live in the house, Becky said that her room was fine but her bed was smaller than her bed back home, which was an adjustment. She also had to share a bathroom with four other people that was down on a lower floor of the house.

Becky enjoyed dinner conversation with her host family and the other international students who lived there. When I asked what types of conversations they would have she said: The host dad's Korean and the host mom's French, so we have, like, some Japanese students and, like, American students, so generally our dinners are just, like, if we're talking about, like, plane travel, it'll be, like, the differences in domestic U.S. flights compared to, like, domestic, you know... we compare cultures. 
I followed up by asking whether there are sometimes situations during dinner conversation in which the discussion gets heated, and Becky responded, "Not yet, but I'm waiting on it, cause I feel like it might come."

Becky's main friends were American: one or two from her home university, from a university in Kansas, and from a university in Oregon. They are all female, white or East Asian because, as Becky described: "there were only three Black students there my year in France [including me]."

With regard to school, Becky was registered in five courses each semester and liked three of them in particular, Langue, Grammaire, and Traduction (translation) because the primary focus was use of the language. She did not like the $19^{\text {th }}$ century literature class and while she appreciated the History of France class, she was not particularly fond of having to recall the large amount of information that was taught.

Becky had many positive things to say about France. She liked her host family for the most part, she loved the food, and she particularly appreciated the variety of cultures and differences in all of the people that she met. "Maybe it's because I'm around, like, foreign exchange students, and how, like, everyone is different and there are so many cultures and everything here." Other things that she liked was being able to have her own bike for free, the ability to travel just about anywhere for cheap, and the fact that so much was smaller, so less space is needed for things in general, such as houses, roads, cars, and even many food servings.

Of the aspects of France that Becky disliked, unisex bathrooms seemed to be the most annoying and something that she just could not get used to. Not unlike most American study abroad participants, Becky was also frustrated by the inconvenient and decreased hours that French stores and service businesses like banks and the post office held, such as closure on 
Sundays, but also in the evenings and sometimes in the middle of the weekdays. Finally, she remarked that there were just about no water fountains there and so she was always obligated to buy bottled water:

There's no water fountains anywhere, like, anywhere! Like, you have to buy water all the time, that gets kind of annoying too, especially, like, when you go to play sports, last time I found out there were no water fountains and went to go play basketball - no water fountains anywhere in the building and I thought I was going to die.

\section{Sasha}

Sasha, a white, upper-middle-class English major from a Midwestern town, was halfway through her junior year at the university when she began her study in Angers. Sasha was a very grounded person who did not put on airs because when she spoke, her affect was calm and strong, slow and deliberate. She did not have an exaggerated tone. As a result, I wondered how she coped with unexpected things in her life and how she might handle such situations in France, so I asked her and she answered, "Sometimes I get really flustered and upset, mostly I just take things slower if I'm uncomfortable cause I shouldn't be expected to know everything when I'm there. Just, like, take a breath, get through it, you know?" My initial reactions to Sasha were of a young woman who was very open to other ways of life. She seemed adamant about not making judgmental statements in advance of her semester abroad. For example, when I asked her what she thought she might not like about France, she answered:

I just don't go into things expecting something. So I'm not let down or it's, so, I don't know, I'm expecting to experience some new things, some of them I may not like so much, but I haven't really thought about it in that way, you know? 
Sasha took exploratory foreign language in junior high (French, German, and Spanish) and while she enjoyed French most, she chose Spanish because she felt it would be the most useful. She did not do well in Spanish and quit after her sophomore year of high school to begin taking French. She then did not take French at the university level until her sophomore year, and up to the point of her departure for Angers she had taken three semesters of college-level French (FRE 111-115); the final one was the French class that I teach, Intermediate French Part II (FRE 116). Sasha described her ability to write and read in French well but her listening abilities as "not so great" because "they speak faster." She loved French because "When I speak it, I just have fun! Languages are so cool. That's why I study English now.” I administered an informal pre-departure OPI and Sasha rated at approximately Intermediate Low. She was able to speak in short sentences in the present tense about her family, her neighborhood, her house, her university studies, and some of her likes and dislikes. Her grammar was marked with incorrect gender/agreement and verb conjugations. She reverted to English words at times instead of circumlocution. Sasha did more than just repeat common phrases, she was able to create with language up to a certain point, however, when attempting to speak in the past tense, while she exhibited some understanding of past tense structures, there was significant breakdown. She was able to ask simple questions and interacted somewhat with the content of my responses.

Every once in a while, during our discussions she would open up about some concerns or some ideas that she had heard from others about the French or France, such as when I asked her if she had any preconceived ideas about how the French would be, she answered, "Um, well, I don't want to be perceived as, like, the dumb American, because I know that happens a lot." But she would always return to trying to be fair in her statements and expectations and most certainly 
not fall back upon stereotypes. I asked her what she expected to like about France and she answered:

Probably the buildings and stuff, cause I know when I was in Ireland, um, the different architecture, you feel like you're in the U.S. because everyone speaks English but it's, like, so foreign at the same time cause it's just so old and.... I do want to go around the countryside and see it.

As a student, Sasha's mom had studied abroad in France, which probably influenced Sasha's love of travel and openness to new places, people, and ideas. However, Sasha was quick to point out that she was her own person and came to the decision to study abroad independently of her mother's experiences.

In Angers, Sasha lived with a divorced, white woman who was an employee at a local hospital and one of her daughters on the other side of the Loire river. Sasha loved her host family, saying, “They're great!” Her host mom did not speak English, so Sasha got a lot of practice speaking French. While Sasha was initially concerned that she would not fit in with her host family, they eventually clicked. Her host mom and sister told Sasha that she was their favorite of all of the five exchange students who had lived with them. She and her host mom and sister talked with each other every day, although Sasha felt that she could not always fully get her message across because of her level of French. In school, Sasha took five classes, Langue, Grammaire, Compréhension Orale, Expression Écrite, and Histoire d'art. Sasha had a very strong dislike for her Grammar teacher because she was rude and "mocked the Asian students" in the class. She wondered if this might be a cultural difference that she did not understand. Sasha really enjoyed her Art History class because she loved that the content did not focus solely on French grammar and language learning. 
Sasha's host sister, Véronique, became one of her closest friends, although Sasha explained that it took some time for them to build this friendship. Eventually, they found that they had a lot in common: family demographic, they are the same age, and they both like the same music. Sasha's friends outside of her host family are mostly white and a few are from the Middle East. Sasha also spent time with one of the participants of this study, Becky, who was there for the academic year. They would try to speak in French together as often as they could.

\section{Charlotte}

Charlotte, a 19-year-old, white American French major from an upper-middle-class background, came from a relatively small Midwestern town. Charlotte was upbeat, bubbly, and sincere in her intent on making the most out of her year abroad with regard to travel, learning about new places, meeting new people, and learning to speak French better. When I asked what she anticipated liking about France she responded:

Of course I'm excited to do all of the touristy, live in the Loire Valley, visit Paris, and travel and do all that kind of thing, too. And I've talked to a lot of students who have studied abroad about, like, hanging out with people there and that sounds really exciting, meeting French students - I'm so excited for that. We'll check that out, I'm sure, but that sounds really cool to me and then, like other international students - you have to be pretty gutsy to study abroad-well I guess if you're in Europe, not too much.

Charlotte took French in $7^{\text {th }}$ and $8^{\text {th }}$ grade, as well as through all four years of high school. She took one year of intermediate French (FRE 115 and 116) at the university before her year abroad, including one semester as my student. Charlotte came from a family with a rather religious background, and grew up never really questioning cultural and societal norms, because her family and religious notions informed her understanding and did not elicit further questions. 
Charlotte rated approximately Intermediate Low on her pre-departure informal OPI because she was able to create with language consistently about herself, daily life, personal preferences and responded in short sentences by combining what she knew and heard. Charlotte was not Novice High because she could create with language and was able to ask many satisfactory questions, despite some grammatical issues. She could answer most questions despite a struggle with verb forms and often, use of the infinitive. Charlotte was not IM because there was minimal quality and quantity at the Intermediate level. She used simple sentence structure in which the verbs were not always conjugated. She had no ability at the advanced level besides a few rare instances of using the future and past, but without consistency. She would be understood by a sympathetic interlocutor.

As she imagined her impending year abroad, Charlotte anticipated that everything would be beautiful and even professed a desire to eventually live in France:

I'm kind of one of those people where when I travel, like, I instantly, I think everyone is like this actually, but, when I travel, like everything is, like, "Oh my gosh that's so beautiful, like, I want to live here, I want to move here!” Like, everywhere I go I, like, fall in love with it. So, I'm definitely expecting that to happen, but I'm also anticipating that because I'm going to be there for 9 months, like, that's going to wear off, and so I'm really excited for that, but I'm also kind of, like, cautious and making sure that I'm not just expecting that.

Charlotte hoped that living with a French family would be comforting and looked forward to meeting French children, French students, and other international students-people who are also studying abroad like her: "And so I think it'll be cool to meet people that are similar to me in that aspect, but different because they're from all over the world." 
When I asked her what she thought she might not like about living in France, Charlotte had several concerns. She admitted that if she felt lonely she probably would not go out. She was nervous about the classes being taught in a foreign language and it affecting her GPA. She described it as potentially humbling and hard to make so many mistakes in another language in front of other people. "I don't know if my language is quite there yet. I don't think I'll like having to make so many mistakes with another language in front of people, that's going to be pretty humbling, and kind of hard.” Finally, she was nervous that she would meet Englishspeaking friends and they would spend the majority of their time together, including travel, and she would not learn French, "I'll just not learn French and then my oral will be terrible. Just, I can't do that!"

Once in Angers, Charlotte lived with a white, French host family in a huge house not far from the Loire river part of town. There were several children still living at home, and others who were already old enough had moved away. Initially, Charlotte liked her host family, and during the first month, Charlotte took steps to spend time with them. She went to one of the son's boy scout ceremonies with the mom and attended her first French picnic. She also went to Catholic mass with the family and enjoyed following along in French in the little book provided. Charlotte's host dad was a tax accountant and host mom was an administrator and English teacher for young children (who, according to Charlotte, could not speak that much English). Charlotte recounted that the couple had nine children, three of whom were still living at home. There were three other boarders in the house, and overall, to Charlotte, living there felt "more like a hostel."

When asked what she liked about her first months in France, she immediately responded that she loved the food, like potatoes, raclette, cheese, and pizza. Charlotte also said that she 
loved seeing the world differently, even though not all of her opinions or beliefs had changed, but now she questioned things that she previously accepted as true and looked at them from other cultural points of view. Charlotte appreciated that all of her classes were taught in French. She also appreciated her mindset of not limiting herself and doing things that she never thought she would do. Charlotte really loved the relationships that she formed while in France; without her family and friends from home, she relied heavily on those friends in Angers. Charlotte emphasized that she could not remain in Angers without her American friends. Even though it was difficult, she appreciated living a life where change was the most consistent thing for her to hold onto.

Charlotte did not like how unfriendly French people were in the streets; i.e. they did not say, "hello" to you or "acknowledge your existence," although in certain situations they would stare at her. Charlotte found the women who worked in the department office of the school quite rude. She complained that customer service in stores was terrible and that it was awful that stores were closed on Sundays. Finally, Charlotte did not like French people her age. When I asked for reasons why, she said because she did not "click" with them.

The majority of the friends that Charlotte had in Angers were Americans with whom she spoke in English. These friends were mostly white, two African-American, and four East Asian. These are students primarily from Notre Dame, although there were a few from a university in Oregon during her first semester. She was also friends with some Japanese students during her first semester, with whom she spoke French. Charlotte admitted that she had less motivation to speak in French and really preferred her American friends. 


\section{Summary}

Looking at my data as a whole and across participants, they are all women, one identifies as African-American, and the reminder as white. They were all from 19-22-years-old and were from generally middle-class families. There were similarities in their pre-departure expectations and fears. Many could only anticipate more superficial appreciation for things in France such as the buildings, architecture, the food, and travel. Most of them described a fear of missing their family and friends and feeling lonely. Many of them referred to the importance of staying in touch with their loved ones via messaging, Skype, or other means. Most of them had some kind of concern about other people's perspective of them in France, from the way that they look (wearing bright-colored, American-looking clothes) to the way that they sound (their accent or making mistakes when attempting to speak French).

On a personal note, I want to express how much I enjoyed getting to know in more depth each one of my participants. It is rare that university professors or administrators have such access to their students' perspectives. As this story continues, I describe details about my participants' reported actions and comments that may be perceived as my displeasure for them as people, but I do this because the approach of this study is via a critical lens. I would not want this to be mistaken for me not having a deep appreciation and respect for each one of them. They are people with whom I have a connection, and with whom I hope to remain in contact in the future. 
Table 2

Demographic Data

\begin{tabular}{|c|c|c|c|c|c|c|c|}
\hline Participants & $\begin{array}{c}\text { Length } \\
\text { of } \\
\text { Stay }\end{array}$ & Race & Gender & Age & $\begin{array}{l}\text { Major/ } \\
\text { Minor }\end{array}$ & $\begin{array}{l}\text { Year in } \\
\text { School }\end{array}$ & $\begin{array}{l}\text { Experience } \\
\text { Abroad }\end{array}$ \\
\hline Magda & $\begin{array}{c}\text { One } \\
\text { Semester }\end{array}$ & White & Female & 21 & $\begin{array}{c}\text { French } \\
\text { Ed }\end{array}$ & Junior & France \\
\hline Lesley & $\begin{array}{l}\text { One } \\
\text { Year }\end{array}$ & White & Female & 19 & French & Sophomore & France \\
\hline Becky & $\begin{array}{l}\text { One } \\
\text { Year }\end{array}$ & Black & Female & 22 & French & Junior & No \\
\hline Sasha & $\begin{array}{c}\text { One } \\
\text { Semester }\end{array}$ & White & Female & 21 & $\begin{array}{c}\text { English/ } \\
\text { French } \\
\text { Minor }\end{array}$ & Junior & Ireland \\
\hline Charlotte & $\begin{array}{l}\text { One } \\
\text { Year }\end{array}$ & White & Female & 19 & French & Sophomore & France \\
\hline
\end{tabular}


Table 3

Unofficial OPI Results

\begin{tabular}{rlll}
\hline Participants & Pre-departure & Midterm & Return \\
\hline Magda & IL/IM & IM/IH & AL* official \\
Lesley & IM & IM & IH \\
Becky & IM & IH & AL \\
Sasha & IL & IM & IM/IH \\
Charlotte & IL & IL/IM & IH/AL \\
\hline
\end{tabular}

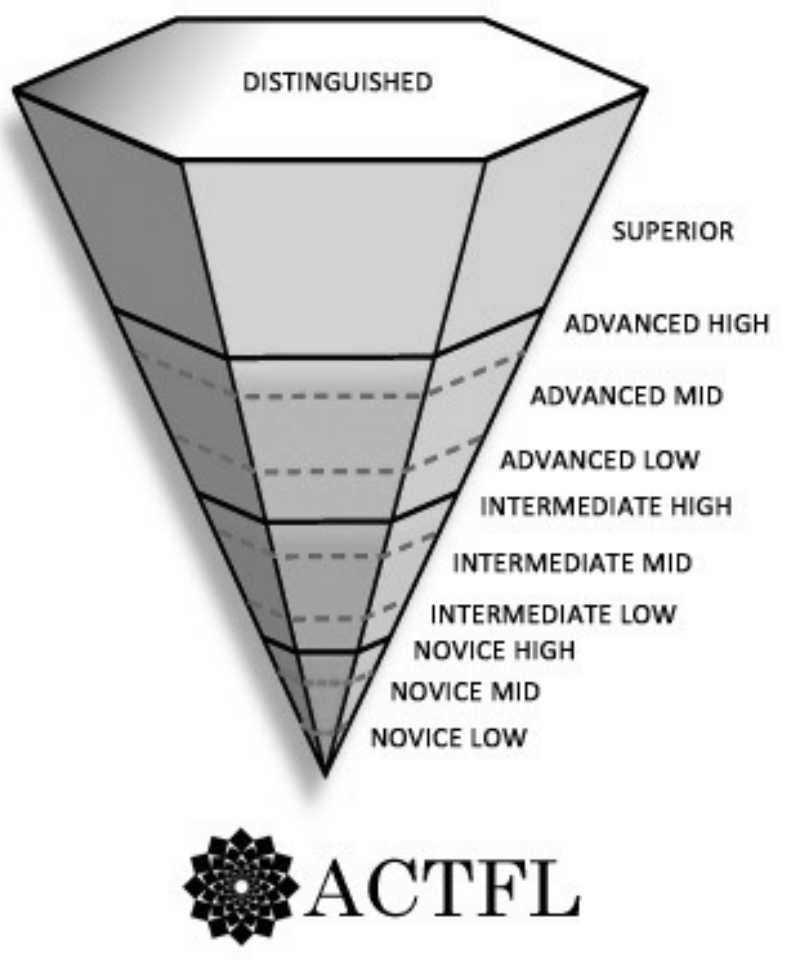

Figure 1. OPI Levels and Sublevels. 


\section{CHAPTER VI: ANALYSIS}

Wolcott (1994) says that analysis is what we do "in the process of cautiously constructing studies out of data" (p. 174). It is the organization of data "along analytical lines" from which the qualitative researcher picks out "a few factors at work in a particular situation" from which s/he gives a systematic description of the relations among them (p. 175). In qualitative research, according to Wolcott, the purpose of analysis is to lay out your case for the reader and ask them to be a passive coinvestigator by saying: 'I've presented what I've observed. I have attempted to identify what I see as critical components. To this point I assume you concur with the analysis I have offered. I ask you to share responsibility in taking it from here” (p. 174). This is the approach that I have taken in my study. I have searched for critical components within my participants' interviews and other communications and have compared them through themes of power within critical linguistics in order to call attention to features that merit heightened awareness. Critical linguistics involves raising awareness in order to enact change through a critical view, or "the perspective of someone who questions, who doubts, who investigates, and who wants to illuminate the very life we live...by examining conventions and beliefs" (Alim, 2010 , p. 205). Areas of focus were divided into categories of critical themes, which I will describe in this next section, followed by analysis of each participant through the themes.

In this chapter I analyze the student interview data using critical applied linguistics, which focuses on issues such as ideologies, institutions, systems and notions of gender, race, ethnicity, sexuality, social class, and discourse (Anya, 2011). These themes focus on how participants connect language socialization (a multifaceted theory that includes notions of identity, investment, and membership applied to understanding second language acquisition of in-class and study-abroad participants over the past two decades) with notions of power, 
"disparity, difference, and desire" (Pennycook, 2008, p. 170). Alim (2010) describes how "critical language highlights language conventions and language practices...invested with power relations and ideological processes which people are often unaware of" (p. 205). The themes in this section all relate to how this conscious and subconscious power is maintained and reinforced by white privilege. For the purposes of this study, they can also help show how ideologies of study abroad are sustained as 1) a privileged endeavor that is primarily within reach of white, middle-class (or richer) Americans and as 2) a way in which Western society, more specifically American national identity and linguistic superiority of English as the Lingua Franca permit students to both maintain and use this privileged identity as well as reify it through Americanized communities of practice while abroad, which consequently has a negative effect on L2 language learning. I apply this toward instances of SA students who choose to interact, travel, and study within American communities of practice. While the theory of language socialization, CoP and LPP would emphasize that students do this for reasons of comfort, reifying their identity and feeling of belonging, in critical applied linguistics this is further connected to power. Power exists at all levels of human interaction and practice, manifested through norms of people and institutions. Such terms as "standard," "official," "appropriate," "normal," and "respectful" represent and perpetuate accepted codes of power (Alim, 2010) and hide behind broad categories of social, cultural, and political power or capital which are all inextricably bound. In this chapter I describe the key themes within critical linguistics (nationality, social class, gender/sexuality, race/ethnicity, and discourse/linguistic inequality) followed by how they were revealed by individual participants. I end by describing participant trajectories in terms of shifts in their thinking and ways of understanding the world. 


\section{Key Themes in Critical Linguistics}

The themes that critical linguistics explicitly focuses on are nationality, notions of gender/sexuality, notions of race/ethnicity, social class, and discourse/linguistic inequality. Below I define these for the purpose of their use in my research using frameworks of power to describe, analyze, and interpret participant data.

\section{Nationality}

Study abroad is an experience during which the significance of nationality comes into question because the participant is physically disconnected from the imagined community at home that reifies these ideas, causing the participant to reassess both what nationality means, and how the participant personally identifies with it. Block (2014) characterizes national identity as: ...individuals growing up in particular places and times, as a complex of common or similar beliefs or opinions internalized in the course of socialization... and of common or similar emotional attitudes as well as common or similar behavioural dispositions...relating to a particular nation state. (p. 35)

Block also asserts that nationality is constructed through repetition of and exposure to specific discourse. People do this by using expressions such as being "proud" to be American, by placing high respect for symbols such as the American flag, the military, and gatherings and events considered to be typically American such as picnics and baseball.

Anderson (2006) describes nationalism as an imagined community, saying that most people of the same national identity will never meet each other or know of each other's existence, but find communion with each other through the "image of their communion" (p. 5). National identity relies on the individual to reify behaviors that encourages the formation of larger groups. Block (2014) says that these behaviors include food eaten and language spoken as 
well as other symbols and activities such as flag waiving or celebration of historical events to reify their significance to the group. Block points out that nationality is not an "objective or a stable construct" because it requires constant reinforcement through discourse and symbolic actions (p. 36).

These stereotypical national symbols are grounded in whiteness. There are other equally American passtimes, genres, and symbols such as rap, soul food, and slavery that are just as American, but not immediately recognized or institutionalized as "American," despite their ubiquitous presence in American culture because American nationality is firmly situated within white supremacy. While it often goes unspoken, the history of the United States has honored whites as the primary founders and builders of the country while people of color are rarely given credit for their large part in back-breaking, self-sacrificing, and most-often forced contributions. As a white person, McIntosh (2002) explains, "When I am told about our national heritage or about 'civilization' I am shown that people of my color made it what it is" (p. 98). In other words, race cannot be separated from nationality. Herndon (2003) argues that this influence on our understanding goes back to when people of color (i.e., African Americans and Native Americans) were explicitly not considered citizens, “The nation's first naturalization act passed in 1790 reserved the privilege of naturalization for aliens being free white persons - only they had the rights of citizenship" (p. 229). Being American infers whiteness. Each as a social construct, race, and nationality are constructed in relationship to each other and has ultimately shaped racial discrimination in the United States.

Understanding nationality as a social construct is significant to understanding how it affects the study abroad experience. Dolby (2004) asserts that the study abroad context elicits a significant encounter with the American self not previously part of a student's consciousness 
claiming that it may be the most significant component of a student's study abroad experience. This is because of participants' lack of understanding of who they are before they begin their sojourn and the contradictions that they encounter as they meet new people who hold their own views of what it is to be American. In essence, the imagined national identities of students are challenged and reshaped while studying abroad because they encounter a different discourse about what it means to be "American" than to what they had been accustomed.

\section{Gender/Sexuality}

The idea of gender as specifically connected to one of two sexes, either female or male, has followed a deficit model for years that it has "certain characteristics which are determined by the environment and which are stable through one's lifetime" (Block, 2014, p. 41). Other definitions of gender identity are connected to establishing power and superiority such as "modes of behaviour laid down by men," or that "men and women are different but equal," or even that women "perform their femininities in patriarchal societies in which they negotiate, as best they can, their position of relative powerlessness vis-à-vis men" (p. 41). Butler (1999) discusses the significance of how gender is assigned through a term referred to as genealogical critique, which investigates the "political stakes in designating as an origin and cause those identity categories that are in fact the effects of institutions, practices, discourses with multiple and diffuse points of origin" (p. xxix) in order to destabilize power structures. I look at the theme of gender in study abroad because society's varied understanding and response to gender identity can affect perceptions and treatment while studying abroad.

Polanyi's (1995) study is one example of differential treatment abroad based on gender. Data from student journals who took part in a study abroad in Russia showed a difference in L2 learning experiences between American male and female students. While male students were 
encouraged and helped along in L2 learning situations, female students were often harassed and experienced unwanted sexual advances.

Block (2014) defines sexual identity as "the systems of mutually constituted ideologies, practices, and identities that give sociopolitical meaning to the body as an eroticized and or reproductive site" (p. 43). Similar to gender identity, sexual identity (a construct focused narrowly on sexual orientation) is created in the minds of people for various erotic reasons and needs (Block, 2014). I look at the theme of sexuality to refer to explicit or implicit experiences that occur during a study abroad related to issues such as sexual advances or harassment, perception or prejudgment based on learned or locally set standards of sexuality.

SA research has shown varying results with regard to sexuality. Kinginger's (2008) study of Bill, a marketing and International Business major who spent a semester in Dijon, France, is one in which the student draws upon his normative view of gender from his own upbringing and popular culture to inform his study abroad experience. Bill saw American women as submissive and childish while he viewed French women as both exceptionally strong and kind. On the other hand, he regarded French men as self-absorbed people who tend to harass those of the opposite sex. Bill described having to come to women's rescue many times to save them from aggressive French men, an act that in essence built his own identity and shed a positive light on his L2 experience in that it helped him gain access to certain local communities of practice (Kinginger, 2008). Students must often negotiate their gender and sexuality in a new culture as it affects their L2 acquisition and membership of communities of practice.

\section{Race/Ethnicity}

As Howard (2010) describes it, "Race is our historical lightning rod, equipped with centuries-old baggage, uninformed epistemologies, and sordid axioms that, at its mere mention, 
quickly can divide people who are seemingly united citizens" (p. 92). Kubota and Lin (2009) argue that race cannot be verified by biological constructs (p. 2). Furthermore, they cite the Human Genome Project (2002) which shows "99.9\% of human genes are shared in common" (p. 2). While race is often immediately considered "a classification based on biological or genetic methods" it is a category that has only developed over time and is based purely on "historical and social contexts" (Block, 2014, p. 34). For most white people, race remains an invisible and largely ignored aspect that informs their SA experience because, as Dalton (2002) asserts:

Most white people, in my experience, tend not to think of themselves in racial terms. They know that they are white, of course, but mostly that translates into being not Black, not Asian-American, and not Native American. Whiteness, in and of itself, has little meaning. (p. 15)

Block (2014) describes ethnicity as "a form of collective identity based on shared cultural beliefs and practices, such as language, history, descent, and religion" (p. 22), but it is often used to refer to skin color. More significantly, the idea of race and ethnicity creates divisions between people because of the boundaries of difference that are drawn through social constructs. Block asserts that while racial boundaries are created based on physical markers, and ethnic boundaries are made based on cultural markers, these boundaries are often blurred.

Singleton and Linton (2016) point out the symbolism that has been attributed to race in this manner:

Scientifically, race is nothing more than the color of our skin, texture of our hair, and shape, color, and dimension of physical features such as eyes and lips. So much social and political meaning has been attached to these determinations of race, however, that the 
simplicity has given way to a complex phenomenon in this country over the past four centuries. (p. 158)

As Dalton (2002) explains, "While ethnicity determines culture, race determines social position" (pp. 16-17) and social position is indelibly connected to whether one studies abroad at all and how one approaches the situation while on site. Talburt and Stewart's (1999) conclusion was that race is integral in influencing what students "do and do not learn" (p. 173, emphasis in the original) in study abroad. There exist several studies in which the notion of race in SA is discussed such as African-American SA participants' in Brazil, a country in which many of the citizens "look just like them" (Anya, 2011), Talburt and Stewart's (1999) study of Misheila's racialized SA experience in Spain as the only African-American participant in the program, and Simon and Ainsworth's (2012) study that focuses on race and whiteness, or the invisibility of race during SA programs where "no white students reported that their race was a concern for them, even when they studied in predominantly non-[w]hite nations..." (p. 13). However, very few studies refer to how SA is primarily an endeavor of white, middle-to-upper-class students. Race shapes the experience of students of color in ways that most administrators ignore, just as most SA participants ignore, because they are white. My use of this theme is thus because both SA participants as well as the local population are informed by beliefs about race, whiteness and ethnicity and those beliefs are often invisible because of the way in which subconscious ideological and institutional standards are reified in society.

\section{Social Class}

Social class is often explained by economic status, however social class is a complicated representation of power over social norms and standards through divisions of wealth, education, occupation, and symbolic behaviors. Study abroad is a situation in which participants become 
more aware of divisions and differences in their social class and reaffirm their own social power in their identity. Fairlough describes class as "groupings of people who are similar to one another in occupation, education, or other standard sociological variables" (as quoted in Pennycook, 2001, p. 51). These groups have generally been categorized in three classes: working, middle, and upper, each of which represents varying amounts of power over social norms and standards which are "inextricably bound to inequality, struggle and opposition" (p. 51). Much of one's standing in social class is influenced by social capital and "having the right cultural resources or assets" creating "connections to and relationships with less, equally or more powerful others" (Block, 2009). Some examples of resources that affect power relationships are "behaviors such as attitude or accent, association with particular artifacts such as books and qualifications, and connections to certain institutions such as universities or professional associations" and even clothing (p. 45).

A particular aspect of social class that pertains to study abroad participants is what Murphy-Lejeune (2002) refers to as "mobility capital" or the privilege of access to international travel and terms this the "migratory elite" (p. 5), a group of travelers (monks, artists, aristocrats, conquerors) throughout history that contributed to the globalization that we know today. While Murphy-Lejeune sees some differences between this group and SA participants, perhaps our SA participants should be included in this grouping. While, as she argues, their integration as students into the local environment should be easier than the expatriate, their actions can be compared to those of "temporary expatriates" because "their return home is scheduled" and the "privileged" circumstances of their stay abroad often "exempt(s) them, if they wish, from involvement in the local society" giving them an "out" from language and culture learning if 
they are not so inspired (p. 5). It is quite possible that this is also the mindset of modern study abroad participants.

Block (2014) admits that social class can act as a "screen that prevents researchers from seeing other important elements that are factors in human interaction" (p. 44) such as nationality, race, ethnicity, and gender. I use this comment to argue that given the general demographic of SA participants as both white and middle to upper class, their reactions to situations that they experience may often fall under this theme, but can quite easily be conflated with other critical themes.

\section{Discourse/Linguistic Inequality}

Linguistic identity is the "relationship between one's sense of self and a means of communication" (Block, 2014, p. 47). It is shown through various acts of identity within ethnicity, nationality, gender and social class and thus can be conduits through which power and systems of power work to delegitimize. "Linguicism co-articulates with class, racism, and sexism, and needs to be resisted like all mechanisms that condone injustice and inequality" (Phillipson, 2016). As previously discussed in chapter two, linguistic inequality, or linguicism, refers to an unequal division of power based on the languages that people speak or discrimination carried out through language (Pennycook, 2001, p. 61). Phillipson (1992) posits that as English becomes more dominant and accepted through its common and frequent use across the globe, it becomes English linguistic imperialism, as it perpetuates "continuous reconstitution of structural inequalities between English and other languages" (p. 47). English is the language of communication in global business, art, culture, politics (Hancock, 2007). According to Pennycook (2001), those who do not speak it or who do not speak it well are "othered" which permits people to be placed in inferior social and economic classes. Othering 
highlights English's superiority, carries it across societies, and spreads understanding and acceptance of its power and social capital to those who speak or know about it across the world. English-speaking communities of practice (CoPs) in SA are based on linguistic inequality. This inequality comes from several different factors. It comes first from those who (consciously or subconsciously) impose cultural aspects of their nation (manners, art, and language) over another, also called cultural imperialism (Hsiao, 2014).

An additional point of view is from that of the L2 learner because SA participants can feel linguistically delegitimized as much as they delegitimize other languages. As they negotiate their L2 language abilities on site Block (2014) points out that an L2 learner cannot always have control over their audibility, or "the combination of the right accent as well as the right social and cultural capital to be an accepted member of a community of practice" (p. 49) affect their perception of their personal second language identity. SLA literature also refers to the discomfort that L2 learners experience in immersion situations in which they are unable to express themselves in the complex manner to which they have become accustomed in their native tongue (L1). Pellegrino Aveni (2005) describes it this way:

Stripped of the comfortable mastery of their first language and culture and societal adroitness, learners in immersion environment, such as study abroad, often report feeling as if those around them may perceive them to be unintelligent, lacking personality or humor, or as having the intellectual development of a small child. (p. 9) In response, American students may feel more confidence using their L1 to communicate than SA participants from other countries, and in doing so, invoke their linguistic power as English speakers. American SA participants may very well experience a form of linguistic inequality for the first time in their lives, which on the one hand could be an appropriate learning experience 
for them to understand inequity, but may be less pronounced without proper pedagogical interventions that give them the tools to think critically about it.

This negotiation of linguistic power of L1-speaking SA students and the power that they must give up in L2 learning situations provides a complicated ground on which L2 learners stand during a study abroad. On the one hand, they are there to learn the L2 but often find themselves embarrassed, humiliated, and feel infantilized because their abilities reflect back on these almostadults as weakness. They are surrounded by other Americans who are often experiencing the same things and so they create English-speaking communities of practice in which they reify their identities as SA participants who are struggling at varying levels of assimilation. As members of these CoPs, they use the power of their national identity and language to justify and legitimize their actions, ultimately perpetuating American cultural and linguistic imperialism both at home and abroad. A synthesis of the data regarding identity will be addressed more fully in my final chapter.

\section{Negotiation of Critical Themes in Identity}

In this section, I explore data from interviews with my SA participants to ascertain how they negotiate the previously described themes within critical linguistics theory. I end with a summary and some conclusions. I give a synthesis of the identity data more fully in my final chapter.

\section{Magda}

Nationality. Prior to her departure, Magda discussed Americans in symbolic terms such as people who eat corn dogs and who are English speakers. She also said that Americans are very friendly, and it was very easy and convenient to be American. On the other hand, she had concerns about Americans being hated abroad and worried that she might be "othered." Her 
mom suggested that she pretend to be Canadian. Magda very consciously understood that Americans tend to feel that they are entitled to both physical and speaking space wherever they are. Once abroad for a few months, Magda remarked on several issues pertaining to American nationality. First, she noticed in both class at the French university as well as in a discussion with a woman originally from the Ivory Coast who had lived in France for years, how differently French history was taught in France versus in the United States, claiming that there is a different "spin" on it in the U.S, inferring that she noticed a bias in the way it was taught back home. She also noticed that being American in public settings attracted people to her, wanted and unwanted. She noticed that Americans assume that it is ok to speak English in whichever setting that they want.

At the midterm, Magda did not necessarily show a shift in her mindset about being American. She continued to see it as easy, convenient, and Americans as loud. She pointed out a sense of entitlement in Americans abroad, who believe that they should have special treatment because of their nationality. Finally, Magda did feel integrated into French life after a few months of living there and worked hard to make local connections to facilitate this because she knew that this would help improve her L2 learning.

Upon her return to the United States, Magda continued to have a negative view of Americans abroad because of their attitudes and behavior, especially with regard to speaking in English/French. Magda learned that to understand someone else's story, she had to make local connections and learn it from them, not learn it in some disconnected way or through a filter such as the American classroom.

Although Magda believed that Americans in their own country are friendly and kind, she remained unchanged throughout her time in France in her understanding of them as entitled, 
English speakers who speak noisily and take up space as if it were their own while abroad. She also learned that there is a bias within the way that history is taught and plans to carry that knowledge with her to her own classroom. From the beginning to the end of her SA experience, Magda did not show a vast shift in her mindset, but she did have realizations that cemented her understanding as a language learner and as a future educator, and while she seemed to think highly of Americans at home, she did not think highly of them as exchange students or tourists.

Gender/sexuality. Prior to departure, Magda referred very little to her gender or sexuality, except to say that she would be leaving behind a boyfriend with whom she would try very hard to remain in touch. Magda's mindset of having a boyfriend back home had an effect on how she approached her semester as a female abroad.

By the time of the midterm interview, Magda, referenced her boyfriend at home when discussing advances by French men and conflicting feelings that arose because, while those advances put her in an uncomfortable place, they did help advance her L2 learning. Magda gave several examples of situations in which she was able to practice French all while permitting French guys to flirt. On Montmartre at Sacré Cœur she mentioned French guys who were "hella creepy" but being with them permitted her to speak French all evening long. Magda also described how going to bars always meant propositions from French guys, but since they were not openly, "Let's bang, babe!," she accepted it. Finally, Magda described an uncomfortable situation in which she met a couple of African guys at the grocery store who wanted to practice English and French. She tried in many ways to tell them that she was not interested, but one in particular pressured her to give him her phone number. He called her over and over, and was upset when she did not call back, even though she explained that she was not interested. 
Magda did not elaborate on any of these subjects in her return interview, except to say that she had stopped talking with the Nigerian guy. Overall, she complained about the lack of opportunities to make meaningful social connections to help with a sense of belonging and help improve L2 learning, even though she did find a way to get L2 learning out of the less-thandesired attention from French men.

Magda's main objective from her semester abroad was to learn to speak French better. She realized that she would have to put herself in some uncomfortable situations in order to facilitate this, including some that were sexually uncomfortable. In doing so, she was in many settings in which she received advances from the opposite sex that she accepted in the name of L2 learning. She was often proud of herself for conducting such extended conversations in French during those times. However, it appears that she would have ultimately desired preestablished communities of practice for students who want to learn French so that she might not have had to put herself in the position of such sexual advances in the first place.

Race/ethnicity. Magda did not bring up any notions of race or ethnicity in the predeparture interview, but did refer implicitly to a few things in the midterm. First, one of her roommates was from Japan and she had begun making friends with (among others) Chinese and Japanese and other students to which she referred as "international." Second, Magda's experience involving some harassment based on her gender (and probably her nationality) was with a man from Nigeria, but she only mentioned his origins because I asked whether he was French or American. Magda also took part in what she considered a very positive and informative conversation in a bla-bla car (kind of like Uber and carpooling in one) with a woman who is originally from the Ivory Coast.

Magda referred to issues of race or ethnicity just once during her return interview. 
She spent a lot of time with students from East Asia and really appreciated them as friends and as people who either could not or preferred not to speak English. I cannot be sure why she did it, but she referred to them as "kids" in reference to making friends with them, "I mean, there was a lot of, like, the Korean kids are over here, the Japanese kids are over here.” The use of this raced term essentially established her superiority over them, as an adult might use in reference to a child. Magda's use of deficit language manifests the conflation of American and white identities and highlights the notion of invisible white privilege.

Magda did not recognize her own raced experience as a white woman abroad. She did point out other students' race or ethnicity, specifically students from East Asia. While it was certainly not meant to be negative, it did in effect "other" those students. Magda certainly enjoyed her friendships with them; in fact, it was from the community of practice with East Asian students that Magda was able to speak primarily in the L2.

Social class. In her pre-departure interview, Magda looked forward to the ability easily to get around in Angers and in France in general. She anticipated enjoying the food, and being perturbed with their inefficient bureaucracy.

At the midterm interview, Magda described herself as integrated, having many American friends, but also friends who were Japanese, Chinese, and students from Hong Kong. Magda noted the importance of quality of life in France and by them generally being less busy than Americans. In social settings Magda noticed a difference in behavior by the French versus Americans. The French tended to be reserved and relaxed and easy-going, while Americans were more animated, dancing, and moving around tables. Magda confirmed that the ease of travel was something that she indeed enjoyed, especially because it was not expensive. At school, Magda 
was frustrated with the less-than-encouraging nature of French teachers compared to American teachers.

In her return interview, Magda reported that there was not enough opportunity for creating community and building relationships within the host family, but even more so at the university. She reported not liking how international students were separated from the regular French students at the university and would have liked to have built relationships with them, as well. Overall, Magda needed support for the frustration and lack of confidence, as well as lower linguistic levels that she had while there.

In sum, Magda made a great effort to establish connections and friendships abroad and ultimately was frustrated at the lack of support from program administrators for the frustration and lack of confidence, as well as lower linguistic levels that she had while there. Magda did not assert much social hegemony regarding material expectations. She was most invested in making connections with people who would help her learn culturally and linguistically.

Discourse/linguistic inequality. Before leaving for her semester abroad Magda discussed how "truly awful and frustrating" she expected the language barrier to be, especially because she was a person who liked to talk. She decided that it would be better to speak bad French than no French, and so that was her plan.

By midterm, Magda still expressed frustration at not understanding everything that was said, however, she had had positive linguistic experiences such as paying the student entrance fee into the Louvre because she was able to explain to the ticket agent that she was a student in Angers. She said that spending time with Americans had a negative effect on her French because they always "defaulted to English" all day long. Even on excursions when university administrators would remind them to speak in French, Americans would ignore it and continue 
in English. Furthermore, Americans spoke in English even in class as they worked in groups. In Magda's return interview, she pointed out many instances during which people chose to speak English instead of French. She also spoke at length about how she would have preferred more opportunities to be in French-speaking situations. Furthermore, Magda often denigrated her ability to speak French.

Magda was disappointed that our university program did not provide more opportunities for social interaction and wished that there were more opportunities outside of the classroom to practice French, even with others who were in the same situation as she was. Magda also wished that our program had been made up of a larger group of students so that there might have been more of a chance that she would meet someone with similar interests and language abilities. Magda did meet some like-minded people, especially students from East-Asian countries, and really enjoyed speaking French with them. She recognized in them the same goals as she had, as opposed to the goals of most other Americans who attended the school. She made friends with a French woman who taught English at a local middle school and enjoyed time with her. Magda was not confident in her French abilities and would often denigrate them and point out her shortcomings. However, she did recognize in herself an overall positive shift toward L2 learning. Like the other participants, spending time speaking English with Americans often resulted in taking away time from L2 learning.

Overall, Magda was critical of the program and situations surrounding it, something that might be connected to social class, nationality, and whiteness, but she was just as critical of herself as a learner. This may have been advantageous to her L2 learning and her motivation to invest in COPs with her host family and school mates in which the L2 was spoken during her semester abroad. 


\section{Lesley}

Nationality. At the pre-departure interview Lesley expressed concern at being stared at while abroad, and while she did not mind people knowing that she is American, she was uncomfortable with the idea of their gaze upon her. Lesley showed a desire to come across as a cultured American who fit in, and she felt that the way that she dressed would affect this, and spoke out against certain ways of dress. Lesley described being an American, as one who shows pride and is also happy about this identity, especially given the many different cultures that make up the United States. At the midterm interview, Lesley was still concerned with appropriate ways of dressing. She did not like it when the French would ask her questions about our history, politics, or any other subject that she did not know a lot about. It would make her defensive and revert to a proud American stance. Upon her return to the United States, Lesley had had so many conversations with French people during which she felt threatened by their expectations of her as American that did result in some shifts in mindset, but also a strengthening of a previous one. On the one hand, Lesley felt strongly that she not have to represent global perceptions of Americans. She did not want to have to answer political questions as if she represented our government or the typical American. This resulted in Lesley asserting that she was not American but simply a human being who did not represent the masses. On the other hand, those conversations and questions made Lesley feel that French people thought she was dumb. The combination of it all ultimately caused Lesley to fall back on and proudly accept herself as American. "Oh yeah, I'm an American - accept it!" Lesley's reversion to her nationality demonstrates the invisibility of white privilege and the ability of Americans to reify their powerful stance all while studying abroad. As Wildman and Davis (2002) describe, "the invisibility of privilege strengthens the 
power it creates and maintains. The invisible cannot be combated, and as a result privilege is allowed to perpetuate, regenerate, and re-create itself' (p. 89).

Kinginger (2009) suggests that individual national identity is reified abroad as SA participants "may find that their national identity influences the ways in which they are 'located in conversation' and they may devote significant reflective energy to positioning themselves as representatives of their home countries" (pp. 183-184). Lesley notions of her nationality were strengthened throughout her year abroad. She was concerned with being stared at perhaps in an attempt to "other" her, and she was fine with people knowing that she was American, as long as they did not threaten her with questions that she could not answer about American history or its presence in the world. Lesley was concerned throughout her entire year abroad with being cultured and dressing right. The more people asked her about her Americanness and the less she was able to answer, the stronger she identified with being American in the end.

Gender/sexuality. Lesley did not refer to issues of gender or sexuality at all during the pre-departure or midterm interviews. She did have a French boyfriend, who she had been dating since long before her year abroad, and she would refer to spending weekends with him all year long.

At the return interview Lesley described how strange it was that there was a bathroom in the center of the street roundabout area in front of the school, and how uncomfortable it was to see men as they went to the bathroom there. "I saw a couple people peeing on walls.... Yeah! One homeless man was doing it in the middle of the day! That was creepy. That was the creepiest part for me. The first time I walked past it I was, like, 'That man's peeing on a wall!' and, like, 'Yeah, it's a bathroom!'” 
Overall, what sticks out about Lesley's gender and sexuality from pre-departure to the return is how spending so much time with her French boyfriend did not have more of a positive effect on her L2 learning. Similar to Sasha's situation with her French boyfriend, Lesley did not feel comfortable speaking French with him and took advantage of his stronger linguistic abilities in English to communicate with him in English.

Race/ethnicity. Lesley does not bring up any notions of race or ethnicity during the entire year abroad except to refer to herself as a redhead who has had incidences of being stared at. Lesley is white. However, the previous section on nationality shows an obvious conflation with race because 1) American nationality infers whiteness, and 2) as Lipsitz (2002) explains, "whiteness never has to speak its name, never has to acknowledge its role as an organizing principle in social and cultural relations" because it is "an unmarked category against which difference is constructed" (p. 61).

Social class. In her pre-departure interview, Lesley showed concern over the way Americans should dress and act when abroad, citing some previous experience she had had with how Americans reiterated the typical tourist through their fashion choices. Lesley may have had some pre-judgments about the French. She had been there before and had also had a native French, French teacher in high school who she described as rude and as someone who did not like Americans.

At her midterm interview, Lesley expressed that she appreciated that the drinking age was 18 and that the university program was indulgent regarding not turning in homework or turning it in late. Lesley described her friends as mostly American, and she particularly appreciated hanging out with friends who were going through the same thing as she was. As 
anticipated in the pre-departure interview, Lesley did not like the transport system, particularly the trains because she viewed them as inefficient, unreliable, and confusing.

In the return interview, Lesley described that overall, she loved the food, she avoided fashion no-no's all year long, and she did attempt to follow politics more since the French tended to do that. Lesley was still leery of French transportation, not having taken the tram or the bus, having begrudgingly taken the train, and being completely opposed to renting and driving a car. Lesley did enjoy travel. She went to several different European countries. In her interview with me she described them as cheap, clean, oozing money, and was happy that she could find American restaurants there. Lesley's year-long best friends, beside her French boyfriend, were Americans from Notre Dame and some from her own program.

Lesley's social interactions were very influenced by this conflation of nationality, social class, race, and linguistic inequality. Lesley took part in primarily American communities of practice in which she spoke English. She took part in American colonial practices of travel, and particularly sought out American establishments and comforts such as Starbucks and well-known monuments that show that she had been there.

Discourse/linguistic inequality. Prior to her year abroad, Lesley discussed what she would do to improve her L2 while in France. She planned to put an effort into classes, immerse herself in the experience, and take part in local groups. She also recognized that she should speak French with other English speakers while there. However, it was important to her to remain in contact with her friends back home since she would eventually return back to them. As for making friends with English speakers, Lesley thought that it might be nice to make friends with people with similar backgrounds and languages because they might be able to help each other by being in the same boat. 
At the midterm interview, Lesley pointed out that her classes at school had the most positive effect on her L2 learning. She said that she spoke a lot of English outside of class, which she also blamed on others not being at her level of French, so it was just easier to speak English with them. She did say that she would speak French with Magda as well as with her host mom, and sometimes with her roommate, although the roommate spoke five languages, which made Lesley feel "worthless."

Lesley described not having been able to meet many French people, but when I brought up her French boyfriend who she spent every weekend with, she explained that their relationship started in English and her boyfriend's English was much better than her French. She admitted that she could try to be friends with Asian students if she wanted to speak French more often.

In the return interview Lesley described her French as having improved, but she was still sometimes uncomfortable speaking it and felt that she was not fluent. She explained that classes helped her L2 gains the most, as well as dinners with her host mom. She said that she was fully immersed in French while in class, as well as at lunches with the Directors. She also spoke in French with Magda at times. She admitted speaking too much English overall and she said that it was difficult to make French friends, and she never changed her online or computer settings to French.

While Lesley's initial intention was to immerse herself as much as possible into the culture and French speaking groups, once she was in France, she instead spent the majority of her time with groups of people who spoke English. She also spoke English with her French boyfriend. However, Lesley did eat some dinners with her host mom and would speak in French with her. Lesley found that she learned the most in class because that was where she invested the most time in speaking French. Otherwise she spoke too much English. 


\section{Becky}

Nationality. Before leaving for France, Becky showed concern over sticking out as an American while abroad, while simultaneously worrying that her very identity would be threatened if she actively pursued not sticking out. In terms of her national identity, Becky believed as it seems many people do, that being American is connected to the American Dream:

I guess to try to live the American dream I guess. We have a lot of freedoms a lot of people don't, a lot of opportunities a lot of people don't. So, you have basically every chance to succeed.

Once she was in Angers for a few months, her mindset began to shift. She described Americans as unaware of their actions and what is going on in the world, that being American "kinda also makes me ignorant to some things" and she also noticed that Americans are more "privileged" and that she carried an underlying sense of entitlement to having things as an American that actually were not available to her in France. Becky's idea of what an American was shifted to a simple affiliation with the label and only because of the legal status. "I see the French Dream, and the French Dream doesn't seem like, um, I wouldn't compare being American to the American Dream [any longer]."

Upon her return, Becky came to a greater understanding of the entitlement that Americans feel they have to whatever space they currently inhabit, both physically and spiritually. Becky referred in particular to how loud Americans were and as a result of this realization, Becky made an effort to adjust her own behavior and speak more quietly. In reference to what it is to be American, Becky again shifted her beliefs and said that there is not one fitting definition because of the variety of cultures and backgrounds that make up each American. 
Looking back on it, I think that everyone, like each American is different, you can't label...because we all have different cultures, we all have different backgrounds, we all get something different from this country and so I think that it's up to each person to define who they are as an American, but I don't think that an American, like, completely, like, I feel like, being like, it's more of a label than who I am.

Becky's initial understanding of what it is to be American follows a socio-culturally dispersed idea called the myth of meritocracy, "a social system as a whole in which individuals get ahead and earn rewards in direct proportion to their individual efforts and abilities" (McNamee \& Miller, 2013, p. 7). This myth appears true only when others invest in its premise too. Belief in it comes from repeated exposure not only through advice from family and friends, but through news stories, national holidays, school work ethic, and other symbolic modes of communication, and especially through the term the American Dream. Americans believe the (false) idea that they have every opportunity to succeed because we live in a land where "citizens are free to achieve on their own merits" (p. 8). Certainly, neither of these opportunities are truly available to everyone despite their persuasive notions. In expressing this perception in her interview and as an American abroad, Becky perpetuates the power of meritocracy and the American Dream, as well. As Becky spends time at a distance from these ideals, although she is initially concerned about losing her identity, it appears that her allegiance to being American holds less meaning and furthermore permits her to recognize and reflect on some of the negative aspects connected to effecting power as an American. She chooses to speak more quietly, which means that she not be a member of the noisy American COPs to which she refers which permits her to focus more on L2 learning and speaking. 
Gender/sexuality. Becky did not refer to gender or sexuality before her departure, but at the midterm and upon her return from her year abroad, she said that in addition to her race, her gender made it difficult for her to get ahead in the U.S., more so than in France.

But in the States, like here I don't feel stereotyped, in the states I do. In the states I feel the need to like work harder just cause of like my gender and my race, so I would definitely prefer it here than in the states.

In reference to shifts or realizations over time for Becky, it appears that whether she had issues with gender or sexuality abroad or not, a return to the U.S. signified a decrease in social standing because of both her gender/sexuality and her race. This could suggest that Becky was more comfortable taking part in local COPs in France than in the U.S. and that her L2 learning was positively affected by that.

Race/ethnicity. Before leaving for her year abroad Becky showed concern for how her race might be interpreted by the French. She began by saying that "Some people can't tell the difference between Africans and Black Americans. So, I'm worried." When I asked her to elaborate she responded, "Some people, if you're Black American, some people expect you to have a lot of knowledge about things that's going on in Africa, so I have not, whatsoever!” So, I asked her if she thought that there might be the possibility for mistakes or prejudgment and she answered:

Well, cause you know here in the U.S. I've come to expect it and, like, you know, here I know what stereotypes are associated with me and my skin color here, but there I don't know what stereotypes are associated with my skin color so that's going to be a...and then maybe there might not be any, so I don't [know]. 
Once in France, Becky described both positive and negative experiences regarding her race. One of the only positive experiences (her emphasis) was a daily occurrence walking down the street and being greeted by an African guy whose English was not very good, but who asked her questions and struck up a slight friendship that continued over time. Becky described being happy every morning when she walked along that same path and he would greet her with, "Hey, Chicago!" Negative experiences with race occurred when people would ask her where she was from and when she would reply that she was from Chicago, they would reply, "No, where are you from?" and she would have to get into an extended explanation to explain that her family was not directly from Africa.

And I'll say "Chicago.” And they'll be, like, "no, where are your parents from?"

“Chicago!” “No, no, no.” And I’m, like, “my family’s American, we're not ...from Africa," and so some people don't understand that.

In these interactions with Becky, French people seemed to equate being American with being white and being African with being Black. In short, not only does American discourse about American nationality infer whiteness, the discourse of people from other nationalities infers it, too.

Another negative experience was at the dinner table with her host family, of which one of the parents was French and the other Korean. She really enjoyed their dinner conversations because they would discuss all sorts of subjects, but there was one subject that Becky did not appreciate:

"Oh Becky, you'll like this because it's about_it's a story about these kids from Africa," like, this, this and this. And I'm, like, "Yeah-I probably would like it, but you are also assuming I'd like because I am also African!" 
An additional negative experience that Becky had was related to her hair. She explained to me that her hair was styled in Senegalese braids at the time, and it seemed to have made people believe that she was from Senegal.

Because [of] my hair, I have my hair braided in the Senegalese braids like the braid in Senegal, and people come up to me, like, in Paris these people came up to me and were, like, "Oh you're Senegalese? What part of Senegal?," and I'd be, like, “No, I'm American!," and then they're, like, "Really?" So, all the time I just get, "Where're you from? How's Africa?” "I don't know! I’ve never been!”

Becky overall felt that French people were not purposely trying to offend her, she believed that it came out of curiosity. Becky claimed that she felt more stereotyped and had to work harder because of her gender and race in the United States than in France. Becky did not have much more to say about this upon her return from France. She reiterated that French people stereotyping her as African was because they did not know any better and that she was definitely more stereotyped in the U.S. than in France. She did point out that the stereotypes in the U.S. come from both "white people but from the Black community, as well."

Based on Becky's responses, we can see that being African-American study abroad participant can be difficult for a few reasons. First, African-Americans are already used to differential treatment in the U.S. and the concern with how they will be treated in another country is legitimate. We know this already from Twombly (1999) when the female, AfricanAmerican study abroad participant had a very different experience than her white counterparts from the same university on the same program in Spain. In Becky's case, it appears that she did not have difficulty feeling that she belonged in a COP, although it was a group of American and East Asian students, and not French. The one positive experience that she had with a local person 
was a Francophone African. This brings up my second reason. Most administrators have no idea that a student of color would have an alternate experience because most administrators are white and believe that we are on an equal playing field. I am implicated in this as an unaware white person conducting the study. In the pre-departure interview, Becky was basically telling me that she was worried about racism in France, but I did not give it the attention that her statement deserved because I do not have the experience or understanding to think of the import it might have held for her or to assuage her concerns. Once in France, while Becky had some positive experiences, she also did experience various types of micro relations of language use within macro relations of social context (Pennycook, 2001) and I added to it when I ignorantly asked Becky whether the relentless questioning by her host family and others in France had piqued her interest in knowing where in Africa her ancestors were from and she responded:

I could ask my grandma about our ancestry but I'm not too sure how much she knows because it was before, during slavery, so many people got separated, and so after that no one really knows anything, just, like, “oh we're in America, we're Americans.”

Social class. From a social standpoint, before leaving for her study abroad Becky had concerns about the proper way to dress but by the midterm she had to worry less than anticipated, although she could not wear bright colors or sweatpants. Becky seemed to have shifted more toward a capitalist mindset as a result of her study abroad. Upon her return she noted how much she missed French food, specifically pointing out wanting a baguette and a good Camembert.

I went to the store the other day cause I really was craving a baguette and some Camembert, and uh, I could not find it, I could not find it anywhere, and I was like, "Is it so much to ask for a baguette, is it too much to ask?" 
She remarked how happy she was to be back to American business hours because it was almost "impossible" in France with the business hours they held.

Um, I'm not missing um, I'm loving American hours, because in France everything is done at like dix-neuf heures, and that is impossible. The banks, like, don't get me started on the French banks. That is just ridiculous.

Becky loved to travel during her year abroad and this ignited the travel bug inside of her, saying that she wanted to travel to many more countries, using the verb "to do" a country.

Sasha hasn't done Paris yet and so she was going to do Paris with (her boyfriend). I really want to go to Japan. Um, I also want to, if, I feel like I haven't done Germany. I feel like I need to do Germany. Um, and some more European countries, maybe Sweden or someplace like that.

I cannot be certain because of my own whiteness, but I question whether the study abroad experience as a white endeavor of power, privilege, and entitlement might have nevertheless empowered Becky upon her return. It is possible that after an academic year abroad, Becky identified more with a pan-European mindset. She did not complain about many social expectations prior to her year abroad, but she did upon her return. I discussed mobility capital earlier in this chapter, what Murphy-Lejeune (2003) describes as the privilege of access to international travel and the several stages that participants pass through in order to feel that they acquire mobility capital (p. 5). One of these is a time of adaptation, then followed by construction of a shared history, especially with locals. I suggest that another kind of mobility capital can be acquired through negotiating membership in a COP of study abroad participants (non-locals) in which the access to and experience of international travel constructs a social capital sur place only to continue back home. 
Discourse/linguistic inequality. In terms of language, Becky's intention for when she was abroad was to not spend a lot of time speaking with Americans. She did point out that her family wanted to be in frequent contact with her while she was gone, which would be in English. She also imagined that there would be days when she would not be in the mood to speak in French. She hoped that if she remained immersed while there, her French would be "amazing" when she got back.

At the midterm, Becky described how much nicer people were with her in France compared to in the states. She said that when she spoke French in public settings, they would help her when she got a word wrong. On the other hand, at basketball practice, she realized that she did not have the vocabulary needed to play on a team and could not communicate as she would have wanted. When Becky first arrived, everything on the internet on her computer was in French, but Becky found a way around that and changed it back to English. There were times when Becky really just wanted to speak in English and she knew how easy it was to find an American to speak English with.

I have those moments, but I have a lot less of those moments and I found that because there's so many Americans here when you find them you find them...like, my roommate, is a, she's American, so, like, if I need to speak English, I would just, like, find an American and just speak to them in English.

Ultimately, Becky admitted that spending too much time with English speakers hindered her L2 learning. At the midterm interview when I asked her whether she made an effort to hang out more often with people who do not speak English, she hesitated and instead responded: 
Generally, I speak, I think I speak a lot more English than I do in French, but I've noticed that if you go out to the bars, everyone is trying to speak in French, so maybe I should start....

At the return interview, I noticed a shift toward more French use. Becky explained that her desire to speak in English changed from the first semester to the second because once her first semester friends left, she had fewer prefabricated social occasions to use it. Becky and Sasha also decided to speak in French when they spent time together.

It was a lot higher first semester than it was second semester. Um, and, what, and I think it was just the people who we were with maybe it was our mindset second semester, but, the people who we were with like Sasha came in and Sasha heard me speak in French and she's just, like, hey ready to, like, "just speak to me in French!," like, all the time. And so, like, people second semester, like, we were really trying, um, whereas first semester it was minimum effort to speak in French.

Becky explained that culture shock was one of the reasons why she defaulted to English so much more during the first semester than the second.

Honestly I think that the things that kept me from furthering my French came in the first semester because I think the first semester was more, like, we were all new, we were all figuring it out so we were all, like, speaking in English, and we were all like hitting those culture shocks and, like, fighting them, and, like, after Christmas break, it was just very, like, like you're comfortable, like, you know it, um, when you get trapped - and this is how I know - when you get trapped in Paris and you have to only speak in French to figure out what you're doing, like, that's when you know. 
With her first semester friends gone and her confidence increasing in French, Becky made friends with French people and went to bars that she liked more often during the second semester.

Yeah, you know second semester all the first semester kids were gone and so, um, you know so, like, I didn't feel that, like, need to like speak in English, everything we did, we were doing it in French. And, um, by second semester I had met a lot more French people and had found very good bars that we really liked, um, and so it was very, like, I don't know, it was very, like, like second semester was more comfortable.

Another thing that improved her L2 learning the second semester was the extensive work on a thesis paper that she wrote and the time spent with her professor as she revised it.

Meeting with people to get the references I needed, and then, um, I was working with my Langue professor and my Litt professor and, um, just being able to, like, because I wrote about a complex idea that's complex in English, so to even talk about it in French was hard to do, so I learnt so many new vocabulary, like, vocab words and um, like, be having to, like, read and sift through all that information.

Overall Becky described a decreased temptation to speak English during the second semester because she had much more inherent motivation.

Becky lacked confidence and motivation to speak in French during the first semester and kept from having to speak much in French by relying on English in several ways. First, it was the technological lingua franca for her through her computer and internet settings in English. She used her social and cultural power of being an English speaker to help her through times when she did not feel like speaking in French. She had a good group of friends her first semester who were mostly American with whom she felt justified and supported speaking in English. Once her 
group of friends left after the first semester, Becky reevaluated her language abilities and social actions, finding that she could go out more often to public places where French was spoken, and she could choose to spend time speaking French with non-French people as well. Becky also negotiated a heightened identity as French speaker through her research and work on her thesis.

\section{Sasha}

Nationality. Before leaving for her semester abroad, Sasha expressed a strong desire not to approach her sojourn with preconceived notions of how it would be or stereotypes of who the French are. She felt comfortable with the idea that Americans are different and she understood that where one is from shapes their identity and that is what one carries wherever one goes. However, Sasha was aware of the power exerted by Americans as travelers and intended to shift her expectations while abroad. She explained that American tourists impose their standards when travelling and she planned to be careful to not do this. Admitting that stereotypes exist, Sasha did not want to fulfill the expectation that French people have of Americans being dumb. She did not want to either prejudge or be prejudged. Once she had been in France for several months she remarked that the stereotype of loud, English-speaking Americans is true. In turn, she tried to speak more quietly and continued to try not to push her cultural expectations on her experience (and other people) in France. She did notice, however, that French people adhere to the stereotype of being more emotional than Americans. According to Sasha, Americans are less willing to feel strong emotions than the French which I took to mean that the French are more apt to approach and discuss topics that might evoke strong emotion. A few months after her return from France, Sasha, who had all along not wanted to perpetuate negative stereotypes of Americans abroad by suppressing her American expectations and actions, had a shift in awareness toward increased pride in being American. Not only did she no longer want to label 
herself half-Irish, half-German because she instead considered herself 100 percent American. She was proud of where she grew up and how it made her who she was and realized that she had never before appreciated being American as she did upon her return.

Kinginger (2009) describes how SA participants know that "any allegiance to their new communities can be temporary. They may, if they so desire, opt to close down the process of language socialization in favor of renewed affiliation with their home societies" (p. 183). Sasha appears to have over-compensated and over-suppressed her national identity before and during her trip, so much so that it was a relief to her to re-inhabit her previously determined identity. While on the one hand, Sasha was very concerned with not perpetuating the stereotypical image of Americans abroad and she worked very hard to subvert that, it was as if coming home to the U.S. was also a return to her actual self.

Gender/sexuality. Prior to her semester abroad, Sasha spoke about others encouraging her to meet a French guy and fall in love. She commented that a number of women told her stories about female students who studied abroad and came back married to a French man. Sasha was not interested in purposely pursuing this and did not want her study abroad to be framed by having a romance with a French man. By the midterm interview, Sasha had met a French guy but she did not tell me much about the relationship other than he was about to leave out of the country for an internship and that she really liked him. In the return interview, she described her boyfriend as "not typically French" because he was so open-minded. I asked her what made him so open-minded and Sasha remarked that, for example, French people in general are less conscious about LGBT issues than Americans, something that she had learned through conversations with her host sister about different personal pronouns, but he was. Unfortunately, 
being with her French boyfriend made Sasha too self-conscious to speak French because it showed a vulnerable side of herself that she was not ready to share.

Another issue related to her gender abroad was when Sasha and her friend were verbally harassed by a man in Paris. This man followed them from one place to another making comments and became angry in response to their rebukes of him. Sasha said that it was not the only experience like this, and she said that when it happened it was "mostly African men" and remarked that, "most French guys, they leave you alone if you want to be left alone."

Whereas Sasha resisted the idea of meeting and marrying a French man in her predeparture interview, she wondered out loud in the return interview about whether she might marry the man that she met in France, saying that she was attracted to foreign men because of their different points of view.

Sasha also had an experience on one of her vacations from school in which she and another female student were harassed by a male in Paris. While this experience was upsetting, it did not appear to influence future actions, L2 learning. She seemed to feel generally safe. Sasha felt that the French were not as evolved about LGBTQ issues. She pointed out that her host sister could not understand why a person might not want to use the gendered pronoun she or he.

I do not see much of a shift in Sasha's mindset with regard to gender or sexuality. I do think that some of the things that she brings up affected her perception of the French and her experience in France such as their ability to be open-minded, and how she needed to remain aware of unwanted advances by men as she travelled. These experiences appear to have reiterated Sasha's perception of herself as socially conscious and they may have created a negative bias against African men. 
Sasha was relatively secure with notions of sexuality and being female as a SA participant. However, she did have a romance with a French male that introduced her to a community of practice in which she was with a French person with whom she did not speak in French. Sasha's romance with a French man was a greater influence on her lack of L2 learning than her notions of power related to her gender, however.

Race/ethnicity. As neither did all white participants in this study, Sasha did not discuss race or ethnicity in terms of her own whiteness. She also did not note issues of inequity or raced experienced at the pre-departure interview but at the midterm, she recognized and described incidences of what she considered racism. One was by a French instructor in the CIDEF program. She told me that while she liked most of her classes, she did not like her grammar class because of the instructor who mocked the Asian students' pronunciation and culturally evident examples that they gave as they spoke. Another incident was when Sasha was harassed by an African man while in Paris on her way to Amsterdam. While this is categorized under notions of gender/sexuality, it should be mentioned under this theme as well: “And, like, I don't want to generalize, but it was mostly African men who would do it. Like, mostly the French guys, they leave you alone if you want to be left alone."

In the return interview Sasha had several observations with regard to race and ethnicity. In discussing that France has a more autonomous culture, and while there are other ethnicities living there, the French culture remains strong and seems much more singular than the massive mix of cultures in the United States. As an example, Sasha addressed the topic of immigration. I think that's why they have such an issue with all this immigration, is because they've just been French for so long and now that they have more immigration they're having a 
big issue with it, because they're kinda closed-minded about those things. And, like, honestly, they don't like those cultures coming in.

In reference to the midterm interview, Sasha again returned to the topic of her grammar instructor's racist remarks against Asians and described one incident in detail:

There was one student, um, her name was Teo-way, and she, her sentence was, like, really well-structured because we had to do this one thing where we had to put different parts of a sentence together and make up another thing. And, her sentence was something about, like, contracts, like, it was super-well-thought-out, and she's [the instructor], like: "Oh you would say that because you're Chinese!" Yeah, because Chinese are all about business! [said in sarcastic tone], and we were just, like, "Okay!" I mean that, "China is really good with business, but that's not their culture!' You know?

Sasha was one to point out unjust treatment of others and had a very strong reaction to this raced experience in her classroom. However while Sasha said that the French were closedminded in terms of race and migration she indicated that the United States were more evolved. While that may in part be true, based on her character, Sasha could have scrutinized racial issues in the United States more, and I wonder whether her growing appreciation of being American shaded her ability to fully scrutinize her home country's racial inequity.

Social class. Prior to her semester abroad, Sasha discussed looking forward to different architecture and being able travel, especially since she was first exposed to travel at age 18 and really anticipated taking advantage of her time abroad to do this.

Once she was abroad, Sasha described the French service industry as paying less attention to customers than in the U.S. She did not completely blame them, however, as she also wondered 
whether her lacking linguistic and cultural skills had caused decreased attention from servers at restaurants.

Upon her return Sasha noted several issues. First, she felt that the program in France lacked academic rigor. She explained that it had been the easiest semester that she had ever had and entered into a discussion with me about programs catering to Americans. She also did not appreciate that a student could not earn a perfect score in France, because that is culturally not acceptable or possible.

I did not recognize much of shift overall in the category of social class for Sasha. She was able to highlight how being American may have affected the academic rigor of the program. This could be a good learning moment for students to discuss why this might be and what power might have to do with it.

Discourse/linguistic inequality. At the midterm interview Sasha spoke in detail about the significance that speaking French with her host sister had on building a friendship. She explained that while it took some time to establish (because of her decreased language abilities) once they did, her confidence increased. On the other hand, Sasha described having anxiety speaking in public because of her American accent. For example, when she was on the tram and needed to pass by people to exit at her stop, she would be embarrassed to say, "Pardon," because they would realize that she was foreign. However, others told her that her accent was fine, so it was more her own perception than others'.

Sasha recognized that being on a different linguistic level than others made it difficult to fit in. She admitted that other than her host sister, most of her friends were American and they spoke a lot of English. Sasha did not want to be friends with Americans because she knew that 
they would primarily speak in English. For this reason, she tried to make friends with a variety of people so that she would not always revert to English.

At the midterm, Sasha divulged that she had recently started dating a French guy, but while they spoke French at the very beginning, once she found out how good he was at speaking English, she stopped speaking French because she did not like to show a vulnerable side of herself.

At the return interview, Sasha discussed the importance of L2 learning on her relationship with her host sister. Sasha knew that in order to make friends with her, she would have to make her know her true personality, and the use of the L2 was critical to that. Sasha liked telling jokes but found that difficult, so she used more body language and told simpler jokes. Her investment in this helped the friendship blossom, which in turn gave Sasha more confidence. Sasha admitted that American friends and Netflix hindered her L2 learning. She said that it was so much faster to speak English with other English speakers even when her intention was to speak French. Furthermore, when she was feeling down, her motivation to speak French was also low.

Overall, Sasha said that the greatest influence on her L2 learning were her host mom, host sister and her French boyfriend because she spoke the most with them. She reported that the better her relationships with them got, the more L2 she learned. Sasha invested quite heavily in her French CoPs and felt that this investment produced significant returns in both friendship and L2 learning. Of particular note, Sasha points out that she would be able to make friends better with her host sister once she was able to joke in the L2 because telling jokes would reveal attractive parts of who she was. Sasha recognized that her American CoPs would not provide the L2 gains that she would like, but she also admitted that they gave her comfort from those situations in which she had low linguistic self-esteem. 


\section{Charlotte}

Nationality. Before her year abroad, Charlotte described her identity as intertwined with her American nationality. She was proud of being American and of the United States' international presence, recognizing that other countries do not agree with this. Despite this assertion of pride, Charlotte did admit that Americans are self-absorbed, egocentric, and loud. She also saw Americans as defined by symbolic acts such as traditional barbecues and Sunday lunches with family on the deck. Once Charlotte had spent a few months in France, she showed a shift in her ways of thinking. She noted that pride in one's country was no longer necessarily a positive attribute. Charlotte learned that many other countries are not proud of the United States. This caused Charlotte to struggle to come to terms with inconsistencies that she began to notice about the U.S., especially as she learned that there are many other ways of managing situations of conflict than the way that the U.S. does. Charlotte became aware that most other countries in the world provide affordable healthcare to their citizens. She also realized, based on the French response to a terrorist attack in France during her time there that a country does not have to react in fear and lash out in violent counter-attacks. In terms of adjustment to life in France, by the second semester Charlotte felt that Angers was home and she had ownership of living there. Upon her return back the United States, Charlotte had a significant shift in her mindset about American nationality. This occurred in large part because of her realization that she is a citizen of the world, and not necessarily just of the United States. The shift from pride in being American was accompanied by some personal realizations of shame. Charlotte's linked her growing cognizance of her previous identity as the "blond-haired, blue-eyed Midwestern girl who dated the football player" to an imagined community that should instead focus on all of humanity as opposed to exclusively Americans. While Charlotte still admitted to identifying as 
American, she questioned how absolutely one must have pride in and allegiance to an idea that has decisive inconsistencies and flaws. Charlotte most certainly no longer felt connected to the idea of the America that she grew up with because of her revelation that Americans are terribly entitled. She learned this from being in France and noticing that the French are very entitled, too. Post-year abroad, she realized that so many people in the world do not have the privileges that Americans do and felt ashamed and wanted to do something about it.

Charlotte's initial beliefs in being American might be considered what Dolby (2004) calls "infantile citizenship" (p. 168), or a form of citizenship that blindly embraces the policies of the state, as a way of identifying with the nation. Charlotte also identified with certain events and foods as symbolic of being American such as barbecues, Sunday lunch with your family, and eating out on the deck. American traditions help reiterate nationalist identity. Hobsbawm (1983) speaks to how the repetition of tradition enhances symbolic meaning, especially when that tradition is "no longer fettered by practical use" (p. 2). He also points out that we use "existing customary practices... [that may be] modified, ritualized, and institutionalized for the new national purposes" such as hymns or other songs, and flag waving or displays that create a "powerful ritual complex" (p. 7) to enhance national identity. The fact that Charlotte herself connects such rituals specifically with being American heightens their powerful meaning.

Charlotte's shift in national identity demonstrates how interconnected nationality can be with one's personal identity. It also explains how geographic displacement and interaction with new people from new places can cause one to question and transform one's understanding and acceptance of norms. Charlotte went from a proud American to a less-proud American, to a selfproclaimed citizen of the world who felt a more profound connection to humanity, not just to people in her own country. While all of these realizations are laudable, as is Charlotte's desire to 
help effect change, the conflation of whiteness with her nationality never came up, and as Wildman and Davis (2002) argue, "Depending on the number of privileges someone has, she or he may experience the power of choosing the types of struggles in which to engage....making the privilege that enables the choice invisible" (p. 94).

Gender/sexuality. Before leaving for France, Charlotte had nothing to say about her gender or sexuality. By the midterm interview, several experiences came up about it. When she first arrived, Charlotte noticed that she was often stared at, something she attributed to French men, and worried that she might be "assaulted," but later realized that all French people did it regardless of gender. Another instance was at the beginning of her year abroad when she had a short romantic relationship with her host brother that she broke off rather quickly. After this, Charlotte spent the majority of her time with female students (mostly Americans) throughout her year. Upon her return from her year abroad, Charlotte had a shift in awareness of herself as a female. She questioned the importance of being pretty and why her parents had instilled that idea in her. She wondered why only girls are supposed to be pretty and not guys. She concluded that she did not owe it to anyone to be pretty. She questioned her previous identity as the pretty, blond, Midwesterner with the football player boyfriend.

Charlotte's idea of what it was to be a woman and the social norms connected to it shifted during her study abroad. She realized that much of what was expected of her as a woman was not her own idea, but expectations placed upon her by her family, her religion, her school, and her friends. Charlotte likely had a past in which she was given positive attention because of her gender and her looks, something that she likely experienced in France as well.

Race/ethnicity. Charlotte did not bring up issues of her own whiteness. She also did not discuss race or ethnicity at the pre-departure or midterm interviews. Between the time of the 
midterm and return interviews Charlotte had some experiences that affected her mindset about race or ethnicity. First, she visited a concentration camp in Germany at which she encountered painful realization that she "had never been asked to feel before." She described the response to this emotion as "irrational" because it was a pain, anger, and confusion that she did not know what to do with, even though she understood that it was something that "everyone should be asked to feel." Since she was back from her year abroad, I asked whether having this experience made her reflect on current issues back in her own country such as Black Lives Matter or immigration issues. First, she admitted not having ever really thought about them before, "I just didn't think or care about them at all, which feels dirty coming out of my mouth," but that her consciousness had definitely risen having lived in France. She compared issues of race in America with conflict with Muslims in France. She questioned why issues of race, having gone on for hundreds of years in the U.S. had still not been resolved.

Prior to study abroad, while Charlotte's way of thinking was informed by whiteness, she was ignorant to it. Her experience at the concentration camp as well as her growing awareness of the influx of immigrants to Europe during her year abroad may have been the first time she had encountered real human consequences to raced experiences, something to which she admitted. As a white SA participant, Charlotte had the privilege of ignoring her whiteness, because within our educational structures, study abroad is invisibly white. However, coming into contact with tragedies from the past and the present that affect others who are not her color, ethnicity, or religion opened her eyes for the first time. The pedagogical implications of this awareness should not be ignored. 
Social class. In anticipation of her year abroad, Charlotte looked forward to travel and "touristy things." She also looked forward to spending time with other study abroad participants and international students, as well as meet French students.

At the midterm interview, Charlotte described the French service industry as having bad customer service. Charlotte spent a lot of time discussing her friendships and the important place they held in her life. Charlotte did not like the French and therefore spent most of her time with Americans. She mentioned having met one French girl but found her "annoying." She found it much easier with Americans because of the importance of their mutual cultural connection. Charlotte claimed that she would not be able to remain in France without her American friends. Overall, Charlotte loved living there, especially loved the idea of being there. She reiterated that the French are not friendly at all, however one exception was when a middle-aged train station worker extensively helped her organize her vacation when she had been having problems doing it herself.

Upon her return, there was a noticeable shift in Charlotte's talking points. She focused much more on increased awareness of others' struggles, entitlement, and global consciousness. As a result of her travels, Charlotte felt that she was more of a citizen of the world than of one particular country, and she felt that she belonged wherever she travelled, even though she did not necessarily want to live in many of those places. These travels raised Charlotte's awareness about how things that she used to think that she deserved are things that other people would never be able to have. Her travels also helped her gain an understanding of how insignificant her life is in the scheme of things, despite how her parents raised her to believe the contrary.

When she returned back to the U.S. and met with friends and family, she noticed, with dismay, a disconnect between what had become important to her and the unchanging, 
insignificant matters of those back home. As a result, Charlotte expressed the desire that everyone have an experience like hers to ignite the realizations that she had. On top of international understanding, Charlotte had realizations about her religious upbringing that she attributed to times of extended reflection when she was unable to rely on others to answer for her. She referred to this as times where she fully relied on herself, developed her own thoughts, and learned what she believed and trusted.

On the one hand, Charlotte's privilege as a white person was very apparent because of her access to new countries and new experiences; that is to say, Charlotte had no issues crossing borders, she even had an argument with a German police officer and was not afraid of being arrested. Furthermore, Charlotte did not hesitate to feel that she belonged everywhere she went, something that not everyone (race, ethnicity, social class, nationality) is fortunate to experience. On the other hand, Charlotte realized to whatever extent the insignificance of many issues in her life to which she had previously given such great importance, which again, is something that could hold extensive pedagogical meaning.

Discourse/linguistic inequality. In her pre-departure interview, Charlotte showed an understanding that hanging out with English speakers while in France would be detrimental to her L2 learning. At the midterm interview Charlotte told me that the easiest places to speak in French were at the pharmacy, supermarket, and post office. she would only speak in French depending on the level of comfort that she had with the other person and especially who they were, for example, she was not comfortable speaking with her host parents. Charlotte explained that spending time with Americans eliminated the necessity of her improving her French and she did not feel otherwise motivated to speak in French. In the return interview Charlotte admitted generally not being motivated to seek out people who spoke French while she was there. She 
described herself as not at the level where she had confidence to do it, although she said that if she were to return to France now, she would have the confidence needed to speak French. Friendships with Americans provided routine and comfort that Charlotte did not want to disrupt only for the purpose of speaking French. Furthermore, L2 learning was not Charlotte's number one priority. It was instead figuring out herself and seeing the world. She was however glad that she spent one year instead of one semester abroad because it gave her more time to learn French. Charlotte described her accent as American "even after one year abroad" and she seemed a little bit ashamed about that.

Charlotte paid little attention to French learning because she found comfort in the American friendships that she had. Furthermore, learning French became secondary, or perhaps tertiary to the other learning experiences that she had about herself and her place within the world. In doing so, however, Charlotte perpetuated English as the hegemonic language both back home and abroad.

The following tables show the principal themes described above across participants at each interview. They help provide a clearer understanding of patterns and important issues (or lack of importance). 
Table 4

Key Themes-Pre-Departure

\begin{tabular}{|c|c|c|c|c|c|}
\hline Themes & Magda & Lesley & Becky & Sasha & Charlotte \\
\hline Nationality & $\begin{array}{l}\text { Friendly, } \\
\text { privileged; } \\
\text { fear of } \\
\text { being } \\
\text { othered }\end{array}$ & $\begin{array}{l}\text { Many } \\
\text { different } \\
\text { cultures; } \\
\text { Fear of } \\
\text { staring }\end{array}$ & $\begin{array}{l}\text { American } \\
\text { Dream }\end{array}$ & $\begin{array}{l}\text { Many } \\
\text { stereotypes } \\
\text { that may or } \\
\text { may not be } \\
\text { true }\end{array}$ & $\begin{array}{l}\text { Love my } \\
\text { country }\end{array}$ \\
\hline Social Class & Travel & Travel & Travel & Travel & Travel \\
\hline Gender/Sexuality & $\begin{array}{l}\text { American } \\
\mathrm{BF}\end{array}$ & French BF & $\begin{array}{l}\text { Did not } \\
\text { name }\end{array}$ & & \\
\hline Race/Ethnicity & $\begin{array}{l}\text { Did not } \\
\text { name }\end{array}$ & $\begin{array}{l}\text { Did not } \\
\text { name }\end{array}$ & $\begin{array}{l}\text { Concerned } \\
\text { with } \\
\text { perception } \\
\text { of herself } \\
\text { as a POC in } \\
\text { France. }\end{array}$ & $\begin{array}{l}\text { Did not } \\
\text { name }\end{array}$ & $\begin{array}{l}\text { Did not } \\
\text { name }\end{array}$ \\
\hline $\begin{array}{l}\text { Discourse/Language } \\
\text { inequality }\end{array}$ & $\begin{array}{l}\text { Concerned } \\
\text { with being } \\
\text { understood } \\
\text { or not } \\
\text { understand- } \\
\text { ing what is } \\
\text { being said }\end{array}$ & $\begin{array}{l}\text { Intends to } \\
\text { work in } \\
\text { class and } \\
\text { join local } \\
\text { groups for } \\
\text { French }\end{array}$ & $\begin{array}{l}\text { Intends to } \\
\text { speak in } \\
\text { French as } \\
\text { much as } \\
\text { possible }\end{array}$ & $\begin{array}{l}\text { Intends to } \\
\text { speak in } \\
\text { French as } \\
\text { much as } \\
\text { possible }\end{array}$ & $\begin{array}{l}\text { Worried } \\
\text { she will not } \\
\text { speak in } \\
\text { French as } \\
\text { much as } \\
\text { she should }\end{array}$ \\
\hline
\end{tabular}


Table 5

Key Themes-Midterm

\begin{tabular}{|c|c|c|c|c|c|}
\hline Themes & Magda & Lesley & Becky & Sasha & Charlotte \\
\hline Nationality & $\begin{array}{l}\text { Americans } \\
\text { default to } \\
\text { English, } \\
\text { gesticulate } \\
\text { wildly and } \\
\text { are loud }\end{array}$ & $\begin{array}{l}\text { Dislikes } \\
\text { questions } \\
\text { about U.S. } \\
\text { history or } \\
\text { politics; } \\
\text { Staring }\end{array}$ & $\begin{array}{l}\text { Affiliated } \\
\text { with being } \\
\text { American }\end{array}$ & $\begin{array}{l}\text { Americans } \\
\text { are loud }\end{array}$ & $\begin{array}{l}\text { Learning } \\
\text { that other } \\
\text { countries do } \\
\text { not see the } \\
\text { U.S. as } \\
\text { Americans } \\
\text { do }\end{array}$ \\
\hline Social Class & Travel & $\begin{array}{l}\text { Travel as } \\
\text { consumption }\end{array}$ & $\begin{array}{l}\text { Travel as } \\
\text { consumer }\end{array}$ & $\begin{array}{l}\text { Travel as } \\
\text { consumer }\end{array}$ & $\begin{array}{l}\text { Travel as } \\
\text { consumer }\end{array}$ \\
\hline Gender/Sexuality & $\begin{array}{l}\text { American } \\
\text { BF; } \\
\text { Some } \\
\text { unsolicited } \\
\text { flirting in } \\
\text { France; } \\
\text { One instance } \\
\text { of } \\
\text { harassment }\end{array}$ & French BF & $\begin{array}{l}\text { Did not } \\
\text { name }\end{array}$ & $\begin{array}{l}\text { French BF; } \\
\text { One } \\
\text { instance of } \\
\text { harassment }\end{array}$ & $\begin{array}{l}\text { Host brother } \\
\text { BF for a few } \\
\text { weeks; } \\
\text { Concerned } \\
\text { that people } \\
\text { stare b/c of } \\
\text { her gender }\end{array}$ \\
\hline Race/Ethnicity & $\begin{array}{l}\text { Refers to } \\
\text { East Asians } \\
\text { as } \\
\text { international } \\
\text { students; } \\
\text { One instance } \\
\text { of } \\
\text { harassment } \\
\text { by African } \\
\text { male }\end{array}$ & Did not name & $\begin{array}{l}\text { Concerns } \\
\text { validated } \\
\text { regarding } \\
\text { others' } \\
\text { perception } \\
\text { of her as a } \\
\text { POC in } \\
\text { France }\end{array}$ & $\begin{array}{l}\text { One } \\
\text { instance of } \\
\text { harassment } \\
\text { by African } \\
\text { male }\end{array}$ & $\begin{array}{l}\text { Did not } \\
\text { name }\end{array}$ \\
\hline $\begin{array}{l}\text { Discourse/ } \\
\text { Language } \\
\text { Inequality }\end{array}$ & $\begin{array}{l}\text { Americans } \\
\text { default to } \\
\text { English; } \\
\text { Spends time } \\
\text { with people } \\
\text { who speak } \\
\text { French; } \\
\text { Outings and } \\
\text { errands as } \\
\text { well as meals } \\
\text { with host } \\
\text { family in } \\
\text { French }\end{array}$ & $\begin{array}{l}\text { Speaks } \\
\text { mostly in } \\
\text { English } \\
\text { outside of } \\
\text { classes; } \\
\text { Has mostly } \\
\text { American } \\
\text { friends; } \\
\text { Some meals } \\
\text { with host } \\
\text { mom in } \\
\text { French }\end{array}$ & $\begin{array}{l}\text { Speaks } \\
\text { mostly in } \\
\text { English } \\
\text { because } \\
\text { spends most } \\
\text { time with } \\
\text { Americans; } \\
\text { Does enjoy } \\
\text { dinners with } \\
\text { host family }\end{array}$ & $\begin{array}{l}\text { Friends } \\
\text { with host } \\
\text { sister and } \\
\text { mom with } \\
\text { whom she } \\
\text { speaks } \\
\text { French; } \\
\text { Speaks in } \\
\text { French } \\
\text { with some } \\
\text { Americans, } \\
\text { otherwise, } \\
\text { English }\end{array}$ & $\begin{array}{l}\text { Speaks } \\
\text { mostly in } \\
\text { English } \\
\text { outside of } \\
\text { classes; Has } \\
\text { mostly } \\
\text { American } \\
\text { friends }\end{array}$ \\
\hline
\end{tabular}


Table 6

Key Themes-Return

\begin{tabular}{|c|c|c|c|c|c|}
\hline Themes & Magda & Lesley & Becky & Sasha & Charlotte \\
\hline Nationality & $\begin{array}{l}\text { Still } \\
\text { critical of } \\
\text { Americans } \\
\text { abroad; } \\
\text { OK being } \\
\text { American }\end{array}$ & $\begin{array}{l}\text { Still } \\
\text { defensive } \\
\text { about being } \\
\text { American }\end{array}$ & $\begin{array}{l}\text { Being } \\
\text { American is } \\
\text { defined by the } \\
\text { individual }\end{array}$ & $\begin{array}{l}\text { Newfound } \\
\text { appreciation } \\
\text { for being } \\
\text { American }\end{array}$ & $\begin{array}{l}\text { Still loves } \\
\text { being } \\
\text { American } \\
\text { but eyes are } \\
\text { opened to } \\
\text { problems }\end{array}$ \\
\hline Social Class & $\begin{array}{l}\text { Expected } \\
\text { increased } \\
\text { support at } \\
\text { CIDEF }\end{array}$ & $\begin{array}{l}\text { Travel; } \\
\text { Consumer } \\
\text { expectation }\end{array}$ & Travel & $\begin{array}{l}\text { Did not } \\
\text { name }\end{array}$ & $\begin{array}{l}\text { Travel; } \\
\text { Consumer } \\
\text { expectation }\end{array}$ \\
\hline Gender/Sexuality & $\begin{array}{l}\text { Did not } \\
\text { name }\end{array}$ & $\begin{array}{l}\text { Did not } \\
\text { name; Still } \\
\text { with French } \\
\text { BF }\end{array}$ & $\begin{array}{l}\text { Feels it is } \\
\text { more difficult } \\
\text { to get ahead } \\
\text { in the U.S. b/c } \\
\text { of her gender } \\
\text { and race; }\end{array}$ & $\begin{array}{l}\text { French BF } \\
\text { with whom } \\
\text { she speaks } \\
\text { English }\end{array}$ & $\begin{array}{l}\text { Did not } \\
\text { name }\end{array}$ \\
\hline Race/Ethnicity & $\begin{array}{l}\text { Did not } \\
\text { name }\end{array}$ & $\begin{array}{l}\text { Did not } \\
\text { name }\end{array}$ & $\begin{array}{l}\text { Felt less } \\
\text { discrimination } \\
\text { in France than } \\
\text { in the U.S. }\end{array}$ & $\begin{array}{l}\text { Says France } \\
\text { has issues } \\
\text { with racism }\end{array}$ & $\begin{array}{l}\text { Aware of } \\
\text { immigration } \\
\text { issues and } \\
\text { some BLM }\end{array}$ \\
\hline $\begin{array}{l}\text { Discourse/Language } \\
\text { Inequality }\end{array}$ & $\begin{array}{l}\text { Made } \\
\text { friends } \\
\text { with } \\
\text { French } \\
\text { woman } \\
\text { who } \\
\text { teaches } \\
\text { English }\end{array}$ & $\begin{array}{l}\text { Speaks } \\
\text { mostly in } \\
\text { English } \\
\text { outside of } \\
\text { classes; } \\
\text { Has mostly } \\
\text { American } \\
\text { friends }\end{array}$ & $\begin{array}{l}\text { Invested } \\
\text { much more } \\
\text { time in } \\
\text { speaking } \\
\text { French }\end{array}$ & $\begin{array}{l}\text { Very good } \\
\text { friends and } \\
\text { speaks } \\
\text { French with } \\
\text { host sister } \\
\text { and host } \\
\text { mom; } \\
\text { Speaks } \\
\text { English } \\
\text { w/French } \\
\text { BF }\end{array}$ & $\begin{array}{l}\text { Speaks } \\
\text { mostly in } \\
\text { English } \\
\text { outside of } \\
\text { classes; Has } \\
\text { mostly } \\
\text { American } \\
\text { friends }\end{array}$ \\
\hline
\end{tabular}




\section{Trajectories of Nationality}

Students used nationality as a crutch to find community, to legitimize their expectations placed on French cultural practices, and especially to support their continued use of English despite the explicit purpose of this sojourn being to increase one's L2 abilities. As Block (2009) discusses, nationality is a theme with which American SA participants struggle and this study was no exception. Not every participant had the same trajectory of awareness from the start to the finish of their SA sojourn. Some participants for whom I would have expected constructs of nationality more readily to dissolve by the end of their sojourn surprised me with a heightened attachment to it, while one participant changed to the contrary. There are three main trajectories of my participants, which I detail below.

Low to high trajectory (Lesley and Sasha). The first trajectory of participants (low to high) is one in which students had a relatively unimportant relationship with their national identity at the start of their sojourn, but grew to relate much more ardently with it at the end. I recognize Lesley and Sasha as fitting in this category because at the pre-departure interview Lesley had not given much forethought to being American and Sasha would provide only stereotypical ideas about Americans on the condition that I understood that she was approaching her time abroad without prejudgment. Lesley was also worried that people would stare at her, effectively concerned with being "othered." When asked to define being American they generally referred to commonly used symbolic discourse such as Americans being "bible thumpers with guns" or "rednecks" or Americans have a lot of "pride" and are made up of people from many different cultures. Hobsbawm (1983) explains that repetition of tradition enhances symbolic meaning and reiterates national identity. By midterm, like Beatrice in Kinginger (2008) whose opposition to French criticism of the United States political stances 
resulted in opposition to local connections and L2 learning, Lesley had become particularly resistant after experiencing conversations with French people in which they had inserted their own constructs of what it was to be American (knowing a lot about our history, our politics, our international presence). Lesley, lacking knowledge in those areas, responded with anger and defensiveness. Participants in Dolby's (2004) study also experience difficulty negotiating negative perceptions of Americans especially because, as one participant described, "I'm guilty of not knowing the things that they said that Americans don't know" (p. 166). Sasha continued on the course of withholding judgment, although she did point out that American students and travelers were loud and try to push their culture on their surroundings. By the end of their sojourns, both Lesley and Sasha had a heightened sense of being American but for different reasons. Lesley was annoyed by French people questioning how she identified as an American, tired of being asked to justify or know something about America's international presence, and angry that she be expected to represent an entire nation or a state. This was likely because she honestly was not knowledgeable in the areas requested and did not want to put in the effort to reflect more deeply about it. In turn she decided to default to her underlying power as an American in an effort to arm herself against these expectations by ultimately saying, "I'm American - accept it!" Based on studies such as Beatrice (Kinginger, 2008), Lesley was not out of the ordinary in her reaction, nor is Sasha. Sasha had invested so much energy into being fair and withholding judgment throughout her sojourn that I think it ultimately backfired on her. While she was very cognizant of treading lightly as an American in France to not force the expectations of her national identity on others, when she returned home, she experienced a personal shift in which she felt intensified pride in saying that she was from the United States. It appears that her reticence to be fully American while in France may have resulted in stronger 
feelings once she was back home, giving her a newfound appreciation of her American identity. One aspect of the "colonial student" is the retention of their loyalty to their home culture during a temporary sojourn abroad (Ogden, 2008). Lesley and Sasha seem to follow that thinking to various degrees.

Low to mid trajectory (Becky and Magda). The second trajectory of participants (low to mid) is one in which students had a relatively ambiguous connection to their national identity at the pre-departure interview that grew more critical during the sojourn, and remained about the same upon their return. I recognize Becky and Magda within this particular category. At the predeparture interview, both Becky and Magda like Lesley and Sasha defined being American in discursively symbolic terms. Just as McNamee and Miller (2013) describe the American dream as one in which citizens are "free to achieve on their own merits" (p. 8), Becky defined it as connected to freedom and opportunity and the idea that everyone has an equal chance for success. Magda recognized Americans as corndog-eating English speakers who are open and friendly, but who live a life of convenience, are entitled, and take up a lot of space.

By midterm, Becky and Magda both recognize characteristics of what Ogden (2008) calls the colonial student, especially carrying a sense of entitlement and a desire for comfort. Becky, like Magda at the pre-departure interview also recognized that being American made her feel entitled to some things. She shifted away from her original definition of Americans, in fact, she explained that she had begun to see being American as related to affiliation or if one's papers say so. At the midterm, Magda reiterated what she referred to at the pre-departure interview about entitlement, convenience, and English speaking. An additional point of note was Magda's suspicion that history classes taught in the United States were taught through a biased lens, as 
Zinn (2005) describes. Magda explains that the lens used to teach her history class in France was very different and resulted in her questioning the intentions of the American education system.

Upon her return, Becky described Americans as entitled and loud, but pointed out that every American is different and gets something different out of their nationality, and so each person should define their nationality for him or herself. Most importantly, Becky saw being American as more of a label than who she actually is and would not let socially constructed ideas of American nationality define who she is. She was fine with being American, but on her own terms. Becky was not unapologetic like Lesley. As for Magda, upon her return it was clear that her perception of national identity was influenced by how she could be most successful in her L2 learning while abroad. She recognized Americans as loud, not invested in speaking English, and also as people who learn history with an American "spin" on it. Overall, however, Magda had neither a heightened nor a diminished sense of national identity. She was able to critically assess other Americans around her in order to navigate to her linguistic goal, but returned to the U.S. with no ardent feeling about her own personal affiliation with national identity. She did not return with a newfound connection to being American like Sasha.

High to low trajectory (Charlotte). The final trajectory (high to low) is based off of one participant, Charlotte, who started off her year abroad with a particularly high regard for being American. In discussing being American at the pre-departure interview, Charlotte revealed that she loved her country, she identified with it, and she had pride in it and its international presence and force. She did recognize that others find us egocentric, self-absorbed and loud, and saw some truth in that. By midterm, while Charlotte claimed that she still loved the United States, she had had an epiphany upon discovering that Europeans do not appreciate American pride. She also learned that other countries treat their citizens and other countries differently than the United 
States does (i.e., in response to terror attacks, or with regard to universal healthcare) but have positive results and do not need to resort to fear mongering or greed. Upon her return, Charlotte has relatively profound revelations about her previous suppositions. While admitting that she was still American and still proud of and loved her country, she described feeling much more than American, because in her mind, she had become a citizen of the world and American values no longer defined her. She was ashamed to have ever wanted a "Made in America" tattoo on her foot and did not want to be connected to American entitlement. While Charlotte did not completely give up the discourse used to define being American (love of one's country and pride) she expressed shame over her previous suppositions and who that meant that she was when she was unaware of the existence of other perceptions and ways of doing things. Charlotte's view of social hegemony shifted during her year abroad as she became enlightened about some of the socially constructed influences on mainstream culture and beliefs. While this seemed to have had an effect on her language socialization in such ways as, "local concepts of paths to knowledge," it did not influence her desire to become a "fuller member of the new L2 mediated world[s] (Duff, 2007, p. 310).

SA participants' identity affects their experience depending upon the extent to which participants "engage...in negotiation of difference or cement their initial stances" (Kinginger, 2009 , p. 203). These three different trajectories show the variation in student's understanding and negotiation of what it means to be American. Furthermore, they show a lack of participant preparation about the meaning of their nationality on a deeper level than daily symbolic discourse. A sojourn abroad can reveal conflicting feelings about previously accepted understanding of nationality as well as anxiety over newfound revelations. 


\section{Trajectories of Gender/Sexuality}

While all of my participants are female, not everyone divulged that issues of gender or sexuality affected their SA experience. However, four main stories came to the surface of what participants did bring up. The following sections delineate those trajectories.

Harassment stories that are raced. Of the five female participants, two told stories of harassment that were also raced. Both Sasha and Magda had experiences of being approached out in public by someone who refused to leave them alone. In Sasha's case, she was in Paris traveling with a friend, and a man approached them and began repeating that she was so sexy and, in an attempt to expand the conversation asked whether she played sports and whether she spoke English. When Sasha got up and walked away he followed after her and continued to pursue her, eventually getting angry at Sasha's friend when she told him to leave her alone. The man was so enraged that the staff at Starbucks physically kicked him out of the store. After telling her story, Sasha said that although she did not like to generalize, the man is African.

Magda also had a related, albeit less forceful, experience with an African. One day in the check-out line at the supermarket he struck up a conversation with her. Despite her response that she was not interested in meeting up with him, he persisted, ultimately getting her to call his phone so that he could have her number. Magda did not respond to his texts or phone calls and he became upset with her, even though she was very clear with him that she had a boyfriend. This left Magda very uncomfortable and a little worried, and ultimately told him with more force that she really was not interested.

These types of interactions can shake up one's confidence and understanding of one's safety, ultimately affecting their language socialization. I do not think that it hindered Sasha or Magda's further attempts to socialize or go out in public, but it had to have been something that 
they carried along with them that became an unspoken concern, one that women all over the world carry with them whenever they go out in public. For most white people, race remains an invisible and mostly ignored aspect of their study abroad experience (Dalton, 2002). I will not proclaim either of these experiences as dangerous or benign because each is just as likely, but they are an intersection of the colonial white study abroad student with the African immigrant in France, two very different experiences, and at the very least could have been a moment of critical reflection and learning.

I mention the above because, Becky had a completely opposite experience. She was acquainted with an African who she met in her neighborhood and would run into him from time to time and he would happily greet her, which she interpreted as a very positive experience and she did not find at all gendered or related to sexuality, at least to the extent of what she was willing to share with me. In fact, in my member checking interview with Becky, she said that her interactions with African men in France were extremely positive. She did not feel unsafe or uncomfortable at all.

Feeling free. Becky did not tell stories regarding her gender or sexuality, but an important theme that surged from her entire study abroad experience was how she felt that she was less marginalized in France than in the United States. Upon her return, Becky again said that she felt that she could "get ahead" much more easily in France than in the U.S. because of her gender and her race. In her member checking interview, Becky said that it was such a relief to be out of her "bubble of being an African-American all of the time."

Finding love. I suspect that one of the reasons (even if it was not the main one) why Lesley wanted to study in France was because she had a French boyfriend and by studying in France she could be closer to him. They had met more than a year before her study abroad and 
stayed together during her entire sojourn. This meant that Lesley spent just about every weekend with him in the town where he lived outside of Paris and spent less time nurturing friendships in Angers where she was studying.

Prior to her semester abroad, Sasha spoke out against the idea that she might meet a French man and have a relationship with him, but a month or so after her arrival she did meet someone who she really liked a lot. I would have expected that finding love with a French person would result in increased L2 use and learning however neither Lesley nor Sasha spoke in French with their French boyfriends. Sasha felt vulnerable speaking French with her French boyfriend and defaulted to English in order to construct a stronger identity for him to get to know. Lesley spoke primarily in English with her French boyfriend because she said that his English was stronger than her French.

Norton (2013) describes L2 learners as constructing "a sense of who they are and how they relate to the social world" (p. 15), and in these cases, it seemed that ultimately having a boyfriend for both Sasha and Lesley was related less to investment in L2 learning and more to comfort. They needed someone to connect to while being so far away from close friends and family, given that SA participants can feel very lonely and disconnected from home.

\section{Willingness to navigate gendered/sexual power structures in the name of $\mathrm{L} 2$}

learning. Magda was willing to accept a lot of French men's advances because she felt it might help with her L2 learning. Despite having a boyfriend back home and the conflicting emotions that came along with that, Magda saw advances by French men as beneficial to her L2 learning, despite putting her in an uncomfortable place. Magda referred to a time in Montmartre at Sacré Cœur when French guys were "hella creepy" but being with them permitted her to speak French all evening long. She also described how going to bars always meant propositions from French 
guys, but since they were not openly, "Let's bang, babe!" she accepted it. Magda positioned herself in an imagined community of French speakers that included men who made advances at her because she understood that it would result in increased symbolic and material resources, which included L2 learning (Norton, 2013).

Completely shut out romance. Charlotte initially thought that French men were staring at her a lot, but it turned out to be all kinds of French people, not just men. After a short relationship with her host brother, Charlotte withdrew completely from romantic relationships and did not care how it affected her L2 learning.

Trajectories in gender/sexuality show that it can indeed be daunting to be a female abroad. Whether it is blatant, unwanted, and perhaps scary advances, or it is a hesitant willingness to put up with micro-advances for the sake of L2 learning, women must navigate uncomfortable issues with regard to their sexuality abroad, as at home. Some, but not all study abroad participants chose to get involved in relationships while abroad. In this study, given that those relationships were conducted in English, it did not seem to benefit their L2 learning, however it may well have benefitted their cross-cultural learning.

\section{Trajectories of Race/Ethnicity}

Four out of five participants are white and experienced what was I would call a racially invisible, or even arguably a study abroad sojourn embedded in white superiority. One of my participants is African-American and aspects of her sojourn had the additional weight of raced interactions. The following are trajectories of race and/or ethnicity.

Colorblind experience. Lesley, Magda, Charlotte, and Sasha are all white, middle-class Americans studying abroad on a program that is institutionally predisposed to whites. It is important to note that four out of five of my participants did not have to think about the 
consequences of how their whiteness influenced their experience. As I have brought up in previous chapters, so much of the understanding in our society is a product of the collective imagination sustained through unconscious, spoken and unspoken policies, procedures, and actions by institutions where whiteness is the norm over decades and centuries. Study abroad as a structured program is set to welcome, prepare, and protect white students in ways that it does not for people of color.

Color-conscious experience. While most of the group did not at all have a colorconscious experience, Becky was often conscious of her race. Even before she left she was concerned with how people would react to her in France: would French people see her as an African or as an African-American, and would she be expected to be knowledgeable about Africa? Once she was there her fears became a reality, as she often had to explain that she was indeed not from Africa, nor were her parents. Her host family expected her to have a particular interest in issues pertaining to Africa and she experienced racial micro-aggressions from French and Francophone people because of her hairstyle in Senegalese braids. I was unprepared to help Becky navigate this experience and was equally unprepared to recognize the significance of what she was expressing as she told her stories. In Talburt and Stewart's (1999) study one of their participants, Misheila, was African American and her experience was described as "hypervisible" because of her frequent exposure to an emphasis on her race and gender by the Spaniards. These constant reminders negatively affected Misheila's abroad experience. Ultimately, Becky felt that discrimination by the French did not come from a negative place as is affected in the United States; she said that they just "did not know any better" and she felt that she had more of a chance to succeed in France than in the United States based on her race and gender. I'm not so sure that this is actually the case. The French have significant problems with 
racism and are a colonial power with a history of supporting slavery and marginalization. In reference to immigrants in France or those who have lived there most if not all of their lives, Thomas (2013) describes French civilization today as at odds between the ideological and the actual, and an attempt at defining it "serves to point out those who don't belong under that category" (p. 60). While it is true that historically France's issues have pertained more to North Africans, immigrants from other African countries are streaming north through France to Great Britain causing a great amount of racist response (Castle and Breeden, 2015).

Highlighting East-Asian students. Several of my participants specifically pointed out East-Asian students participating in the CIDEF program in a way that othered those students. Lesley referred to them as ones who primarily stick to speaking French and would not speak English. Magda, called them "kids" and both of them called them "international students," as if Magda and Lesley were not also international students.

Study abroad is an endeavor historically taken on by white, socially privileged people. White participants did not notice their whiteness before, during, or after their sojourn, while the African-American participant had concerns about it at all three intervals of hers. Furthermore, Americans show an unspoken superiority referring to Japanese and Chinese as international students without considering that they themselves are also international.

As far back as Twombly's (1995) and Talburt and Stewart's (1999) studies, both of which focused on gender and race, the call is made for an increase in study abroad participants of color, as well as for orientation programs and pedagogical interventions that help students critically interpret instances of othering during their sojourns. Furthermore, without pedagogical interventions, students will refer to their own cultural perspectives when making sense of differences, which may influence their motivation and investment in L2 learning. 


\section{Trajectories of Social Class}

The principle stories that came to the surface regarding social class were as a result of students' feelings of privilege or entitlement to certain aspects of their sojourn. Furthermore, students' approach to their travels was often tied to capitalist consumption. There are two main trajectories for which I provide more detail below.

Colonizer studying abroad. In their pre-departure interview while it is certainly true that all of the participants looked forward to the difference in buildings, the beautiful architecture, and the food, they were very distinctly looking forward to travel. Certainly, travel and seeing new things and places is something that many people hope to experience in their life and there is no exception with study abroad participants. What sticks out more specifically is how travel becomes an aspect of students' capitalist consumer culture more than on the basis of learning more about new places (Ogden, 2008). A strong example of this is the millions and billions of selfies taken on trips to popular places and monuments to show that a person has "been there." Students are unable to put down their phones in general, even when experiencing a new place and culture for the first time. I fear that this is the case for many of our SA participants, and based on their discourse, it may very well be true. SA participants ultimately create and perpetuate a consumerist culture of "doing" countries, towns, and monuments, when they likely leave knowing little more about it than before they got there.

Another area in which the colonizer traveling abroad is recognizable is in the social expectations of the SA participants. Most of the participants did not establish meaningful friendships with locals, claiming that it was either difficult to figure out how or by flat out saying that they did not really like French people. In this way, students consume their experience in France from a distance, from a place of social superiority, retaining many of their social and 
cultural expectations (not being in situations in which their "normalcy" would have been questioned). Students relied on and enjoyed being able to eat at American restaurants such as Chipotle and Pizza Hut, and were actually relieved to be able to continue drinking Starbucks coffee as opposed to frequenting and consuming beverages from French cafés. Ogden (2008) describes the colonial student as the ones who want to study abroad but do not want to have to suffer much if any discomfort.

Many of the participants had very American expectations of business interactions and complained about the way in which the French handle bureaucratic situations inefficiently and in a time-consuming manner. Furthermore, they were very annoyed with the business hours of shops and banks. In the same vein, they found French customer service to be terrible with rude workers. Ogden (2008) argues that the colonial student experiences the new culture as a business transaction, something to be purchased and owned.

Conflation of being American but wanting to look worldly. While they did not mind being American, my participants, especially Lesley and Becky, were very aware of physically appearing too American. They were concerned with making the right fashion choices (no bright colors, no sweatpants, and no tennis shoes) and carrying the proper bag so as not to draw negative attention. This desire to appear cosmopolitan while many of them continued to speak mostly in English and frequent American establishments while surrounding themselves with other Americans emphasizes their mobility capital, or access to international travel and contributions toward reifying American presence and power in the world (Murphy-Lejeune, 2003).

There is an obvious conflation of social class and nationality when considering social class in the categories above. All of the students wanted to travel, but often from a capitalist, 
consumer approach that included a desire for and expectation of American food and comforts along the way. Second, participants felt significantly drawn to "looking the part" of being French, or at the very least, not sticking out based on clothes or accessories. However, when it came down to it, Americans chose to spend time with other Americans, speaking in English.

\section{Trajectories of Discourse/Linguistic Inequality}

My participants experienced linguistic inequality in two ways. They experienced a perceived loss of power through their decreased ability to speak French, and they retained power through their use of English. The situations in which this was most evident became clear through participants' choice of community of practice. The main communities of practice that my participants frequented were ones in which everyone was American and everyone spoke in English, ones in which there were Americans and students from other countries and everyone spoke in French, romantic relationships in which English was spoken, and host family relationships in which French was spoken.

Only American friendships. Of the five participants, all of them had friendships with Americans and for most of them Americans made up their community of practice. Charlotte was unashamed in admitting that she did not care for French people, that she could not manage her year abroad without her American friends, and that speaking French was less important to her. Lesley said that she had a difficult time making friends with French people even though her boyfriend was French and she spent weekends with him and his friends. Lesley's friends in Angers were predominantly Americans with whom she spoke English when she socialized with them. Becky's community of friends was also primarily American over the first semester and she admitted to speaking mostly in English with them. Becky made a significant switch to speaking more French over her second semester, and even though her group of friends seemed to remain 
mostly American, this group was more invested in speaking French. Magda was the only participant who adamantly sought a community of French speakers, some of whom were also American.

Communities of Practice are formed under the guise of joint enterprise and encourage a feeling of belonging permitting members to recognize parts of themselves in others and create an “identity of participation" (Wenger, 1998, p. 56). The majority of participants in my study favored and reiterated the acceptance of English-speaking CoPs and their identity as American and English speakers. This kind of CoP abroad further reiterates Open Doors (2016) statistics that downplay the importance of L2 learning during a study abroad.

Dislike of ugly, English-speaking Americans. Magda was the main participant who had an aversion to spending time with Americans. She was extremely conscious of the commonly accepted behavior by Americans who spoke principally in English when they socialized. She was not only ashamed of that, she may have also been especially concerned with her OPI score upon her return because if she did not have Advanced Low proficiency it would keep her from successfully completing the teacher education program. Magda's investment in L2 Communities of Practice was deliberate and constant throughout her semester abroad. Magda was very aware of the construction of her language identity and the significance it had on her L2 socialization (Norton, 2013). Magda was also the most critical of the five participants and appeared acutely aware of this overall weakness in Americans abroad, mindful of language hegemonies and linguicism to some extent. Sasha was the other participant who was cognizant of her L2 language socialization knowing that if she were to spend much time with other Americans, she would end up speaking in English. Magda and Sasha were in Angers during the second semester of Becky's academic year abroad, the time during her sojourn when Becky felt more willing and confident 
to communicate more often in French, and so the three of them made an agreement to speak in French when they were together.

Finding love, but only in English. Lesley and Sasha both had French boyfriends. Lesley met hers long before her year in France and Sasha met hers after the first month of her semester abroad. Lesley and her boyfriend spoke primarily in English because when they met, Lesley was still a beginning French speaker, and once she was in France, she regarded her boyfriend's English as being at such a higher level than hers in French that their lingua franca remained English. While Sasha and her boyfriend initially spoke in French together, once the relationship became romantic and Sasha realized that he spoke English very well, their communication changed to only in English. Sasha expressed that speaking in French would require her to show him a vulnerable side of her that she was not willing to share.

On a personal level, this particular trajectory is interesting to me because I had a French boyfriend during my year in France and we spoke only in French. Perhaps it was because his English was weaker than mine, but the consequences of my experience had me convinced that finding love would result in increased L2 learning. While both Sasha and Lesley showed an increased ability in L2 learning upon their return (through the unofficial OPI that I administered), little of this shift could have been attributed to having a French boyfriend.

Host family connections. As the literature has already shown, when students have a positive relationship with their host family they have increased opportunities to speak in the L2 it benefits L2 learning (Pellegrino Aveni, 1995; Wilkinson, 1998). However, not all SA participants get along with their host families and not all host families are interested in establishing a close relationship with these students (Kinginger, 2008; Pellegrino Aveni, 1995). Charlotte did not feel at all comfortable with her host family and stopped eating and spending 
time with them after her first month there. Lesley's host mom was very kind to her and they did spend some time together but because of Lesley's frequent out-of-town stays with her boyfriend, she really did not establish a consistent relationship. Becky, Sasha, and Magda all had fairly good relationships with their host families and spent a lot of time in conversations with them over meals. Sasha and Magda took part in additional activities with their host families such as running errands to the farmer's market or the pharmacy, or even attending social events or exercising at the local swimming pool together. Sasha and Magda in particular say that they found the relationship with their host family extremely meaningful and important to them and to their confidence in the L2. At the midterm, Becky described really enjoying dinnertime conversations with her host family, but did not refer to this at the return interview.

Classroom/school connections. Lesley and Charlotte divulged that the community in which they spoke the most French was within the classroom setting. It appears that they could only adhere to speaking in French in a setting in which parameters were explicitly set to require French-only. Interestingly, Magda described frequent incidents of students ignoring these parameters, especially when breaking off into small groups to work on exercises or projects. This would suggest that some students need the institutional structure to insist and maintain pressure on them to use the L2. Unfortunately, it seemed that this became the principal exposure that Charlotte and Lesley had to practice their French since they socialized with English-speaking Americans out in public settings where they could have expanded on their French immersion, but did not. The classroom connection might have become most important because those students were not invested in L2 CoPs, and it still highlighted their experience of human capital development (Kubota, 2016), because they improved their social and professional standing through earning credits from a university in France. 
In summary, a romantic relationship can highlight inequalities of power, instill fear of exposing weaknesses that might result in a further breakdown of power, and ultimately intimidate and instill a lack of confidence and motivation in the L2 speaker. Host family connections, if there is mutual appreciation, can be extremely beneficial to L2 learning, however, not all SA participants make that kind of connection with their host family. In this study, two of the five did not, while three did. Finally, some students' only exposure to full immersion in French was in the classroom because they were unwilling or unable to establish French-speaking communities of practice outside of the classroom.

\section{Chapter Summary}

In conclusion, approaching analysis of my participants by way of the critical themes and then grouping what I noticed into themes and trajectories permitted me to make some connections about how students negotiate their identity and use power (consciously or subconsciously) to become members of CoPs, use English as their Lingua Franca, or speak in French and gain perspective (or not) about themselves, their lives, their country, and that of those in other countries. In the next chapter I give my interpretations. 


\section{CHAPTER VII: INTERPRETATION}

In this section I offer my interpretation of the data speaking to my original research questions. Interpretation comes from consideration of what stands out from the data based on the researcher's own reflexivity. Wolcott argues that in order to really know the people and data you study, you must be reflexive ( or "turn your sights more introspectively" on yourself), as Wolcott (1994) claims that "the personal reflections of the researcher as interpreter have come not only to be allowed but expected" (p. 256). Wolcott explains that we use the interpretive mode in order to show that our understanding and the "implications to be drawn" are "socially significant" (p. 258). In doing this, we must draw in our readers to share and exchange knowledge. As Wolcott describes, knowledge on its own is not enough:

Knowledge is a matter of agreement. Field observations alone, data largely of our own making, cannot achieve status as knowledge. Our analyses reside safely because we carefully link them to the claims-making of others. Our interpretations are our claims to the independent creation of new knowledge. Arrogant work, indeed. (p. 258)

In sharing the interpretation of my findings, I hope to expand the knowledge of critical issues of identity related to study abroad and L2 learning.

My predominant questions in this study were situated in light of the "social turn" in L2 and study abroad research, that is, how language socialization (individuals who participate in social communities and construct identities in relation to them) affects one's linguistic and social development in another society. However, I took it a step further in focusing on influences of power and inequity through participant identity and how this might control social and linguistic issues pertaining to study abroad as an institution as well as the sojourn itself. We do know that L2 learning is influenced by our perception of social constructs of our identity (Block, 2009). We 
also know that statistics show that the demographic of those who study abroad is predominantly white and middle- to upper-class (Open Doors, 2016). But few studies focus on the influence of powerful social structures on this institution and on L1 use and L2 learning. Critical applied linguistics is useful in breaking this down to scrutinize discourse and actions at a micro level so as to encourage action and change and spotlight the inequality within the institution of study abroad itself.

Before undertaking this study, I noticed anecdotally and through our department majors' post-study abroad official OPI scores that SA students' L2 learning seemed inadequate even after one semester or a year abroad. I felt that there was something wrong with this but had only my own experience of L2 learning to compare it to. I initially blamed it on technology, specifically social media and cell phones, without taking into consideration the commanding position that cultural capital and socially constructed norms have over peoples' actions and intentions, including the institution of study abroad itself. I set out to peel back the layers of influential factors on students' mindsets (such as the history of study abroad), by researching human travel and wisdom-seeking through the millennia, and found its basis built upon an institution for the privileged and/or an endeavor for those looking to possess what is not theirs. I also examined the American education system, more specifically which stories within history are considered legitimate to teach and disseminate, which information is permitted in our textbooks, and who has authority to decide. I explored how this manipulation of educational material informs our children to carry notions of what is appropriate and "standard," including how whiteness is perpetuated in an effort to control the discourse of what it is and is not to be an American. It seems generally accepted that part of being American includes the concept that English is 
linguistically superior to other languages in the world, and it is used, whether consciously or unconsciously, as a tool to dominate.

Once I completed the literature review, my intention was to look at how this institutional and social miseducation influenced who actually studied abroad and what their actions and L2 learning were once there. I hypothesized that using the lens of critical linguistics in analysis of SA participant interviews in tandem with what we know already from the literature could shed light through participants' lived experiences, allowing discourse to be revealed.

The following section addresses my first research question.

What is the nature of how students negotiate their identities (racial, national, and gender), L2 learning, and engagement (or lack of) with various communities of practice while studying abroad in a non-English dominant country?

I will address my research question divided into three subsections: 1) Identity, 2) L2 learning, and 3) Engagement.

\section{Identity}

SA participant identity can be defined in several ways. It can be related to L2 learning, or second language identities, that is, how participants see themselves as L2 learners. As a result of the "social turn" in SLA, researchers recognize the need to consider the "whole person." Some studies have looked at the effect of gender on L2 learning and SA participants' experience abroad, and a handful have looked at race. However, few studies have taken an approach of critical identities in which social constructs of power inform students' identities often reified through study abroad. Below I look at some big picture aspects of identity in this study.

Americans are in a privileged position as study abroad participants and in this new context they have the option to be reflective and think critically about what their nationality means in the greater scheme of things. On the other hand, study abroad participants can instead 
take advantage of the power that their identity holds and use it to control and manipulate their experience abroad to remain on their own terms. However, in many cases in this study, students did set aside some notions of who they were in a spirit of openness to new ways of thinking and living. In other cases, students were resolute and unwilling to budge in who they were, even in the name of learning about a new place and way of life.

As Ogden (2008) and others in the literature review describe, study abroad participants take part in a greater endeavor of negotiating their identity as consumers. For many, their experience is marked by access to familiar (American) products and the relief and joy this gives them that reifies who they are despite living in a "foreign" land. This consumerist identity is furthermore marked by students' having met the goal of having "been there" or having "done" a city or a country. In fact, "being there" or "doing" Paris, Italy, or some other desirable locale, however superficial the experience might be, seems to meet an important social rite of passage that may well connect back to the Grand Tour. Benwell and Stokoe (2006) elaborate on how consumer identity encourages othering: "Consumption becomes a means of articulating a sense of identity, and, perhaps even more crucially, distinction from others" (p. 167). There seems to be a very clear connection between students' neoliberal expectations from study abroad, othering, and establishing authority. SA participants as consumers in this study and in others do reify the United States' “dominion's abroad,” as Ogden (2008) claims, by “establishing a colonial-like presence...concerned mostly with access, consumption, and personal gain" (p. 40). As students meet these social goals, all with the comforts of home (using English as lingua franca, built-in American travel companions, and American chain restaurants now found worldwide) their assertion of American cultural expectations re-exerts the dominant nationalistic power of the United States, all through study abroad. 
An important point that arose is that whiteness is invisible for most every study abroad participant in this study. Dalton's (2002) assertion, "In part, race obliviousness is the natural consequence of being in the driver's seat" is valid (p. 17). According to Open Doors (2016), the majority of students who study abroad are white and that is no different in this current study.

Overall, those students do not perceive a personally raced experience because they have unconsciously set the standard for what a SA participant looks like.

Students who are white are not faced with their racial identity being put into question and so they do not have to negotiate it. This was made especially clear because of Becky's participation in this study and the notions of her raced identity that she did have to negotiate. Dalton (2002) describes how whiteness contributes to reification of standards "the extent to which they feel the country is theirs; the extent to which that belief is echoed back to them...is in part a function of their race" (pp. 17-18).

Whiteness is invisible for white SA participants, but it nonetheless contributes to a feeling of belonging, and the sense that SA participants' actions abroad, set by their standards, are justified.

\section{L2 Learning}

When I began this study I naively thought that by the end I would have the answer to what would help improve L2 learning while abroad so that I could make some simple recommendations. L2 learning abroad is especially complicated by the conflation of notions of identity and engagement, on which I elaborate in the next section. It is apparent at the end of this study as at the beginning that L2 learning is a social endeavor that requires engagement in order for progress to be made. Whether or not one is invested in that engagement is crucially affected by one's identity and the ability to negotiate threats to it and a state of conflict that occurs 
between the home identity and the one abroad. Participants in this study did show a shift in L2 learning. Unofficial (and some official) OPIs all resulted in at least one sublevel improvement in proficiency. Whether students' L2 learning could have improved at an even greater rate remains in question, and this, I believe, is related to engagement.

\section{Engagement}

The framework for CoPs and LPP (as manifested in the pilot study with Chev) appears on the surface one in which, if students so choose to invest in the endeavor that includes use of the L2, there would be an increase of L2 use and learning would improve abroad (Lave and Wenger, 1991; Norton, 2013). However, engagement requires that so many other elements fall into place before an L2 learner is willing to invest. As noted in the two previous sections, and as Kinginger (2009) infers in her chapter on Language Socialization and Identity about gender, nationality, and language learning being "tightly connected" (p. 183), it is difficult to separate identity, L2 learning, and engagement because each one is connected to and relies upon the other in some way. Kinginger cites Block's assertion that SA participants' identity becomes destabilized when they find themselves in a place that "serves to upset taken-for-granted points of reference" leaving them to struggle to "reconcile differences between their own practices and those of their host community" (p. 183). In this study, participants' identities as Americans, as women, as students, as white or Black, as consumers, as L2 learners, as English speakers, had an effect on their desire to engage, and were the impetus to create and join CoPs related to those notions of their identity that held greatest importance, often aspects of their identity that they were unwilling to give up. Clearly, students in this study were most likely to engage with other Americans and those who also spoke English because they had a strong need for comfort and support by those who understood and reified who they were. On the other hand, some 
participants were able to be more flexible with their identity and developed a solid connection to their host family, ultimately finding community and support within their adopted home in Angers. In these cases, their host family CoP likely had a part in students' increased learning in the L2. Of those participants who either did not establish a relationship with their host family or the relationship was not very strong, their American CoP held great importance to them, to the detriment of their L2 learning. These same participants engaged the most in the L2 within the classroom setting at the CIDEF and reported that the classroom CoP had the most positive effect on their L2 learning. In these cases, those pre-established classroom boundaries appeared to be a necessary structure for those participants to invest in engagement. In other words, they would not have sought it out on their own.

\section{How can an understanding of study abroad students' identities and participation in communities of practice abroad inform administration and implementation of study abroad programs to encourage $\mathrm{L} 2$ learning?}

As higher education increases investment in a variety of areas pertaining to internationalization, policy makers, faculty, and administration should proceed with care. While the need for increased revenue is vital to the survival of many American universities, this cannot be implemented at the sacrifice of quality programming and education. As beacons of higher education and research, universities should provide the moral high ground on which myths and social standards perpetuated by $\mathrm{K}-12$ schools and popular culture are reconfigured and transformed. It is clear that students who take part in study abroad programs approach them with preconceived ideas of who they are that are deeply seeded in institutional racism, whiteness, and social and cultural capital. Study abroad could and should be an opportunity for students to learn how to question, to become more informed; in sum, to think critically at a pragmatic level in a diverse world, not based off of superficial ideas relayed through textbooks or confined to a 
classroom. Participants during this study show varying degrees of increased awareness about what it means to be American, to be a woman, to be socially privileged or entitled. Participants demonstrated some unconscious behaviors that they never fully understood. Some participants felt that it was wrong to stick out like an American but did not reflect upon why. White participants were unaware of their whiteness, and unconsciously perpetuated the idea of "study abroad participant as colonizer" (Ogden, 2008). Many of my participants pointed out that it was typical for Americans in the program to speak primarily in English whenever they were together even during university-sponsored excursions, ignoring requests by professors and administrators on site to speak in French. Not only are SA participants taking advantage of their privilege as English speakers, they perpetuate linguicism, contributing to English as the dominant language (Pennycook, 2001). Results such as these should inform university internationalization endeavors and study abroad programming. Universities must establish what their goal is with these programs. Is it financial? Is it making students happy consumers? Is it encouraging a more informed and reflective citizenry as Dolby (2004) describes, such as learning how to see things from a new perspective, providing students an opportunity to understand themselves, their way of life, and their place in the world?

Americans are surrounded by innumerous unacceptable justifications for not learning a second (or third) language that impact a student's mindset. From subtitles to dubbing, to books in translation, from Google translate to much of online technology available in English, to "not having enough time" to take it and graduate on time, from colonization to colonial mentalities, English has gained worldwide standing as the lingua franca. Devlin (2015) shows that most European countries require the study of two or more world languages, the first of which must begin by the age of nine (although a good number of European countries require it by the age of 
six). Furthermore, as Hsiao (2014) argues, speakers of English as one of the world languages are able to hold all linguistic rights, placing others in inferior social positions. One of the greatest problems is the standard that Americans set by relying on English as the most studied language across Europe and in many countries around the world, a blatant weakness permitting a default to this position, given as previously stated, that many other countries support learning multiple languages.

There are explicit and implicit reasons for supporting and requiring that Americans learn world languages that could be reinforced through university programming in general as well as during study abroad. Some people might highlight national security on the global stage. During World War II, Americans scrambled to learn foreign languages for strategic purposes in the Army Specialized Training Program in which we needed interpreters, code-room assistants, and interpreters, but realized almost too late how important it would have been to know other languages beforehand. While the ASTP only lasted for two years, foreign language teaching grew after World War II in partial recognition of this need. Unfortunately, it has again decreased to very low levels, putting our security again at risk. However, learning a world language is beneficial for more than strategic reasons. We must advise our students that it enhances a resume, even if the language will not be necessary in future jobs. As the company Google recently pointed out about their top leaders, the soft skills ("being a good coach; communicating and listening well; possessing insights into others (including others different values and points of view); having empathy toward and being supportive of one's colleagues; (being a good critical thinker and problem solver; and being able to make connections across complex ideas," meaghan, 2018) sought out by big companies are those acquired through world language study. 
Furthermore, and more importantly from a moral standpoint, language-learning can lead students to be more engaged citizens through acquiring critical, philosophical, and ethics-based ways of thinking. This is the culture that we should be encouraging in higher education.

Certainly, we want our students to graduate and get jobs in order to make a living, but is not the goal of higher education to create a more knowledgeable and reflective citizenry? Why then do study abroad offices publicize that students do not need to know a world language in order to study abroad? They play into our national culture of superiority and linguistic hegemony. They play into the discourse of American tourist as colonizer. They are complicit in producing students who perpetuate this power structure. What good are study abroad programs in which students not only spend most of their time with other American students, but they also take their courses in English and learn little to none of the local language and ways of life? We as educators and administrators are complicit in accepting this standard and should work to shift the discourse to change it.

This study shows that the way in which a student understands who they are and the world around them greatly affects learning during a study abroad experience. If educators want to help students make critical interpretations it requires pedagogical interventions, and many of them would not be very difficult to enforce with buy-in from the institution. Students could learn through readings about the power that language holds, the power that they reinforce when speaking in English, and how much one can learn about a culture through the local language, and this of course has intersectional connections.

Provided that the resources exist, students should be required to take a pre-departure crash course in the local language of the country of the study abroad program. Students would learn a minimum of greetings/salutations, how to request commonly needed items, how to ask 
directions, and how to show politeness based on local cultural values. Students would also learn about country-specific pertinent issues such as politics and social issues. Furthermore, they would take a short course in which they would reflect on who they are and where they come from, including readings about nationality, social status, race, gender, and language. Over the course of their study abroad, students would complete a bi-weekly journal with feedback from educators in which they would reflect on the above notions, and they would write down new linguistic expressions that they learned or needed. A final auto-ethnographic paper, reflecting back on critical junctures of their experience could help them understand themselves and the multiple layers of their experiences.

None of this will work, however, without hiring administrators and educators who understand, promote, and believe in this approach and mandate the same of themselves, becoming as much of the process of reform as is expected of the students. Howard (2010) says in his chapter on developing cultural competence that administrators and educators must be able to "sufficiently address the complex nature of race, ethnicity, and culture" despite the "incredibly difficult" nature of this process (pp. 125-126). Furthermore, administrators and educators must create a critical definition of what internationalization and diversity really mean, what they mean within the structure of the institution in which they work and how they are going to ensure that students reach that end-goal through a study abroad as well as reintegration to the home university.

Administrators in study abroad positions are pressured with increasing frequency to boost the number of participants by any means necessary, leaving them to minimize educational aspects in favor of the fun, touristy characteristics of study abroad. 
In terms of race, those who represent study abroad must represent racial and ethnic diversity. Without representation, how will students connect with the idea that study abroad is also for them? Furthermore, how will students of color, should they decide to take on a study abroad, navigate unknown territory like Becky did? Should white students benefit from white administrators' understanding of the characteristics of study abroad while people of color are left to figure it out for themselves? As Marable explains in Howard (2010, p. 95), we must include race when examining schooling opportunities in an effort to improve them.

Instead of talking abstractly about race, we should be theorizing about the social processes of racialization, of how certain groups in U.S. society have been relegated to an oppressed status, by the weight of the law, social policy, and economic exploitation. (2002, p. 10)

This means that administrators must continue to acknowledge what Howard (2010) calls "the elephant in the room" (p. 92) as they work to make study abroad programming inclusive and equitable. In a world of higher education that focuses increasingly on capital ventures for which study abroad has become just another marketing tool, it is all too easy to ignore these critical themes.

Ideally, study abroad programming would be restructured to allow for a decrease in capitalist influence on its approach, but I do not imagine that to be realistic. However, programming is currently inequitable and informed by notions of whiteness. At present, study abroad benefits the system first, white students and institutional racism second, and students of color who are willing to be a part of it, last. Howard (2010) points out the significance of the ways in which educators interpret meaning from their students of color that become especially important when they have had limited interaction with that demographic. If study abroad 
administrators have little experience with people of color or other marginalized demographics, how can they sufficiently welcome and support them through study abroad programming? Furthermore, administrators and educators must come to understand that race has nothing to do with physical characteristics, but instead the ideas that others project onto them, or what Lewis (2003) says are "signifiers we must learn about and negotiate in order to successfully move through the social world" (p. 6) in place of approaching study abroad with a colorblind ideology. If SA administrators and educators were to gain a deeper understanding of this, study abroad programming could be a more meaningful experience of learning about self, one's community, and the world in a more comprehensive way. SA administrators and educators must inform themselves through peer-reviewed studies by researchers using critical theory, and qualitative over quantitative methods, so as to inform about the whole person and their lived experience.

In summary, while fear of a lawsuit is at the forefront of all SA preparation and orientation, most study abroad programs have a very hands-off attitude with little to no guidance to help SA participants critically synthesize their experience. Learning a second or third world language not only expands a person's ability to communicate, but language is the very code, the very window to essential understanding of people and their culture in other parts of the United States and the world. Espousing a singular view of English as lingua franca wherever Americans go essentially neutralizes a large part of the essence of learning about a new country and culture and creates an American citizenry that is misinformed and lacking perspective. Furthermore, Americans' lack of world language skills is a national security issue. Pedagogical interventions are needed for both students and administrators to elucidate these very deep-seeded issues of race, power, and privilege within our institutions and study abroad programming. 


\section{Epiphanies (What I did not Expect)}

Realizations that I had over the course of this study run the gambit of simple to profound. I will begin with the simple. I honestly had no idea that transcription would take so long! After the first interview which lasted around twenty minutes, I set forth to transcribe it, and it took around 15-20 minutes to type every five minutes of the interview. I finally bought a transcription pedal when transcribing the interviews of my last participant and it was a life-changer!

Now onto the more serious moments. I am ashamed at how I handled Becky's comments about race in her interviews. I assumed that as long as I remained completely open to what she said (nothing "right," nothing "wrong") that my interviews would be fair and elicit things as they really were. The problem was that I did not understand Becky's raced experience. I had not done enough reading, writing, or reflecting on the subject and so when Becky brought up issues of race, I did not know how to follow up. I remember being afraid that I might say something that made me sound prejudiced or racist and so I mainly honored her words, not understanding the depth of what some of them meant, like "No, where are you from?." My greatest embarrassment is when I asked her if peoples' constant inquiry about her origins did not just make her want to find out more about her roots. Most African Americans are unable to trace their roots even if they wanted to because their families were torn apart through slavery. How could I have been so unaware?

As a white woman, I have lived my life based on the philosophy of "live and let live," but I did not realize how much "letting live" made me complicit in perpetuation of white norms. I was glad to have chosen to approach my study using a critical framework and felt that critical applied linguistics, while helping me interpret my data in terms of power through identity, was also vital in educating myself that complacency and tolerance perpetuate racism and inequity. It 
enlightened me that change, from the personal to the institutional, is not implemented through tolerance alone.

I thought that having multiple cases to learn from and to compare would be beneficial in showing patterns and easily and readily provide me the ability to make a clear inference. While some of the participants showed commonalities through a theme, it was not as easy as I had anticipated to come to many concrete conclusions. Qualitative methods require much more interpretive effort by the researcher than quantitative, however each method depends upon the honest response of the participant, something that can be manipulated in both qualitative and quantitative.

\section{Study Critique}

When I started this study, I was certain that my results would show that addiction to our cell phones and social media was one major influences on students who did not show ample L2 learning after a semester or year-long study abroad. While I still believe that there is a connection, I have learned so much about the intricacies of our identity to which I had given little consideration in the past. The outcome of our SA experience comes from everything that made us who we were before we left (our parents, our teachers, our schools, our friends, our community institutions, our gender, race, ethnicity, our imagined idea of who we were). It is who we come into contact with once we are there and how they react to us and how we react to them. It is the risks (or lack of) that we take while there and their positive and/or negative consequences. It is what happens to us through coincidence and chance and how we deal with it based on all of the above. It is who we want to see ourselves evolve into during and after our study abroad. 
If I had it to do all over again, I would have focused more on who my participants felt they were and what made them that way, that is to say, an ethnographic approach. I would not have asked such specific questions about what they thought would hinder them from learning French and in which situations they use English or French. Those questions do not produce rich responses with layers of meaning and seem more like accusations which likely entice a less-thanforthcoming response. It does not empower students to speak more French abroad by forcing them to focus on what does not help them. Indeed, administrators at the CIDEF are unable to encourage students to speak in French simply by reminding them that they are not. I should have found out more about their familial background, social life, socioeconomic status, areas that bring meaning to their lives, and how they feel about their gender and their race and encouraged them to do the same. I needed to look at my participants even more as whole people with multiple and complex layers of reasons why they do what they do and indeed, have them do the same about themselves.

\section{Significant Contributions}

Few studies have researched critical identities and social constructs of power reified through students' identities during study abroad. As evidenced in my interpretations and conclusions, figuring out how to improve L2 learning outcomes during study abroad is an extremely complex issue, one on which SLA researchers have spent decades of time, some of whom have even approached some critical themes of gender, race, and nationality. But few have done more than look at those critical themes as individual entities unrelated to a greater social and cultural power. I hope that my study will be a building block on which future researchers will construct and develop their studies about L2 learning and study abroad. 


\section{Future Research}

In the future, researchers should continue to look at how the power of critical themes manipulates our lived experience both in the educational setting and in society at-large. Below are some areas that I believe merit continued research.

Focus more on national identity. Researchers should undertake additional studies on American attitudes, the conflation of race and American nationality, national hegemony and colonizer discourse, and the dissemination and reification of these ideas as a result of study abroad.

Focus more on POC. Further study is merited for students of color at the University level in which they should be interviewed to understand why they do or do not study abroad. Some of the issues that Becky brought up about raced experiences abroad should be explored in more depth, such as how to handle questions about her origin and how her raced experience abroad affected her raced experience here in the United States upon her return. It would also be worthwhile to research which kind of study abroad POC would be interested in and the kind of administrative support needed.

Exploratory studies. Exploratory studies would be helpful in which pedagogical interventions would be imposed upon students during different steps of their study abroad. Over the course of their study abroad and in response to journal entries, students would be assigned meaningful readings about real-life SA participants' stories that would relate information about the critical and other themes in this study upon which they would reflect and compare to their current situation and to societal and institutional norms across cultures.

More critical approaches in SA research. While a good number of research subjects are female and research has been conducted on the gendered experience abroad, increased focus 
should be given to the experience of people of color from the point at which they embark on an exploratory process about SA to their actual experience abroad and L2 learning (like Anya, 2012, and Twombly, 1995). Research with a truly critical undertone is needed about our higher education institutions as well as our study abroad programming. A paucity of literature could indicate the depth of socio-cultural and raced inequity of study abroad and the increased need to educate administrators and educators. Given that the average researcher positionality for SA research is white and middle class, it is likely that researchers have not paid enough attention to issues pertaining to colorblindness, invisibility, and white social structures in SA.

\section{Conclusion}

Identity, L2 learning, and engagement are all interrelated. Power, privilege, fear, confidence, ego, and learned understanding of social and cultural constructs inform SA participants' actions such as English-speaking CoPs, the neoliberal, consumer approach to the study abroad experience, as well as resorting to the use of English. Students are ignorant to their whiteness and overall privilege on these sojourns. L2 learning is highly affected by student identity, and a large determiner of engagement is identity, unless the boundaries of that engagement are mandated by the program.

Institutions of higher learning must take steps to study and review their policies, programs, and processes, including student outcomes. There must be a shift in cultural acceptance of world language learning in the U.S, and the university and its study abroad programming is a critical place for this occur.

What have I learned as a whole from this study? My personal conclusions are that the study of human understanding and interaction and notions of power is more complex than I had imagined and difficult to summarize into neat little solutions. I have appreciated qualitative 
methods for this endeavor, even though they can also be extremely messy and frustrating. Instead of trying to solve the problem, I learned that as a researcher, it is more important to contribute to the discussion with the data that I analyze, interpret, and share. I learned that even the most "woke" faculty members and administrators are in a constant process of awakening - and that is only if they (including me) are willing to question what informs our motives and the ground on which we base our decisions.

The results of this study could be part of a call to action - they already are to me - and I hope that they will motivate others who are in positions in which they have the ability to push for change in these areas. 


\section{REFERENCES}

Alim, H. (2010). Critical language awareness. In N. H. Hornberger \& S. McKay (Eds.), Sociolinguistics and language education (pp. 205-231). Bristol, UK: Multilingual Matters.

American Council on the Teaching of Foreign Languages. (2012). Oral proficiency interview familiarization manual. Retrieved from http://www.languagetesting.com/wpcontent/uploads/2013/05/ACTFL-OPI- Familiarization-Manual1.pdf

Anya, O. C. (2011). Investments in communities of learners and speakers: How African American students of Portuguese negotiate ethno-racialized, gendered, and socialclassed identities in second language learning (Doctoral dissertation). Retrieved from ProQuest Dissertations Publishing.

Aveni, V. A. P. (2005). Study abroad and second language use: Constructing the self. Cambridge, UK: Cambridge University Press.

Benwell, B., \& Stokoe, E. (2006). Discourse and identity. Edinburgh, UK: Edinburgh University Press.

Block, D. (2002). Destabilized identities and cosmopolitanism across language and cultural borders: Two case studies. Hong Kong Journal of Applied Linguistics, 7(2): 1-19.

Block, D. (2003). The social turn in second language acquisition. Edinburgh, UK: Edinburgh University Press.

Block, D. (2006). Identity in applied linguistics: Where are we? In T. Omoniyi \& G. White (Eds.), Identity in applied linguistics: Where are we? (pp. 34-49). London, UK: Continuum. 
Block, D. (2009). Identity in applied linguistics: The need for conceptual exploration. In L. Wei \& V. Cook (Eds.), Contemporary applied linguistics volume 1: Language teaching and learning (pp. 215-232). London, UK: Continuum.

Block, D. (2010). Researching language and identity. In B. Paltridge \& A. Phakiti (Eds.), Continuum companion to second language research methods (pp. 337-349). London, UK: Continuum.

Block, D. (2014). Second language identities. London, UK: Bloomsbury.

Bourdieu, P. (1986). The forms of capital. In J. G. Richardson (Ed.), Handbook of theory and research for the sociology of capital (pp. 241-258). New York, NY: Greenwood.

Brockington, J., Hoffa, W., \& Martin, P. (2005). NAFSA's guide to education abroad for advisers and administrators. Washington, DC: NAFSA Association of International Educators.

Carroll, J. B. (1967). Foreign language proficiency levels attained by language majors near graduation from college. Foreign Language Annals, 1(2), 131-151.

Castle, S., \& Breeden, A. (2015, July 29). Britain and France scramble as channel becomes choke point in migration crisis. The New York Times. Retrieved from https://www.nytimes.com/2015/07/30/world/europe/britain-and-france-scramble-aschannel-crossing-attempts-by-migrants-continue.html

Caton, K., \& Santos, C. A. (2009). Images of the other: Selling study abroad in a postcolonial world. Journal of Travel Research, 48(2), 191-204.

Coates, T. N. (2015). Between the world and me. New York, NY: Spiegel \& Grau. 
Collins, G. (2012, June 21). How Texas inflicts bad textbooks on us. The New York Times. Retrieved from http://www.nybooks.com/articles/2012/06/21/how-texas-inflicts-badtextbooks-on-us/

Coleman, J. A. (2013). Researching whole people and whole lives. In C. Kinginger (Ed.), Social and cultural aspects of language learning in study abroad (pp. 17-44). Amsterdam, NL: John Benjamins.

Cox, R. W. (1983). Gramsci, hegemony and international relations: An essay in method. Journal of International Studies, 12(2), 162-175.

Cullen, M. (2016, February 18). Language not an issue for travel, says study abroad office. The Daily Vidette. Retrieved from http://www.videtteonline.com/features/language-not-anissue-for-travel-says-study-abroad-office/article_d7e979f2-d5b5-11e5-b32127d33652cbac.html

Dalton H. (2005). Failing to see. In P. Rothenberg (Ed.), White privilege: Essential readings on the other side of racism (pp. 15-18). New York, NY: Worth.

Devlin, K. (2015). Learning a foreign language a "must" in Europe, not so in America. Retrieved from http://www.pewresearch.org/fact-tank/2015/07/13/learning-a-foreign-language-amust-in-europe-not-so-in-america/

Dolby, N. (2004). Encountering an American self: Study abroad and national identity. Comparative Education Review, 48(2), 150-173.

Douglass, K. B. (2005). Climbing the Eiffel Tower: An activity theoretic analysis of motives in an individual learner of French (Doctoral dissertation). Retrieved from ProQuest Dissertations Publishing. 
Downey, G., \& Gray, T. (2012, December 2-6). Blogging with the Facebook generation: Studying abroad with gen y. Paper presented at the annual meeting of the AARE APERA, Sydney, AU. Retrieved from https://www.aare.edu.au/publicationsdatabase.php/6488/blogging-with-the-facebook-generation-studying-abroad-with-gen-y

Duff, P. A. (2007). Second language socialization as sociocultural theory: Insights and issues. Language Teaching, 40(4), 309-319.

Echtner, C. M., \& Prasad, P. (2003). The context of third world tourism marketing. Annals of Tourism Research, 30(3), 660-682.

Edwards, J., Hoffa, W., \& Kanach, N. (2005). Education abroad at the beginning of the twentyfirst century. In J. L. Brockington, W. Hoffa, \& P. C. Martin (Eds.), NAFSA's guide to education abroad for advisers and administrators (pp. 5-23). Washington, DC: NAFSA Association of International Educators.

Firth, A., \& Wagner, J. (1997). On discourse, communication, and (some) fundamental concepts in SLA research. The Modern Language Journal, 81(3), 285-300.

Freed, B. F. (1995). Second language acquisition in a study abroad context. Philadelphia, PA: John Benjamins.

Giroux, H. A. (2005). The terror of neoliberalism: Rethinking the significance of cultural politics. College Literature, 32(1), 1-19.

Glesne, C. (2011). Becoming qualitative researchers: An introduction. Boston, MA: Pearson. Globalization. (n.d.). In Business Dictionary. Retrieved from http://www.businessdictionary.com/definition/globalization.html

Gore, J. E. (2005). Dominant beliefs and alternative voices: Discourse, belief, and gender in American study abroad. New York, NY: Routledge. 
Gramsci, A. (1971). Selections from the prison notebooks. New York, NY: International.

Hancock, A. M. (2007). When multiplication doesn’t equal quick addition: Examining intersectionality as a research paradigm. Perspectives on Politics, 5(1), 63-79.

Hobsbaum, E., \& Ranger T. (1983). Introduction: Inventing traditions. In E. Hobsbaum \& T. Ranger (Eds.), The invention of tradition (pp. 1-14). Cambridge, UK: Cambridge University Press.

Hoffa, W. (2007). A history of U.S. study abroad: Beginnings to 1965. Carlisle, PA: Frontiers Journal and The Forum on Education Abroad.

Howard, T. G. (2010). Why race and culture matter in schools: Closing the achievement gap in America's classrooms. New York, NY: Teachers College Press.

Hsiao, H. L. (2014). Teaching Chinese in a U.S. elementary school: Identity issues and social cultural challenges (Doctoral dissertation). Retrieved from ProQuest Dissertations Publishing.

Huesca, R. (2013, January 14). How Facebook can ruin study abroad. The Chronicle of Higher Education. Retrieved from http://chronicle.com.libproxy.lib.ilstu.edu/article/HowFacebook-Can-Ruin-Study/136633

Isabelli-García, C. (2006). Study abroad social networks, motivation, and attitudes: Implications for SLA. In M. DuFon \& E. Churchill (Eds.), Language learners in study abroad contexts (pp. 231-258). Clevedon, UK: Multilingual Matters.

Johnson, A. (2009). The rise of English: The language of globalization in China and the European Union. Macalester International, 22(1), 131-168.

Kalocsai, K. (2009). Erasmus exchange students: A behind-the-scenes view into an ELF community of practice. Apples: Journal of Applied Language Studies, 3(1), 25-49. 
Kaplan, A. (2012, March 14). Dreaming in French: On Angela Davis. The Nation. Retrieved from https://www.thenation.com/article/dreaming-french-angela-davis/

Kinginger, C. (2008). Language learning in study abroad: Case studies of Americans in France. Modern Language Journal Monograph, 1. Oxford, UK: Blackwell.

Kinginger, C. (2009). Language learning and study abroad: A critical reading of research. London, UK: Palgrave Macmillan.

Kubota, R. (2016). The social imaginary of study abroad: Complexities and contradictions. The Language Learning Journal, 44(3), 347-357.

Kubota, R., \& Lin, A. (2009). Race, culture, and identities in second language education: Exploring critically engaged practice. New York, NY: Routledge.

Lacey, J. (2015). Considerations on English as a global lingua franca. Political Studies Review, 13(3), 363-372.

Lafford, B. (1995). Getting into, through, and out of a survival situation: A comparison of communicative strategies used by students studying Spanish abroad and "at home." In B. Freed (Ed.), Second language acquisition in a study abroad context (pp. 97-121). Philadelphia, PA: Benjamins.

Lave, J., \& Wenger, E. (1991). Situated learning: Legitimate peripheral participation. Cambridge, UK: Cambridge University Press.

Leinwand, G. (1986). The pageant of world history. Newton, MA: Allyn \& Bacon.

Lewis, A. (2003). Race in the schoolyard: Negotiating the color line in classrooms and communities. Piscataway, NY: Rutgers University Press.

Lindseth, M. (2010). The development of oral proficiency during a semester in Germany. Foreign Language Annals, 43(2), 246-268. 
Lipsitz, G. (2002). The possessive investment in whiteness. In P. Rothenberg (Ed.), White privilege: Essential readings on the other side of racism (pp. 61-84). New York, NY: Worth.

Marable, M. (2002). The great walls of democracy: Essays on race, class, and power. Monroe, ME: Common Courage Press.

Martinsen, R. A., Baker, W., Dewey, D. P., Bown, J., \& Johnson, C. (2010). Exploring diverse settings for language acquisition and use: Comparing study abroad, service learning abroad, and foreign language housing. Applied Language Learning, 20(1-2), 45-69.

meaghan. (2018). Sorry STEM, Google just made the case for more foreign language education [weblog post]. Retrieved from https://blogs.transparent.com/languagenews/2018/01/01/sorry-stem-google-just-made-the-case-for-more-foreign-languageeducation/

Morita, N. (2004). Negotiating participation and identity in second language academic communities. TESOL Quarterly, 38, 573-603.

Murphy-Lejeune, E. (2002). Student mobility and narrative in Europe: The new strangers. New York, NY: Routledge.

Norton, B. (2000). Identity and language learning: Gender, ethnicity and educational change. London, UK: Longman.

Norton, B. (2013). Identity and language learning: Extending the conversation. Bristol, UK: Multilingual Matters.

Nussbaum, M. (2001, February 18). The end of orthodoxy. The New York Times. Retrieved from http://www.nytimes.com/books/01/02/18/reviews/010218.18nussbat.html

Ochs, E. (1999). Socialization. Journal of Linguistic Anthropology, 9(1/2), 230-233. 
Ogden, A. (2008). The view from the veranda: Understanding today's colonial student. Frontiers: The Interdisciplinary Journal of Study Abroad, 15, 35-55.

Open Doors. (2016). Fast facts. Retrieved from https://www.iie.org/Research-andInsights/Open-Doors/Fact-Sheets-and-Infographics/Fast-Facts

Pavlenko, A. (2002). We have room for but one language here: Language and national identity in the U.S. at the turn of the 20th century. Multilingua, 21(2/3), 163-196.

Pellegrino Aveni, V.(2005). Study abroad and second language use: Constructing the self. New York, NY: Cambridge University Press.

Phillipson, R. (1992). Linguistic imperialism. Oxford, UK: Oxford University Press.

Phillipson, R. (2016). Myths and realities of "global” English. Language Policy, 16(3), 313-331.

Pennycook, A. (2001). Critical applied linguistics: A critical introduction. Mahwah, NJ: Routledge.

Pennycook, A. (2008). Critical applied linguistics and language education. In N. H. Hornberger (Ed.), Encyclopedia of language and education (pp. 169-181). Boston, MA: Springer.

Polanyi, L. (1995). Language learning and living abroad: Stories from the field. In B. Freed (Ed.), Second language acquisition in a study abroad context (pp. 271-291). Philadelphia, PA: Benjamins.

Richards, J. C., Platt, J., \& Weber, H. (1985). Dictionary of applied linguistics. Essex, UK: Longman.

Said, E. (1979). Orientalism. New York, NY: Vintage.

Sam, D. L., \& Eide, R. (1991). Survey of mental health of foreign students. Scandinavian Journal of Psychology, 32(1), 22-30. 
Schwandt, T. A. (2000). Three epistemological stances for qualitative inquiry: Interpretivism, hermeneutics, and social constructionism. In N. K. Denzin \& Y. S. Lincoln (Eds.), The SAGE handbook of qualitative research (pp. 189-213). Thousand Oaks, CA: Sage.

Segalowitz, N. (2004). A comparison of Spanish second language acquisition in two different learning contexts: Study abroad and the domestic classroom. Frontiers: The Interdisciplinary Journal of Study Abroad, 10(1), 1-18.

Segalowitz, N., \& Freed, B. F. (2004). Context, contact, and cognition in oral fluency acquisition: Learning Spanish in at home and in study abroad contexts. Studies in Second Language Acquisition, 26(2), 173-199.

Simon, J., \& Ainsworth, J. (2012). Race and socioeconomic status differences in study abroad participation: The role of habitus, social networks, and cultural capital. International Scholarly Research Network Education, 2012, 1-21.

Singleton, G. E., \& Linton, C. (2006). Courageous conversations about race. Thousand Oaks, CA: Corwin.

Stake, R. E. (2003). Case studies. In N. Denzin \& S. Lincoln (Eds.), Strategies of qualitative inquiry (pp. 134-164). Thousand Oaks, CA: Sage.

Sweeney, K. (2013). Inclusive excellence and underrepresentation of students of color in study abroad. Frontiers: The Interdisciplinary Journal of Study Abroad, 23, 1-21.

Swender, E. (2003). Oral proficiency testing in the real world: Answers to frequently asked questions. Foreign Language Annals, 36, 520-526.

Talburt, S., \& Stewart, M. A. (1999). What's the subject of study abroad? Race, gender and “living culture.” Modern Language Journal, 83(2), 163-175. 
Thomas, D. (2013). Africa and France: Postcolonial cultures, migration, and racism. Bloomington, IN: Indiana University Press.

Trentman, E. (2013). Imagined communities and language learning during study abroad: Arabic learners in Egypt. Foreign Language Annals, 46, 545-564.

Twombly, S. B. (1995). "Piropos” and friendship: Gender and culture clash in study abroad. Frontiers: The Interdisciplinary Journal of Study Abroad, 1, 1-27.

Wenger, E. (1998). Communities of practice: Learning, meaning, and identity. Cambridge, UK: Cambridge University Press.

Wildman, S., \& Davis, A. D. (2002). Making systems of privilege visible. In P. Rothenberg (Ed.), White privilege: Essential readings on the other side of racism (pp. 89-96). New York, NY: Worth.

Wilkinson, S. (1998). On the nature of immersion during study abroad: Some participant perspectives. Frontiers: The Interdisciplinary Journal of Study Abroad, 4(2), 121-138.

Willinsky, J. (1998). Learning to divide the world: Education at empire's end. Minneapolis, MN: University of Minnesota Press.

Wolcott, H. F. (1994). Transforming qualitative data: Description, analysis, and interpretation. Thousand Oaks, CA: Sage.

Woodson, C. G. (2010). The mis-education of the negro. Lexington, KY: Seven Treasures.

Zinn, H. (2005). A people's history of the United States. New York, NY: Harper. 


\section{APPENDIX : INSTRUMENTS}

\section{Interview and survey questions, self-evaluation, and unofficial OPI description.}

\section{For first written survey, prior to study abroad:}

1. What are your objectives for proficiency gain (both linguistically and culturally) during your study abroad experience?

2. How do you think that you will achieve these objectives?

3. What do you think about your study abroad experience that will contribute most to your language development? What will hinder your language development?

\section{For first written survey when abroad (to which I will follow up via email):}

Indicate the situation that best describes your living arrangement in France:

a. I live with a French-speaking host family.

b. I live in an apartment with native or fluent French speaker(s).

c. I lived in an apartment with others who were NOT native or fluent French speakers.

d. Other (please explain):

\section{For each of biweekly surveys abroad:}

1. Give the average number of hours each week you spend speaking in French outside of class with native or fluent French speakers during this semester. Explain, if needed.

2. Give the average number of hours each week you spend reading French newspapers outside of class during this semester. Explain, if needed.

3. Give the average number of hours each week you spend reading novels in French outside of class. Explain, if needed.

4. Give the class average number of hours each week you spend reading French language magazines outside of class or Internet Web pages in French? Explain, if needed. 
5. Give the average number of hours each week you spend reading email in English? in French. Explain, if needed.

6. Give the average number of hours each week you spend watching TV programs or movie in English. Explain, if needed.

7. Give the average number of hours each week you spend listening to French television. Explain, if needed.

8. Give the average number of hours each week you spend listening to French movies or videos. Explain, if needed.

9. Give the average number of hours each week you spend listening to French music outside of class. Explain, if needed.

10. Give the average number of hours each week you spend writing homework assignments in French outside of class. Explain, if needed.

11. Give the average number of hours each week you spend writing email in French outside of class. Explain, if needed.

12. Give the average number of hours per day you spend on social media such as Facebook in English. In French. Explain, if needed.

13. Give the average number of times per day (and number of minutes of phone calls) you call English-speaking friends/family. French-speaking friends/family. Explain, if needed.

14. Give the average number of texts per day that you send in English. In French. Explain, if needed.

Provide table for 1-14 to write daily hours/times in order to get weekly averages.

15. Who are the friends that you spend the most time with? Why do you like to be with them? 16. Are there times when you feel uncomfortable? Could you describe why? 


\section{For final written survey:}

1. Think back to the first week of your study abroad experience. Describe the objectives that you had at that time for your study abroad experience.

2. Do you think that you were able to achieve these objectives? Explain.

3. What was it about the study abroad experience that most contributed to your language development? What do you think hindered your language development?

For English oral interview prior to study abroad, the following questions will be asked:

1. Why have you chosen to study in France?

2. How many French classes have you already taken?

3. How would you describe your French proficiency at this time?

4. What do you think you will like about living in France?

5. What do you think that you will not like about living in France?

6. Tell me about an experience that you've had that made you interested in French and becoming a teacher.

7. What do you think about your study abroad experience that will contribute most to your language development?

8. What do you think will hinder your language development?

9. Do you think that social media, Skype or cell phone access will negatively affect your development in the target language?

10. Do you think that spending too much time with English speakers will negatively affect your development in the target language?

11. What does being American mean to you? How do you anticipate your identity to shape your language and cultural acquisition while abroad? 
12. Do you have anything else to add?

The French unofficial Oral Proficiency Interview (OPI) administered prior to study abroad will be based on an Intermediate Level OPI. The course of the interview is very structured with four main parts. First there is a Warm Up where the student is asked to provide general information about him/herself such as their name, where they live, their current activities, their major/minor in school and any other information that they are willing to offer. The interviewer does not coerce specific information, only general information. Second and third are Level Checks and Probes in which the student is asked questions based on the information that they supply during the warm up. This information is used to ask questions that require narration in the past, present and future. Probes are made to encourage a more in-depth answer than what is original given and to see if the student is able to retain the level that the interviewer is checking. A role-play is part of the Level Checks. A typical role-play at the Intermediate level would be asking the student to pretend that s/he is a friend and has borrowed the interviewer's car but has had an accident and must call the interviewer to explain what has happened. The interviewer creates some kind of challenge, for example, that s/he needs the car in 30 minutes for a very important meeting and the student must work through this challenge. If the student shows Advanced Level language, s/he will be asked to discuss some kind of current event, usually of his/her choosing. The final part is the warm down in which the student will be asked about their plans for later in the day and the weekend, perhaps even professional plans if it fits the interview. The interview cannot last more than 30 minutes. 
For mid-term oral interview during study abroad, the following questions will be asked in

\section{English:}

1. Do you like your host family?

2. How much do you interact with them?

3. How many classes are you taking in France?

4. What do you think of your classes?

5. What do you like about living in France?

6. What do you not like about living in France?

7. Tell me about an experience that you've had so far that had either a positive or negative effect on you.

8. How would you describe your French proficiency at this time?

9. What do you think about your study abroad experience so far is contributing the most to your language development?

10. What is contributing the least to your language development?

11. Do you think that social media, Skype or cell phone access is negatively affecting your development in the target language?

12. Who are your friends there?

13. Do you think that spending too much time with English speakers is negatively affecting your development in the target language?

14. Are there times when you have felt uncomfortable for any reason? Can you describe this?

15. Now that you've been in France for a couple of months, has your identity as an American and/or as a French language learner changed?

16. Do you have anything else to add? 
An unofficial OPI will be administered during the midterm interview process that will have the same structure as the pre-departure OPI.

For oral interview upon return from study abroad, the following questions will be asked in English.

1. What is your global reaction to your semester in France?

2. What were the best parts of your study abroad?

3. Were there any negative parts to your study abroad? If so, what were they?

4. Tell me about an experience that you had since the mid-point of your semester that was exciting, frustrating or memorable in some way.

5. How would you describe your French proficiency at this time?

6. What do you think about your study abroad experience contributed the most to your language development?

7. What contributed the least to your language development?

8. Do you think that social media, skype or cell phone access negatively affected your development in the target language? If not, why?

9. Do you think that spending too much time with English speakers negatively affected your development in the target language? If not, why?

10. Think back to the first week of your study abroad experience. Can you remember the objectives that you had for your experience abroad? If so, what were they?

11. Do you think that you were able to achieve these objectives? Explain.

12. What are your plans for the future based on your experience in France?

13. How would you describe your identity as an American and a French speaker now?

14. Do you have anything else to add? 
An unofficial OPI will be administered upon the student's return that will have the same

structure as the pre-departure and midterm OPIs.

Self-Evaluation: To be completed prior to, midway through and post study abroad

\begin{tabular}{|c|c|c|c|c|c|c|c|}
\hline $\begin{array}{l}\text { How would you rate } \\
\text { your current mastery } \\
\text { of the following in } \\
\text { French? }\end{array}$ & Beginning & $\begin{array}{l}\text { Intermediate } \\
\text { Low }\end{array}$ & $\begin{array}{l}\text { Intermediate } \\
\text { Mid }\end{array}$ & $\begin{array}{l}\text { Intermediate } \\
\text { High }\end{array}$ & $\begin{array}{l}\text { Advanced } \\
\text { Low }\end{array}$ & $\begin{array}{l}\text { Advanced } \\
\text { Mid }\end{array}$ & $\begin{array}{l}\text { Advanced } \\
\text { High }\end{array}$ \\
\hline $\begin{array}{l}\text { Please write ORAL and } \\
\text { WRITTEN in the corresponding } \\
\text { columns for self-evaluation. }\end{array}$ & & & & & & & \\
\hline $\begin{array}{l}\text { Present tense verbs - } \\
\text { including irregular. }\end{array}$ & & & & & & & \\
\hline Present Perfect & & & & & & & \\
\hline $\begin{array}{l}\text { Past tense verbs, } \\
\text { including irregular. } \\
\text { être and avoir }\end{array}$ & & & & & & & \\
\hline Pluperfect & & & & & & & \\
\hline $\begin{array}{l}\text { The use of past tense } \\
\text { vs. imperfect. }\end{array}$ & & & & & & & \\
\hline $\begin{array}{l}\text { The future tense (near } \\
\text { and regular future) }\end{array}$ & & & & & & & \\
\hline Future perfect & & & & & & & \\
\hline Conditional & & & & & & & \\
\hline Conditional Past & & & & & & & \\
\hline If clauses & & & & & & & \\
\hline $\begin{array}{l}\text { Indirect and Direct } \\
\text { Object Pronouns }\end{array}$ & & & & & & & \\
\hline Multiple pronouns & & & & & & & \\
\hline $\begin{array}{l}\text { Relative Pronouns } \\
\text { (qui, que, dont, etc) }\end{array}$ & & & & & & & \\
\hline Subjunctive & & & & & & & \\
\hline Past subjunctive & & & & & & & \\
\hline $\begin{array}{l}\text { Narrating a story } \\
\text { about your past } \\
\text { weekend }\end{array}$ & & & & & & & \\
\hline $\begin{array}{l}\text { Narrating a story } \\
\text { about your family }\end{array}$ & & & & & & & \\
\hline $\begin{array}{l}\text { Narrating a story } \\
\text { about your } \\
\text { schoolwork } \\
\text { requirements }\end{array}$ & & & & & & & \\
\hline $\begin{array}{l}\text { Narrating a story } \\
\text { about a social or } \\
\text { political problem }\end{array}$ & & & & & & & \\
\hline $\begin{array}{l}\text { Narrating a story } \\
\text { about your future } \\
\text { aspirations }\end{array}$ & & & & & & & \\
\hline $\begin{array}{l}\text { Narrating a story } \\
\text { about hypothetical } \\
\text { events }\end{array}$ & & & & & & & \\
\hline & & & & & & & \\
\hline
\end{tabular}

$\mathrm{W}=$ written proficiency $\mathrm{O}=$ oral proficiency 